The use of remote sensing to detect the change in land use by date palms cultivation in Baghdad governorate

\author{
Sherin Amad Kadhim \\ sherin_25_11@yahoo.com \\ Asst. Prof. Dr. Dalal Hassan Kadhim \\ dalalh.kadhim@yahoo.com \\ University of Baghdad-College of education Ibn Rushed
}

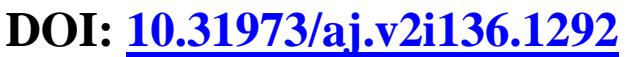

\begin{abstract}
:
The research aims to reveal spatial variation and temporal change in land use by date palms cultivation in Baghdad governorate for the period between 2001 and 2018, Using satellite images recorded by the ETM sensor carried by the US Landsat-7 satellite and the OLI sensor carried by the Landsat- 8 satellite. A series of steps were carried out, starting with the engineering and radiometric corrections, enhancement operations, super and a super classification, based on the classification of Anderson and others (USGS) to classify land use and land cover. Procedure for the change detection in date palms cultivation for the period between 2001 and 2018 using equation of absolute change and relative change. As well as making and distributing a questionnaire form containing 500 questionnaires and field studies to fill the shortage of data and information about the study area.

The study found a set of results, the most prominent of which was the existence of a negative change in the areas of land use by cultivating date palms during the period (2001-2018), at a rate of (-16.8) \% in Baghdad governorate, and at different rates in all districts of Baghdad governorate. Al-Sadr district came at the forefront of the districts in terms of the rate of change of the area, which amounted to $(-100) \%$, while Al-Mada'in district ranked last with a change rate of $(-3) \%$ of the total area of palm trees.
\end{abstract}

Key words: change detection, remote sensing, land uses, date palm cultivation. 


\section{استخدام الاستشعار عن بعد لكثف التغير في أستعمالات الارض بزراعة النخيل في محافظة بغداد}

\author{
1. - ا.م.د. دلال حسن كاظم \\ كلية التربية أبن رشد للعلوم الإنسانية \\ جامعة بغداد - قسم الجغرافية
}

dalalh.kadhim@yahoo.com

\author{
الباحثة شيرين عماد كاظم \\ كلية التربية أبن رشد للعلوم الإنسانية \\ جامعة بغداد - قسم الجغرافية
}

sherin_25_11@yahoo.com

(مُلَخَّصنُ البَحثث)

يهدف البحث الى الكثف عن التباين المكاني والتغير الزماني في استعمالات الارض

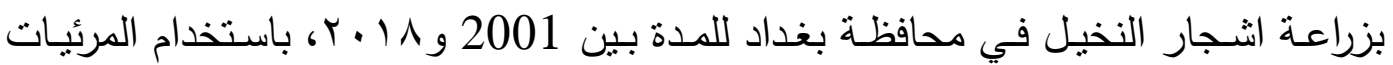
الفضائية المسجلة بالمتحس ETM+ الذي يحمله القمر الصناعي الامريكي لاندسات-7, براعي

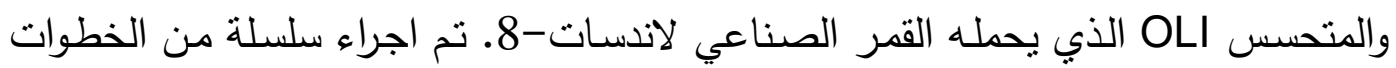

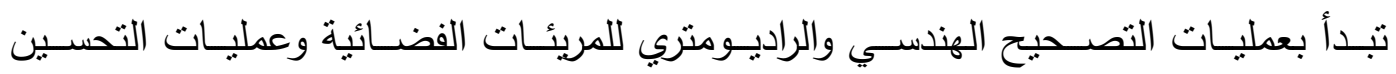
والتصنيف الالي غير الموجه والموجه، اعتمادا على تصنيف اندرسون واخرون (نظام المسح

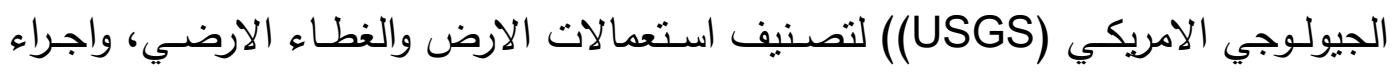

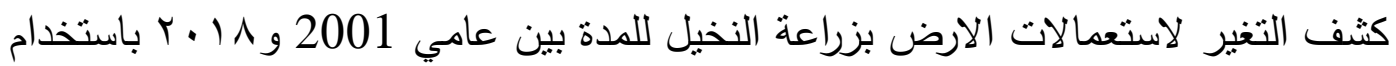
معادلة التغير المطلق والتغير النسبي. فضلا عن عمل وتوزيع استمارة استبيان بواقع 500 استمارة والدراسـة الميدانية لسد النقص بالبيانات والمعلومات عن منطقة الدراسـة. توصلت

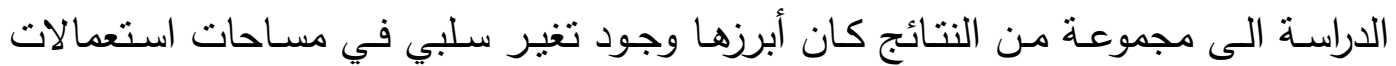

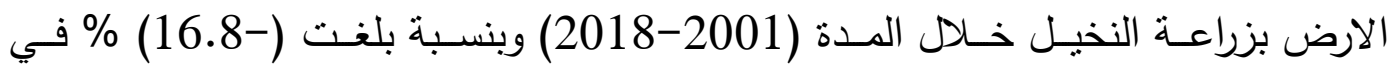

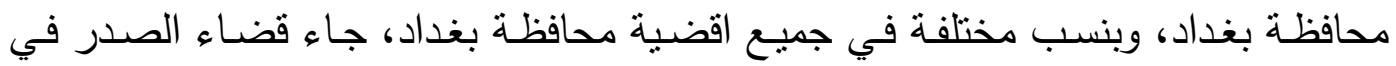
مقدمة الاقضية من حيث نسبة التغير للمساحة بلغت (-100) \% في حين احتل قضاء

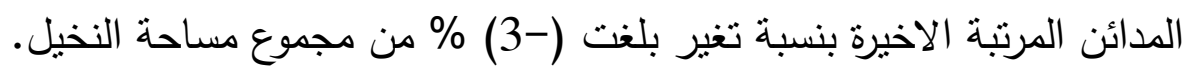
الكلمات المفتاحية: كثف التغير ، الاستشعار عن بعد، استعمالات الارض بزراعة النخيل. المقدمة

يعد العراق من البلدان التي انعم الهه عليه بالكثير من الثروات التي وفرت له القدرة على

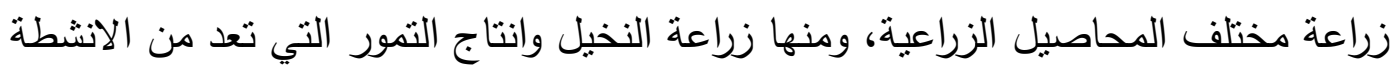
المهمة التي لها دور كبير في دعم الاقتصاد الوطني، لاسيما في ظل ازدياد اعداد السكان

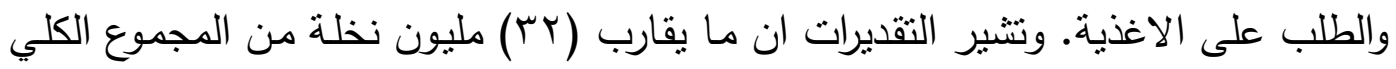
للنخيل في العالم البالغ (ج9) مليون نخلـة كانت نوجد في العراق منذ خمسينيات القرن 
العشرين وحتى الستينات اي ما يعادل (rr)\% الا ان هذه الاعداد اخذت بالتراجع وبشكل

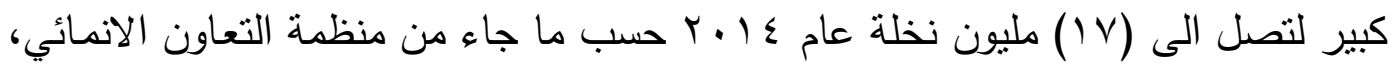

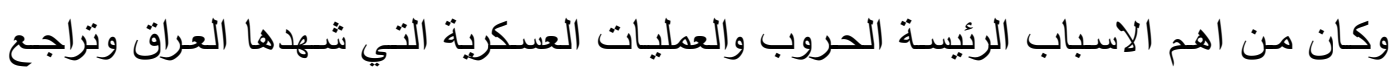
مناسيب المياه اضـافة لاتساع عمليات تجريف البساتين وحرقها والتوسع العمراني عليها،

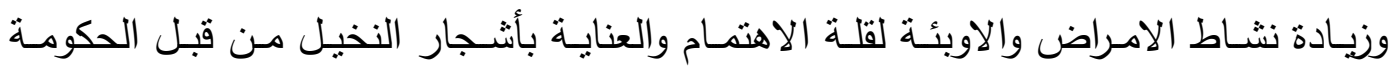
والفلاح على حد سواء، وينطبق الحال على محافظة بغداد منطقة الدراسة اذ نتشهد نغير في

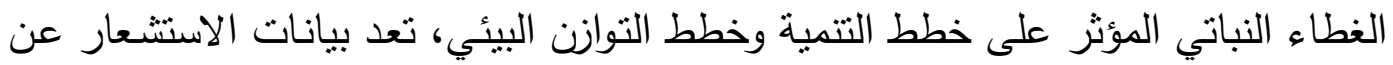
بعد مـن الوسـائل والتقنيات المهمـة والرئيسـة مـن خـلال تحليل المرئيات الفضـائية متعددة

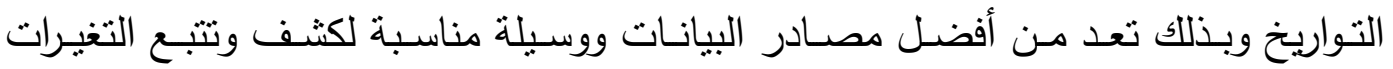
للخصائص المكانية لزراعة النخيل في منطقة الدراسة باستخدام المؤشرات الطيفية والقرائن النباتية.

يهرف البحث الى الكثف عن التباين المكاني والتغير الزماني في استعمالات الارض بزراعة اشجار النخيل في محافظة بغداد للمدة بين 2001 و 2018 باستخدام المرئيات

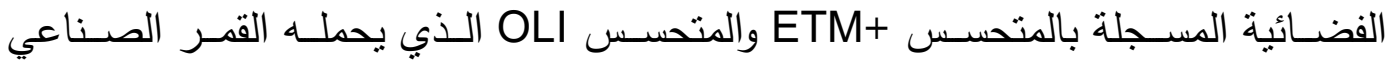
الامريكي لاندسات-7 و 8 على التوالي، وعمل قاعدة بيانات مكانية ووصفية لاستعمالات

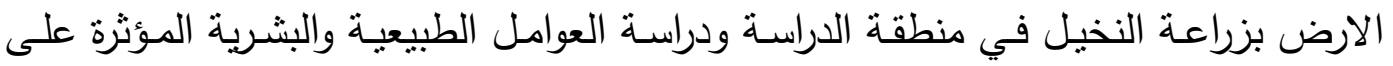

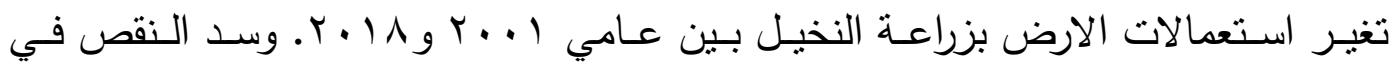

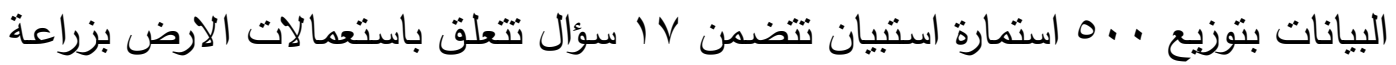
النخيل على العاملين بزراعة البالغ عددهم (.97 ب 1) باستخدام العينة الطبقية العشوائية. تمثلت مشكلة البحث بعدة اسئلة تحاول الباحثة الاجابة عليها من خلال البحث على النحو الاتي: - (- n

1 - هل يوجد ثباين مكاني وتغير زماني لاستعمالات الارض بزراعة النخيل في محافظة

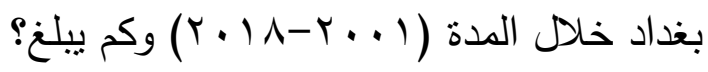
r- هل تمكن تقنيات الاستشعار عن بعد من تفسير وتصنيف وكثف التغير في استعمالات الارض بزراعة النخيل في محافظة بغداد؟ r- ماهي العوامل البشرية والطبيعية التي ادت الى تغير استعمالات الارض بزي بزراعة النخيل

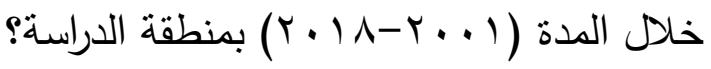

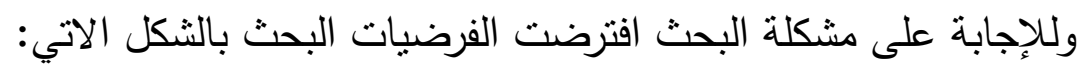
1- يوجد تباين مكاني وتغير زماني لاستعمالات الارض بزراعة النخيل في محافظة بغداد

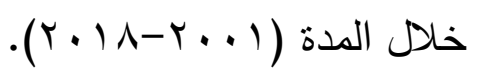


r- تمكن تقنيات الاستشعار عن بعد من تفسير وتصنيف وكثف التغير في استعمالات

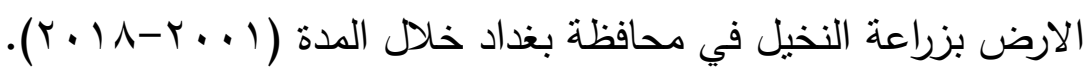

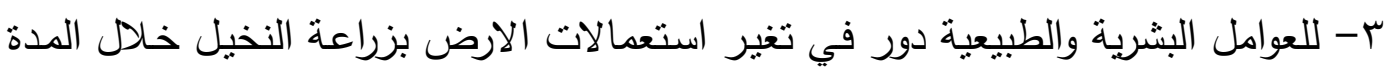

$$
؟(r \cdot 1 \Lambda-r \cdot \cdots)
$$

الاراسات السابقة

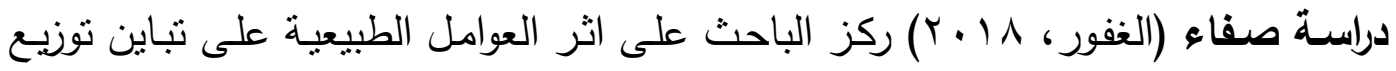

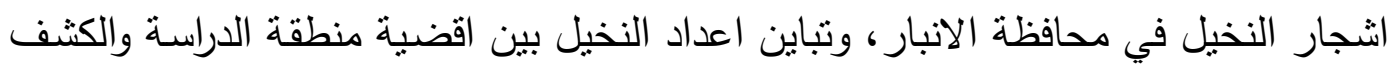

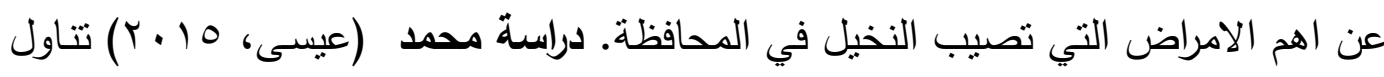

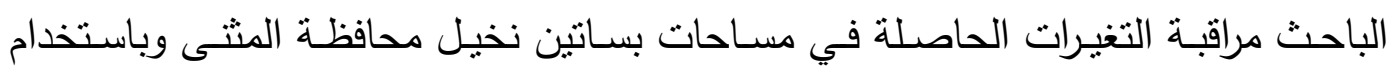
التقنيات الحديثة المتمثلة بالاستشعار عن بعد و (GIS)وتحديد التغير الزمني لها خلاد فترة

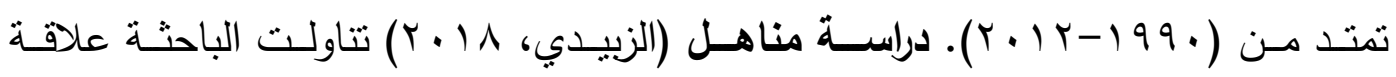

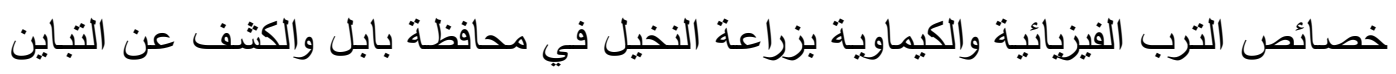

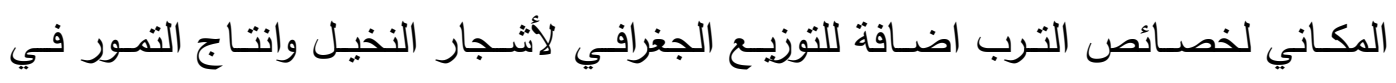

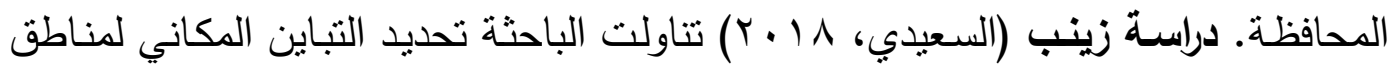

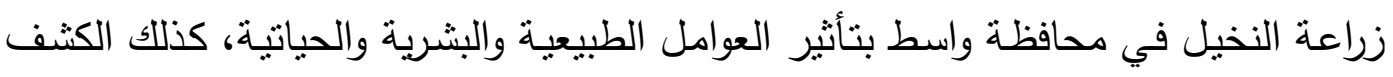

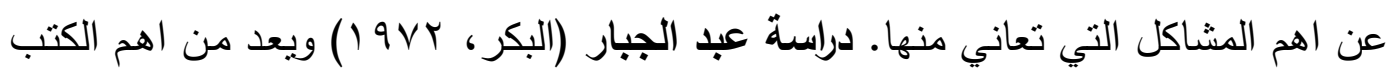

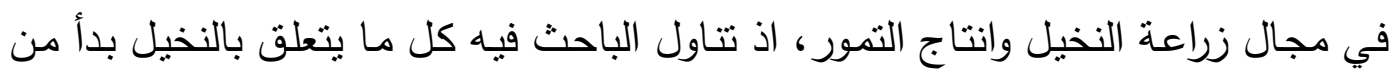

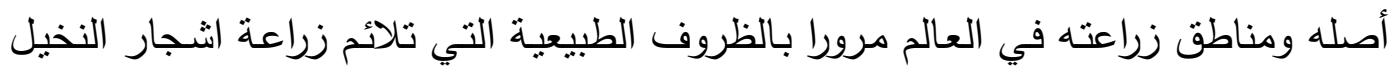

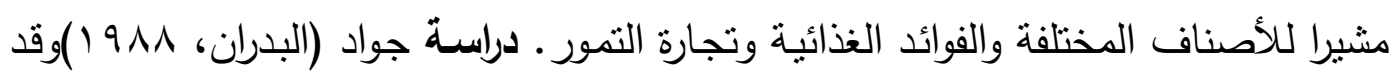

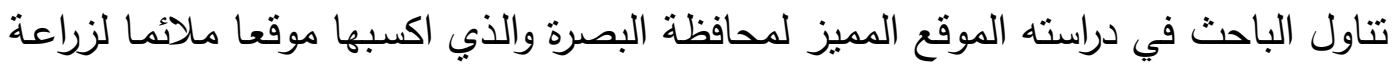

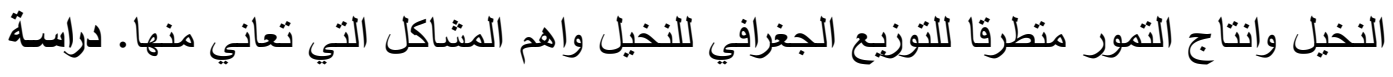
صالح (جاسم، .999 (19) جاء في هذه الدراسة اثر العوامل الجغرافية في زراعة النخيل وانتاج

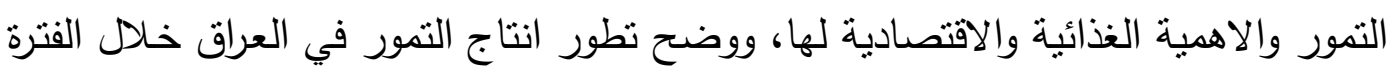

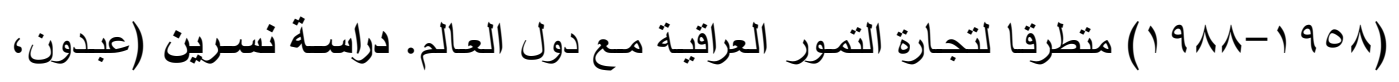

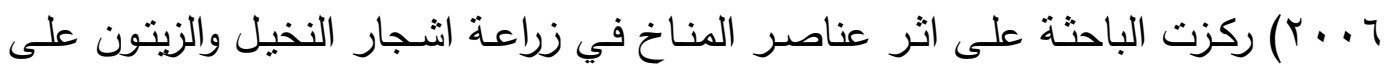

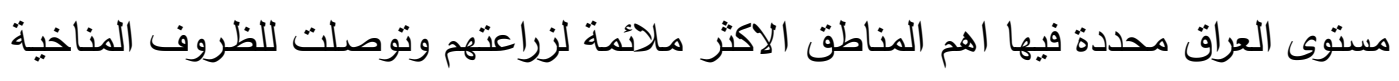

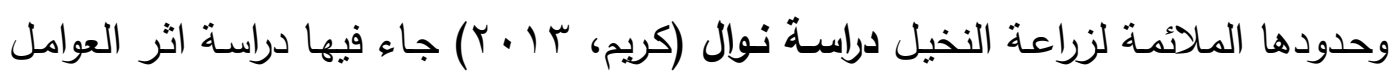

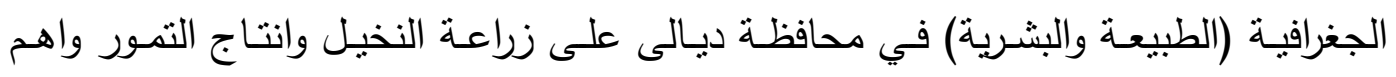

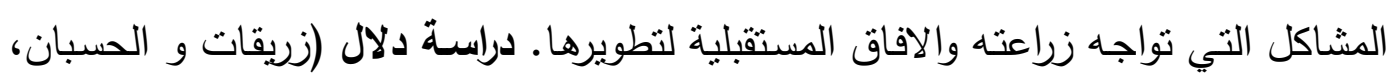

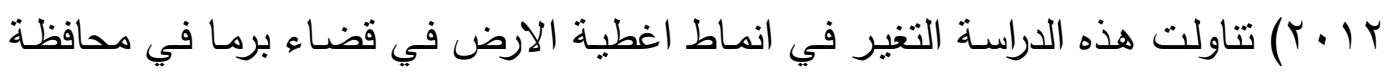


جرش، الاردن منطرقة لأنواع الاغطية واستخدام الارض والاسباب الرئيسية التي ادت الى فلى

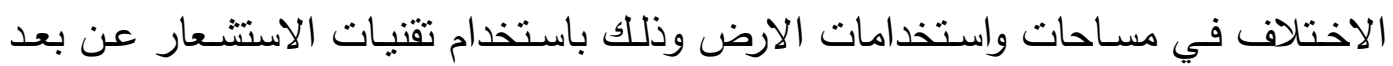

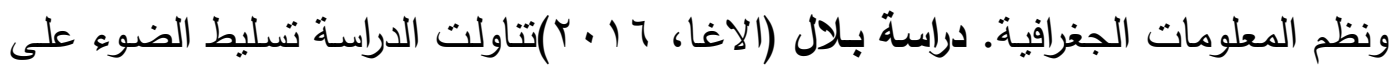

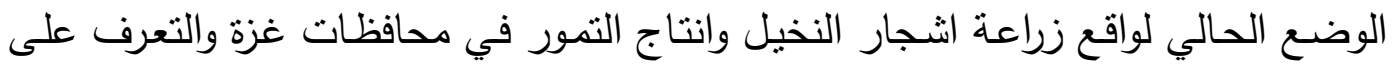
الاصناف المزروعة وتوزيعها الجغرافي واثر العوامل الجغرافية في زراعة النخيل، ومشاكلها

\section{وسبل معالجتها. \\ حدود منطقة الاراسة}

تمثلت الحدود المكانية لمنطقة الدراسة بمحافظة بغداد التي تحتل وسط العراق وشمال

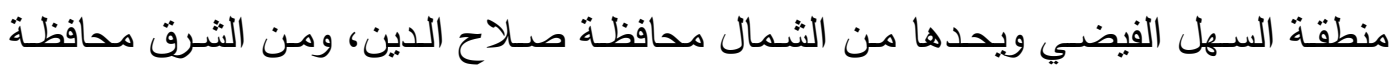
ديالى، اما من الجنوب محافظة بابل ومحافظة واسط، ومن الغرب محافظة الانبار يلاحظ

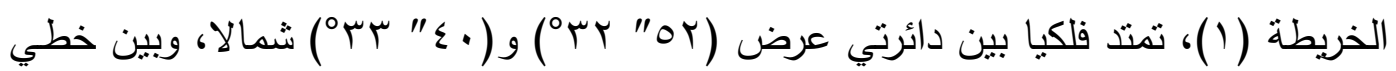

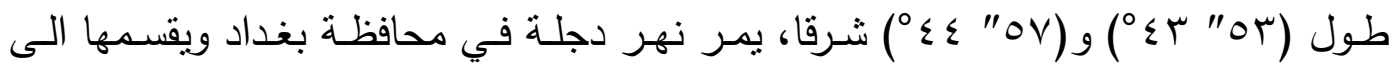

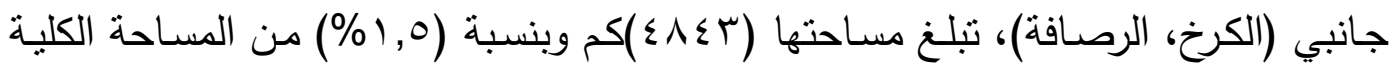

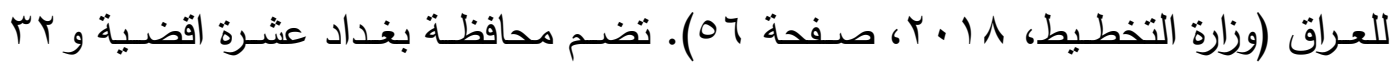

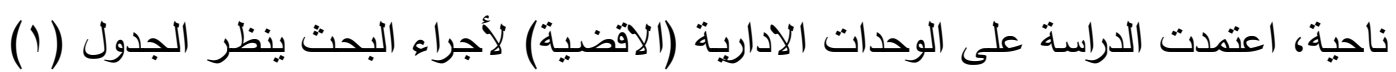

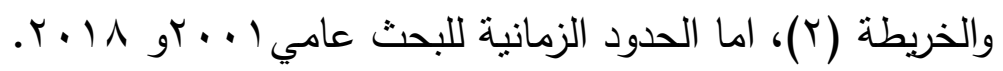

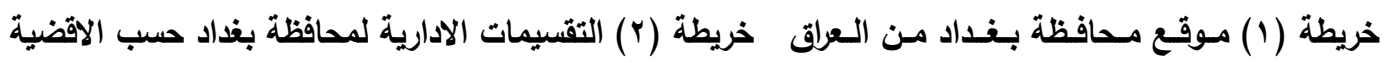
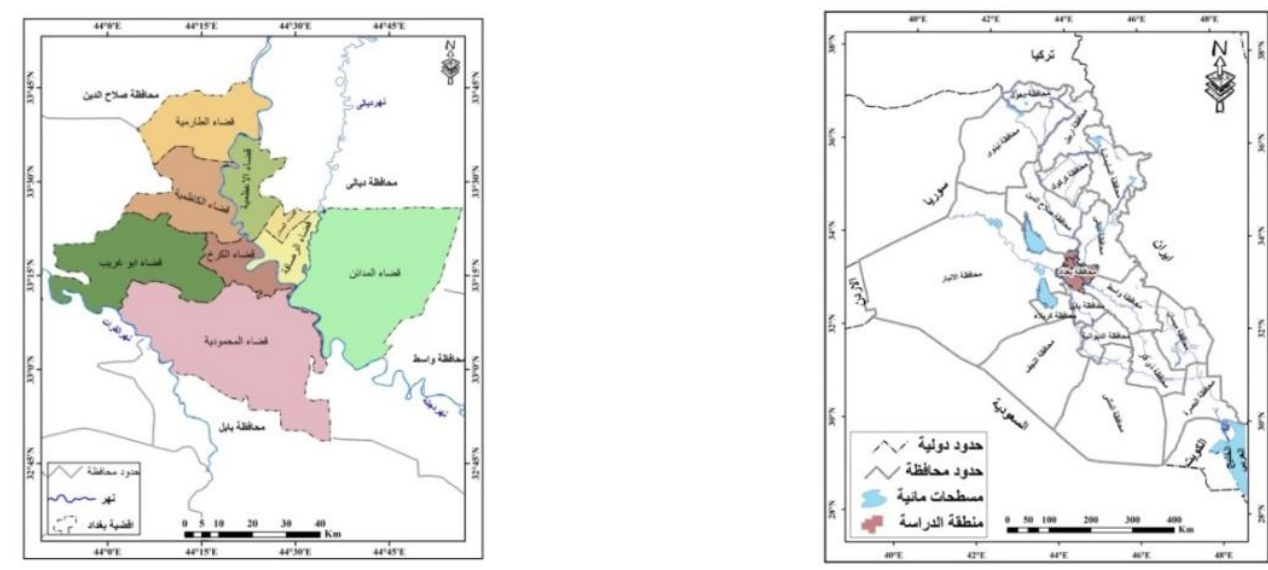

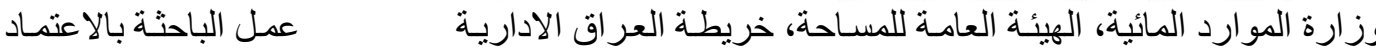

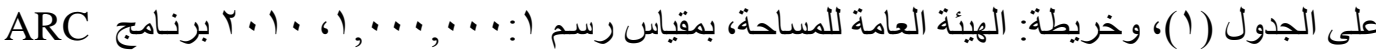

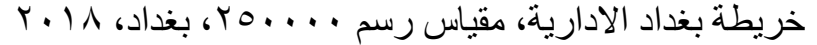
GIS9.3 
جدول (1) الاقضية والمساحة وحجم السكان ونسبهم المئوية للأقضية في محافظة بغداد

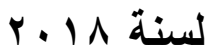

\begin{tabular}{|c|c|c|c|c|c|c|}
\hline$\%$ & حجم السكان & المساحة/دونم * & $\%$ & المساحة/كم² & الاقضية & $ت$ \\
\hline 22.2 & $11.9 \leq 71$ & $7 \leq \ldots$ & $r$ & 17. & الرصافة & 1 \\
\hline 15 & $M \cdot r \leqslant 9 Y$ & $11 \ldots$ & 1 & TVO & الاعظمية & r \\
\hline 19.6 & $10947 V 7$ & $\Lambda \cdot \varepsilon \ldots$ & $\varepsilon$ & $r \cdot 1$ & الكرخ & $r$ \\
\hline 11 & ᄉ $9 \vee r 97$ & IVr... & 9 & $\varepsilon r$. & الكاظمية & $\varepsilon$ \\
\hline 6 & $\varepsilon \wedge \varepsilon \ldots \varepsilon$ & or97.. & rی & $1 r \leqslant 9$ & المحمودية & 0 \\
\hline 4 & אוד.TH & $r \sum \wedge \Lambda \ldots$ & IT & TYY & ابي غريب & 7 \\
\hline 1.7 & $1 \leqslant 01 r_{9}$ & $191 \% \ldots$ & 1. & $\sum \vee \wedge$ & الطارمية & v \\
\hline 5.6 & S097VT & $0.1 \% \ldots$ & r & Iror & المدائن & $\wedge$ \\
\hline 8.7 & $\checkmark \cdot \wedge r \wedge \Lambda$ & $r \ldots$. & r & vo & الصدر *** & 9 \\
\hline $1 \ldots$ & NIYTVOO & $19 R V Y .$. & $1 \ldots$ & $\varepsilon \wedge \leqslant r$ & المجموع & \\
\hline
\end{tabular}

المصدر: جمهورية العر اق، وزارة التخطيط، الجهاز المركزي للإحصساء و التنميـة، المجموعـة الاحصـائية

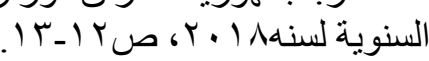

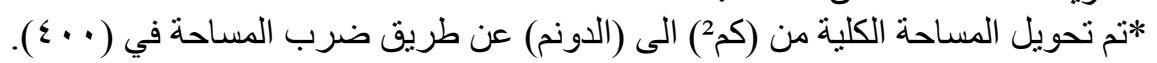

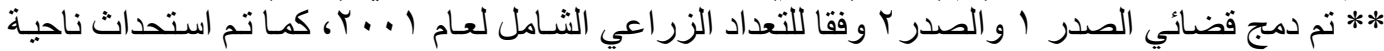

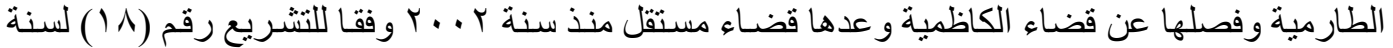

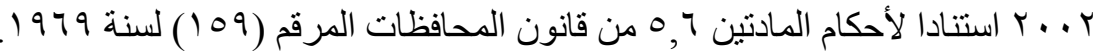

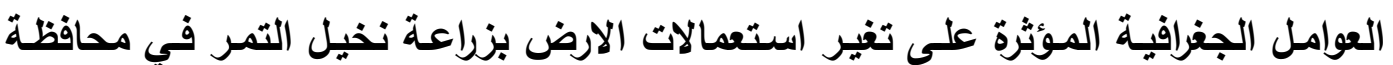
بغداد

1- العوامل الطبيعيـة المؤثترة بتغير استعمالات الارض بزراعة نخيل التمر في محافظة بغداد تعد العوامل الطبيعية ذات تأثير مباشر في زراعة ونمو النخيل وتوزيعها حيث تترابط

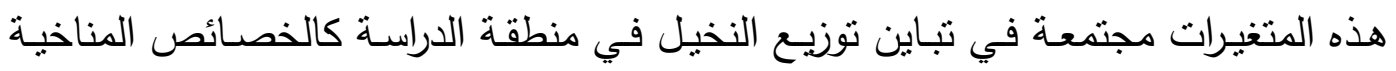
والتضاريس والتربة والموارد المائية

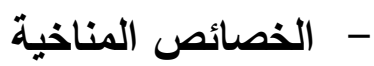
من المعروف ان للخصـائص المناخية تأثثر كبير على استعمالات الارض بزراعـة

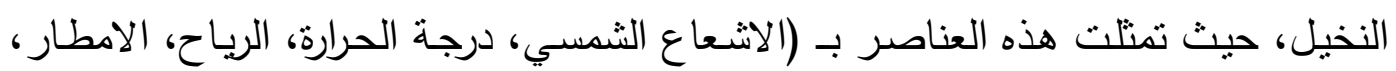

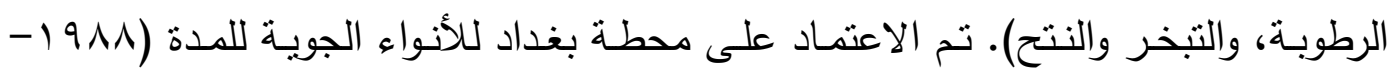

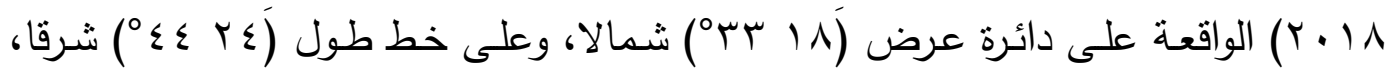


وعلى ارتفـاع تضاريسي (V. (T) م فـوق مستوى سطح البحر (وزارة النقل والمواصـلات، .$(r \cdot) 1$

1- الاثعاع الثمسي: تبرز اهمية ضوء الثمس في نمو اثجار النخيل كونه من النباتات

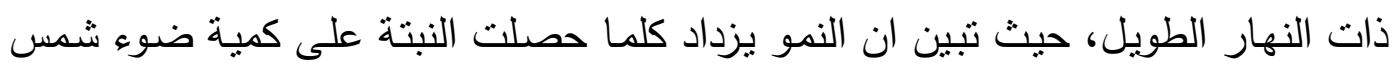

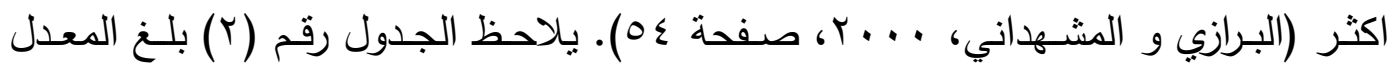

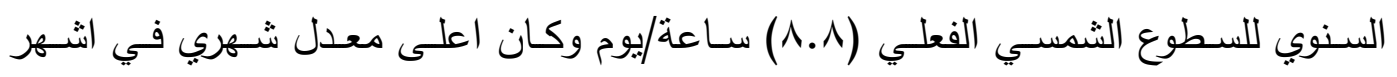

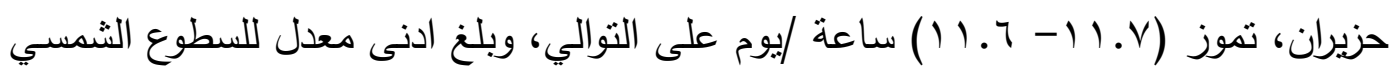

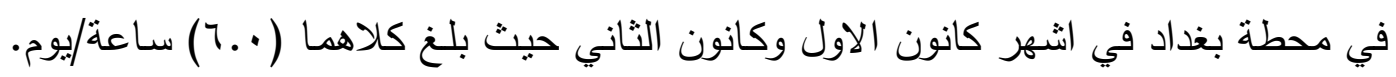

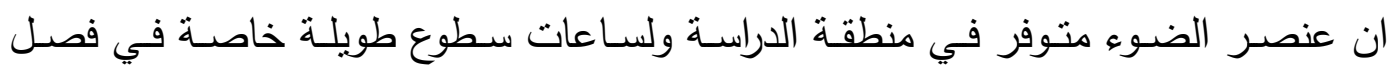
الصيف.

جدول(ץ) المعدلات الثهرية والسنوية للخصائص المناخية في محافظة بغداد للمدة $(r \cdot 1 \Lambda-19 \wedge \Lambda)$

\begin{tabular}{|c|c|c|c|c|c|c|c|c|}
\hline \multirow{2}{*}{ الرياح| } & \multirow{2}{*}{ نتح/ملم } & \multirow{2}{*}{ ملم الامطار } & \multirow{2}{*}{ الرطوية \% } & \multicolumn{3}{|c|}{ درجة الحرارة مْ } & \multirow{2}{*}{ الثمسي } & \multirow{2}{*}{ الخناخية } \\
\hline & & & & الصغرى & العظىى & المعدل & & \\
\hline r.T & 41 & $r \leq .1$ & Vr & 纟.T & 10.9 & 9.1 & 7 & كانون r \\
\hline r. 9 & 1.1 & $1 \varepsilon . \varepsilon$ & זד & 7.1 & 19.1 & $1 Y .7$ & V.r & شباط \\
\hline r.r & 11. & 17.8 & 0 \& & $1 \ldots$ & $r \leq .1$ & iv.. & V.A & اذار \\
\hline r.r & r.. & 10.0 & $\varepsilon v$ & 10.7 & $r . .0$ & rT.r & $\lambda .7$ & نيسان \\
\hline T.Y & TVT & r.9 & rv & $r . . V$ & rv & rq.r & 9.9 & مايس \\
\hline$\varepsilon$ & 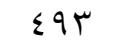 & $\cdots$ & rI & $r \varepsilon .$. & $\varepsilon 1.4$ & rT.I & $11 . \mathrm{V}$ & حزيران \\
\hline r.9 & $0 \leqslant r$ & $\cdots$ & m & YT.Y & $\varepsilon$ «.० & ro.o & 11.7 & تموز \\
\hline r.乏 & ¿9Y & $\cdots$ & $\Gamma \varepsilon$ & ro. $\varepsilon$ & «..1 & ro & $11 . r$ & اب \\
\hline T.A & r70 &. .1 & ra & r.. & $\varepsilon$. & $r . .9$ & & ايلول \\
\hline r.V & rTo & 9.7 & $\varepsilon \wedge$ & 17.7 & Tr.V & $r \leq .9$ & A.) & تثرين 1 \\
\hline T.O & 111 & $r . . T$ & זי & $1 \ldots$ & rT.V & 17.0 & v & تثرين r \\
\hline T.T & $v r$ & $1 V .0$ & VY & 0.7 & $1 V . \Lambda$ & 11.0 & 7 & كانون 1 \\
\hline T.乏 & Tr. & $111 . r$ & $\varepsilon 9 . r$ & 10.0 & M.. & rT.r & $\Lambda . \wedge$ & المعدل السنوي \\
\hline
\end{tabular}

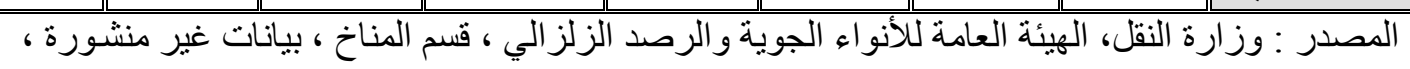


ץ- درجـة الحسرارة: لدرجـة الحرارة دور كبير بزراعة النخيل في منطقة الدراسـة اذ تتطلب

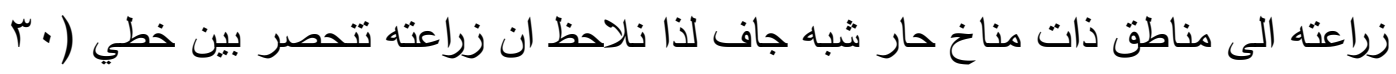

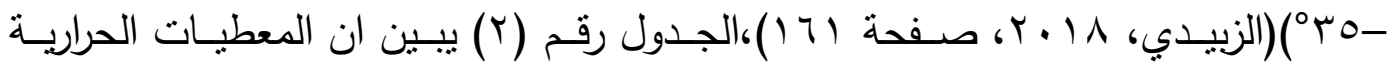

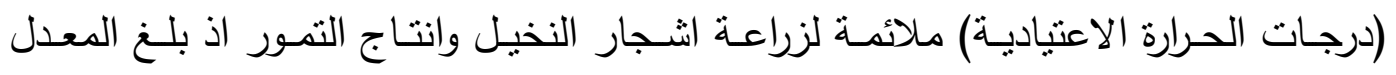

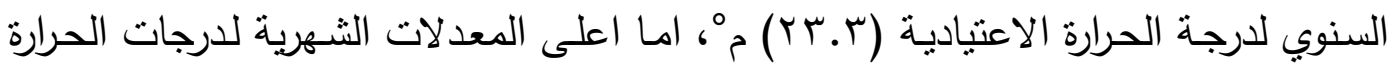

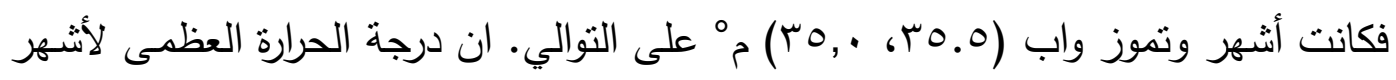

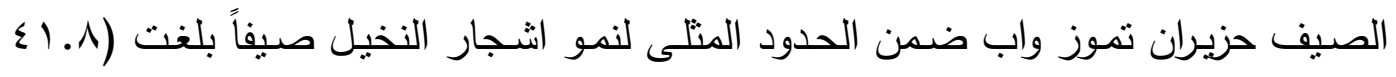

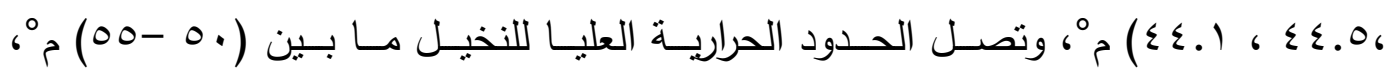

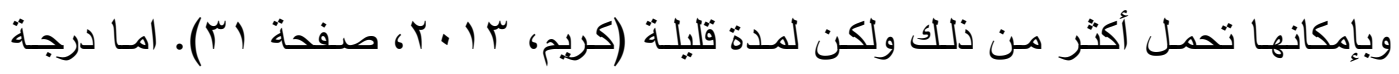

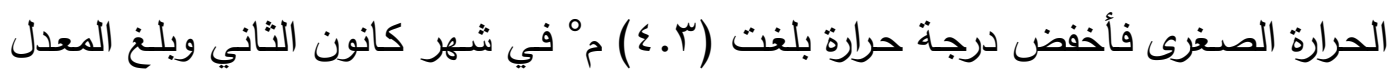

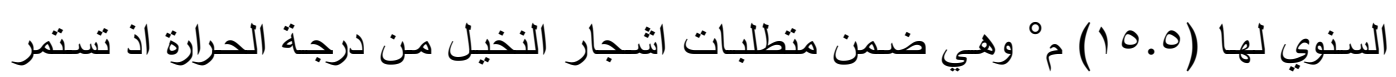

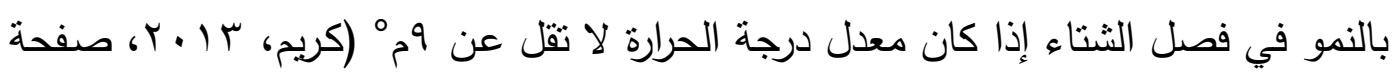

ب- الرطويـة: تعد الرطوبـة من العوامل الهامـة والمحددة لزراعة النخيل كونه يؤئز بشكل

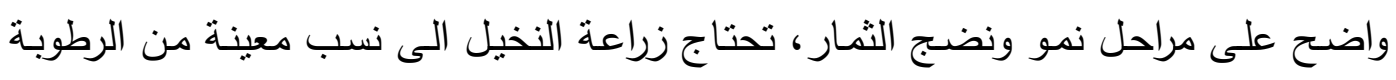

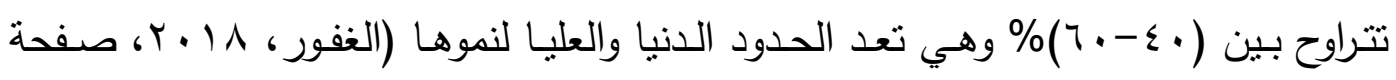

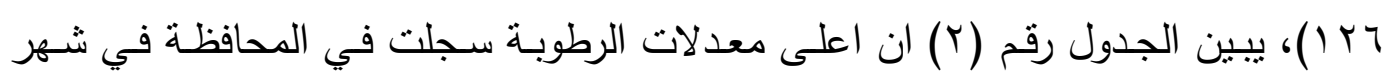

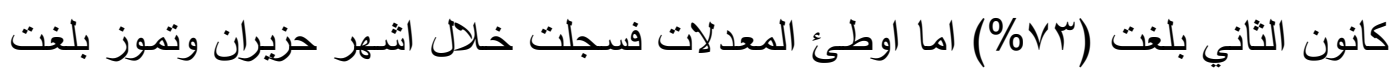

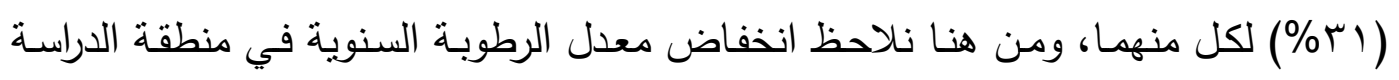
حيث لا يزيد عن (r.9 ؛ \%) تتعكس هذه النسبة القليلة على زيادة التبخر والنتح في النبات

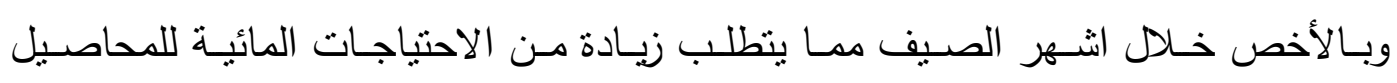
والبساتين.

ع - الامطار : تختلف حاجة النخيل من كميات الامطار وبحسب مراحل نموها فمثلا خلال

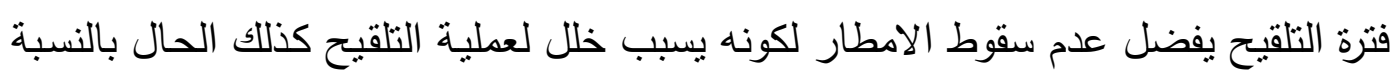

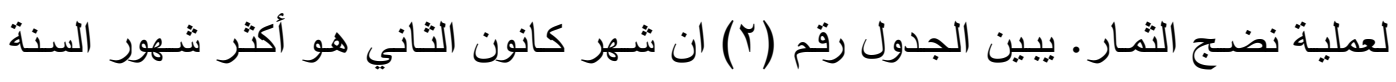

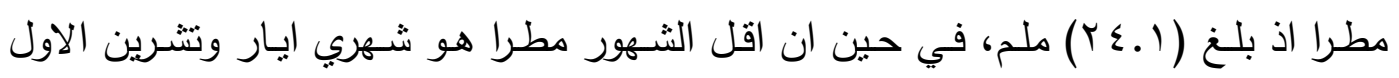

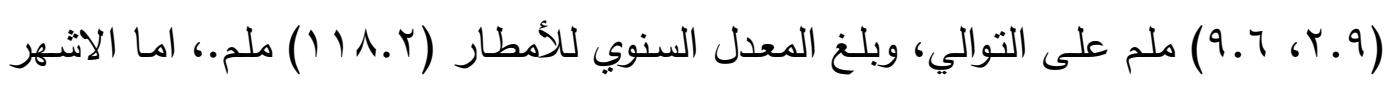

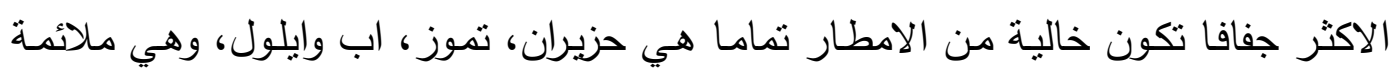
لزراعة النخيل في منطقة الدراسة. 


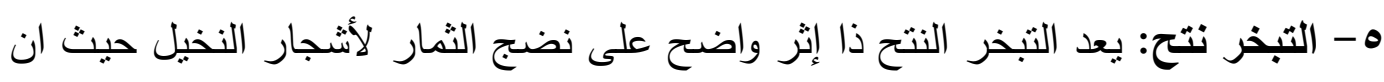
ازدياد ارتفاع درجات الحرارة تؤدي الى ارتفاع نسبة التبخر من السعف ومـع استمرار التبخر

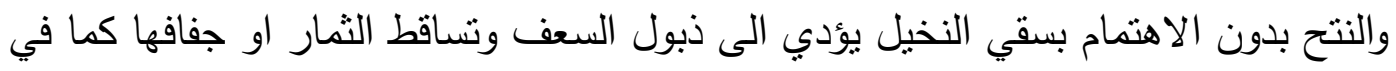

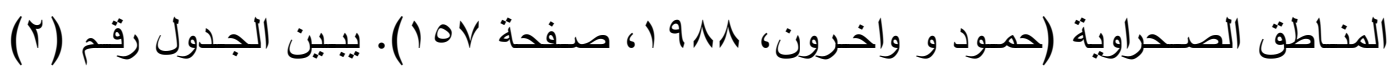

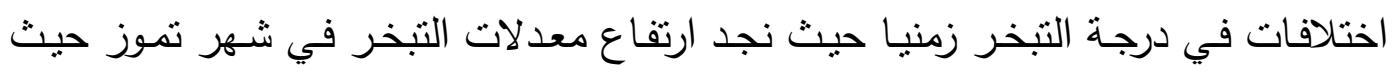
بلغت (r؟ ه) ملم، بينما تنخفض تللك المعدلات في موسم الثنتاء في شهر كانون الثاني

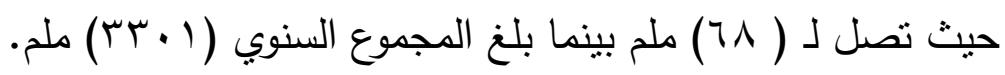

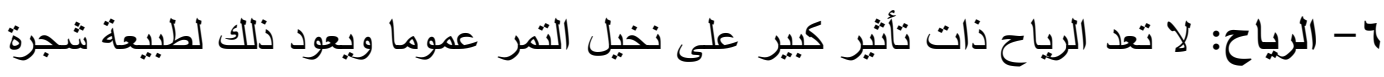

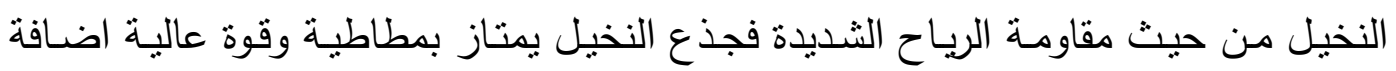

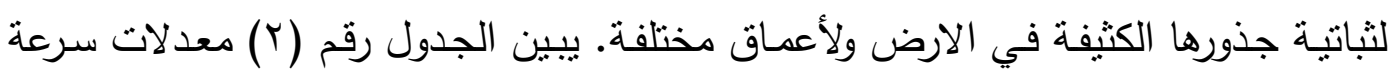

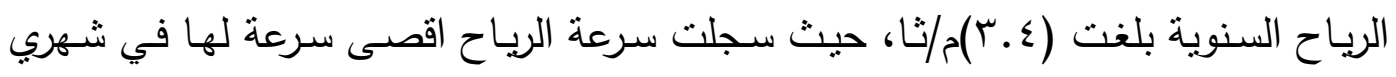

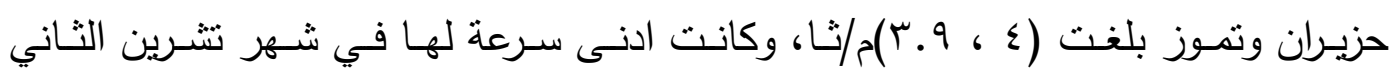

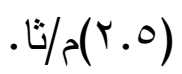
-التضاريس:

للتضـاريس تأثير مباشـر وغير مبـاش على استعمالات الارض بزراعـة النخيل، ان

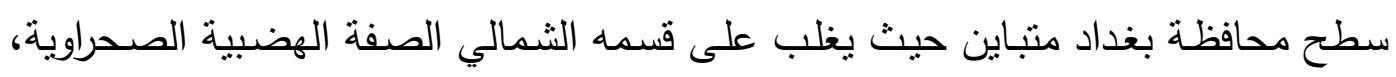

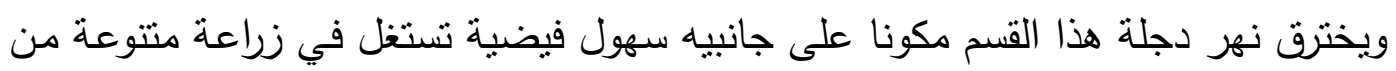

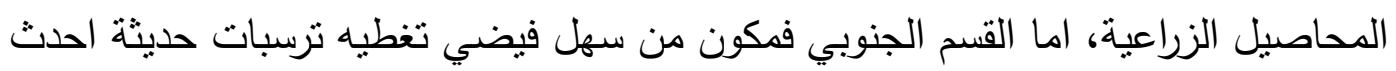

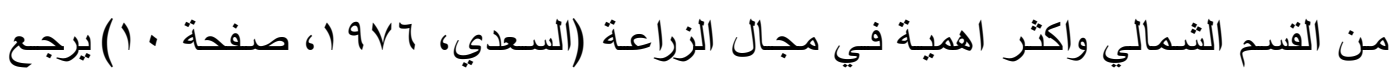

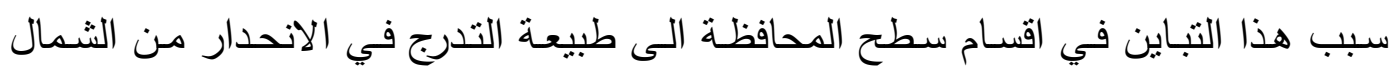

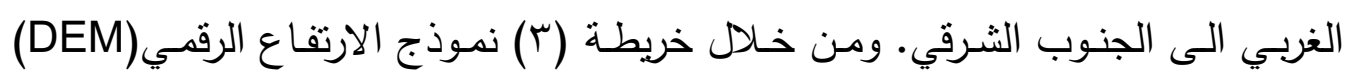

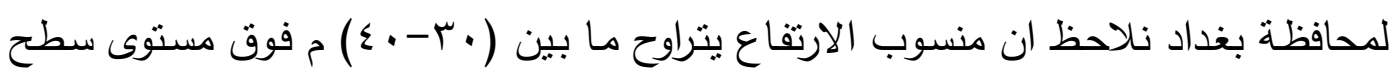
البحر حيث تم تقسيم المنطقة الى خمس فئات للارتفاع وحساب المساحات باستخدام برنامج

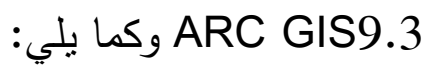

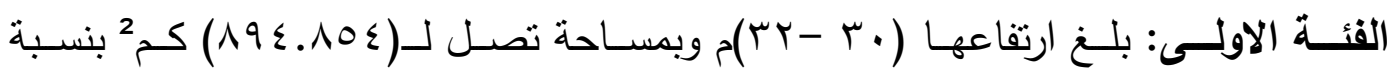

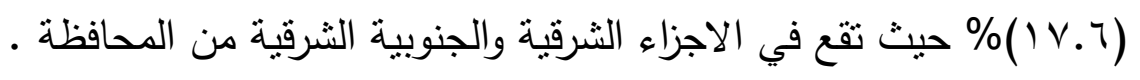

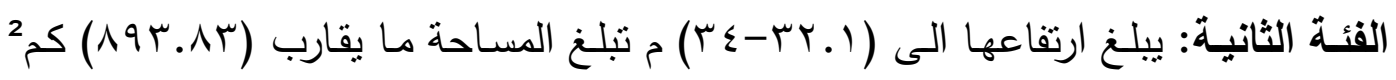

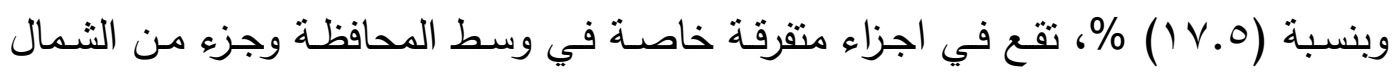
الغربي اضافة لوجودها ملاصقة للفئة السابقة. 


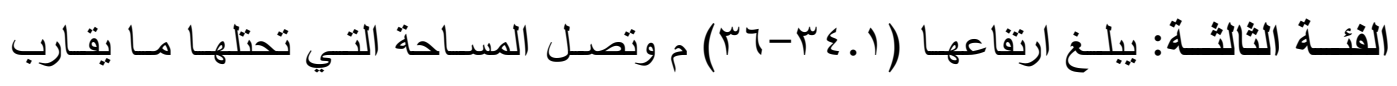

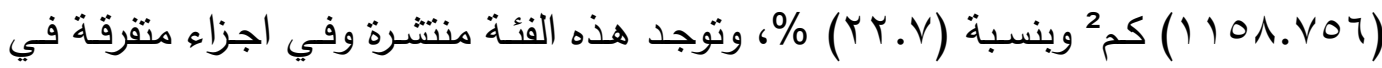

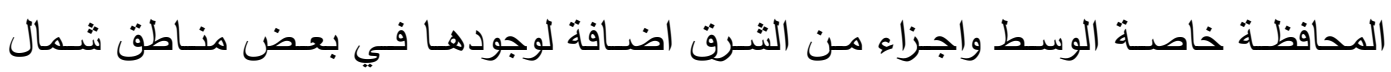

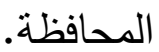

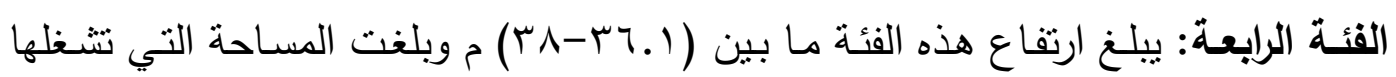

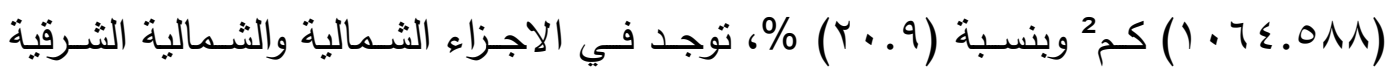
وكذلك في الاجزاء الغربية من محافظة بغداد.

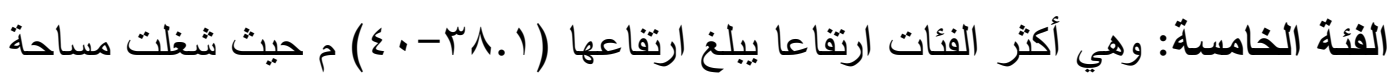

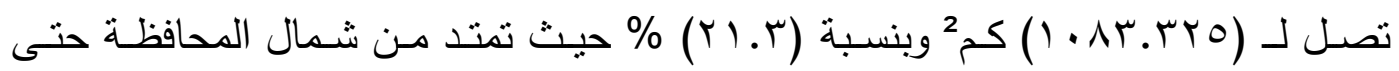
وسطها اضافة للأجزاء الغربية التي تعد امتداد لمحافظة الانبار .

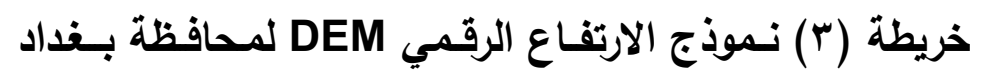

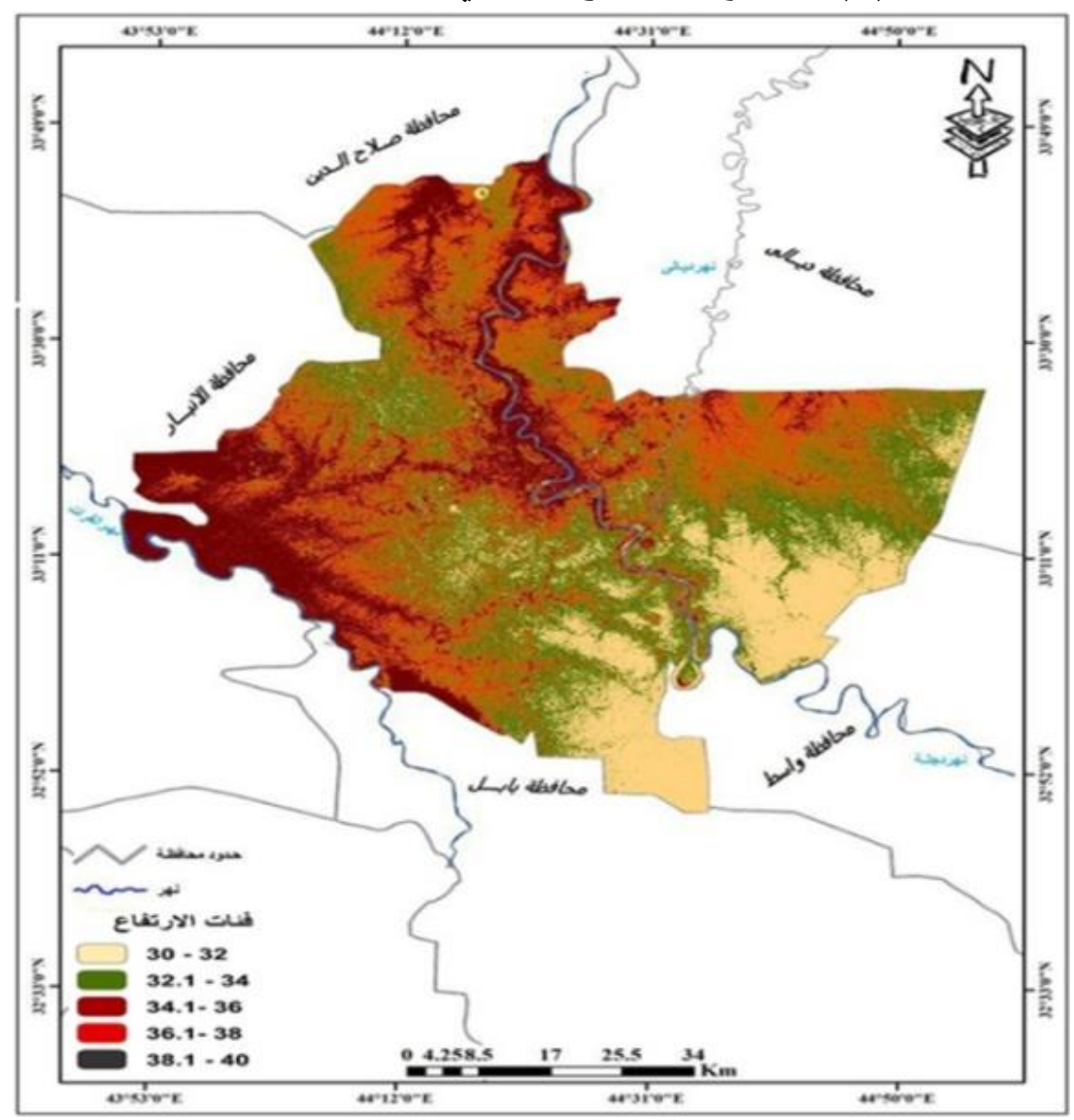

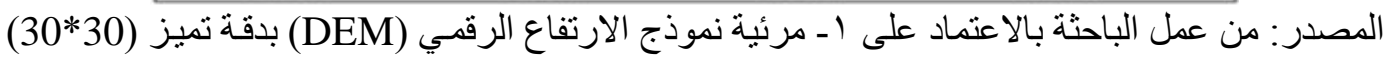

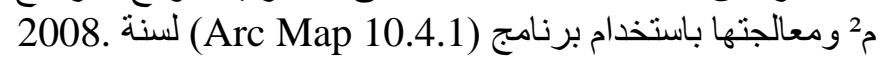

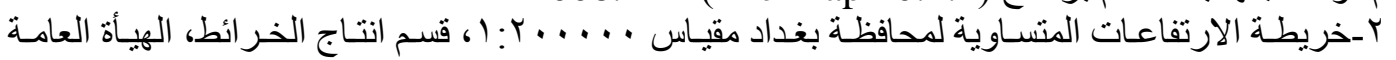

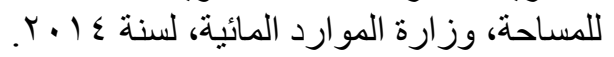




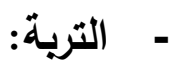

للتربة دور مهم على استعمالات الارض بزراعة النخيل، تتمو شجرة النخيل في مدى

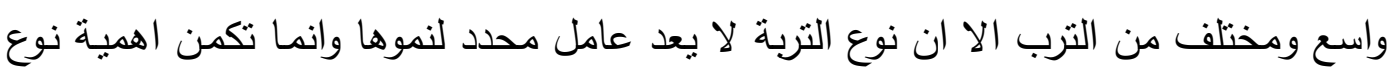

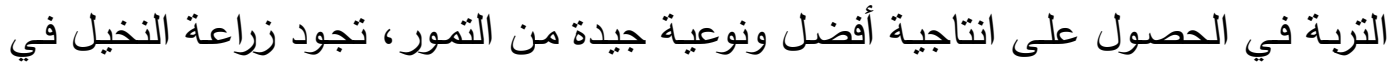

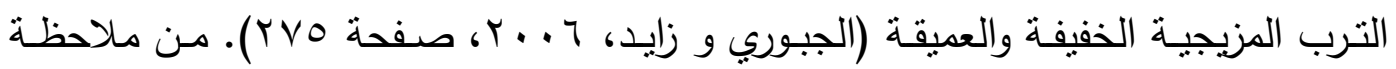
الخريطة (ع) والجدول (r) تبين ان ترب محافظة بغداد بمكن تقسيمها للا يأتي:

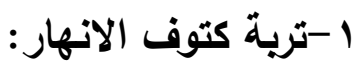

هي ترب مزيجية غرينية ذات نسيج خشن الى منوسط الخشونة مكون من نسب مختلفة

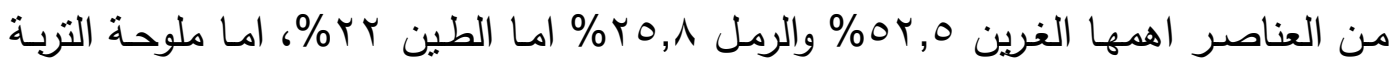

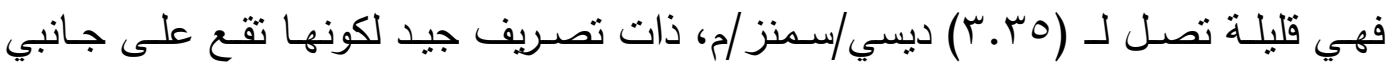

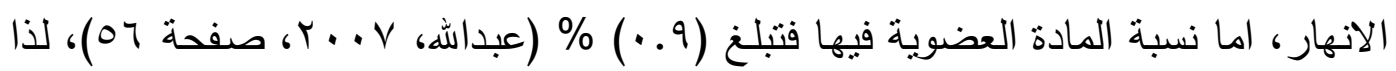

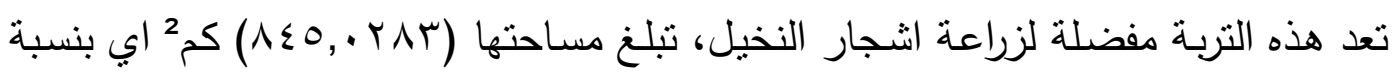
تصل الى 1, 7 (1\% من مساحة ترب المحافظة. r-ترية احواض الانهار المطمورة بالغرين:

توجد هذه الترب في الاجزاء المنخفضة بعد ترب كتوف الانهار مباشرة ذات ارتهات باتهاع يقل

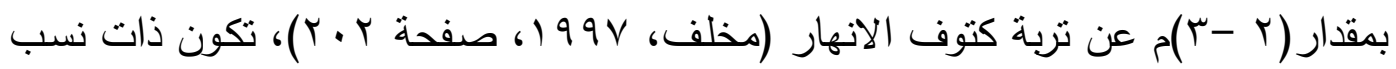

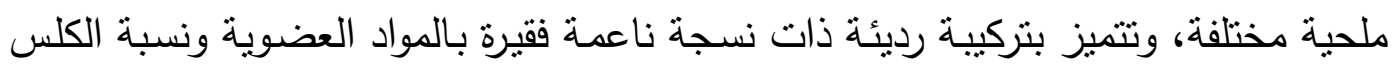

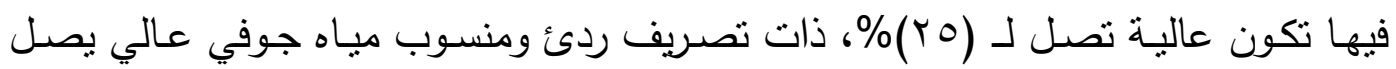

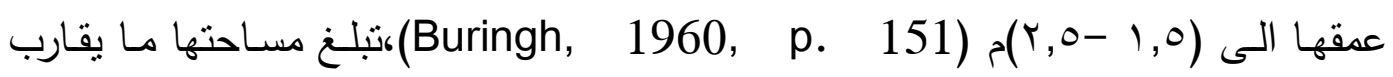

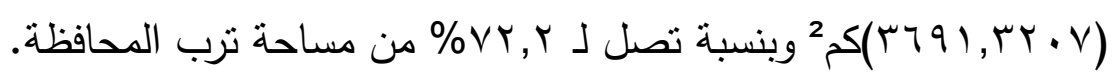
r-تربة السهول النهرية القديمة المطمورة بالغرين: وهي جزء من مدرجات الانهار القديمة التكوين، تكون على امتداد طولي في الاجزاء

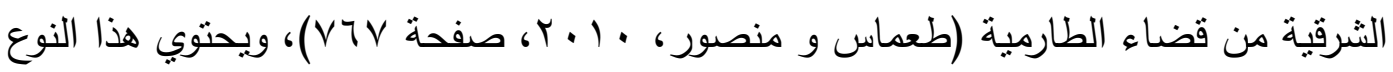

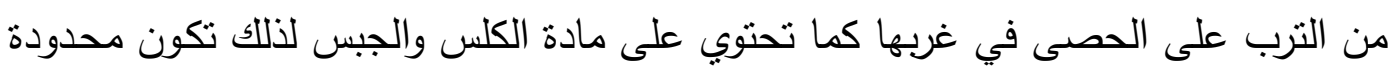

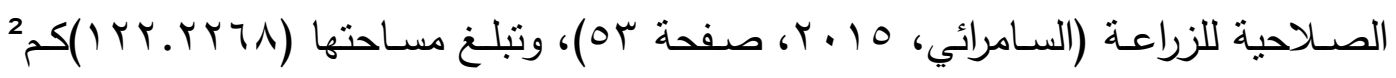
وبنسبة (r.r)\% من مساحة الترب في الدحافظة. ع -التربة الحصوية الجبسية: نتواجد هذه التربة في أنطقه محدودة من المحافظة تحديدا في

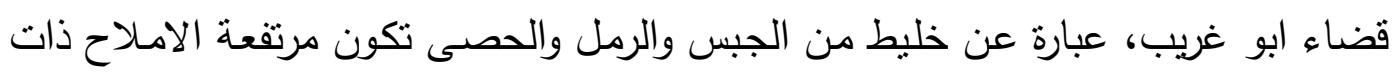

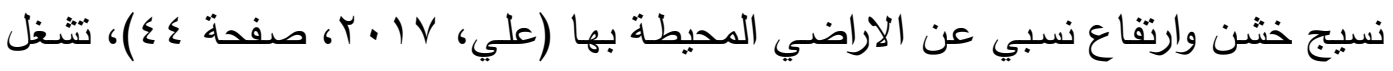

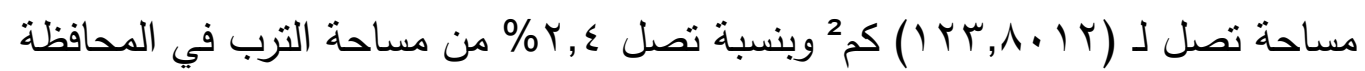


ه-تربة المنذفضات: تعد من اخفض انواع الترب تحتوي على نسبة عالية من الطين تصل الى • ؛ ٪ ذات منسوب مياه جوفي عالي، يعود ذلك لانخفاض سطحها وهي ذات تصريف

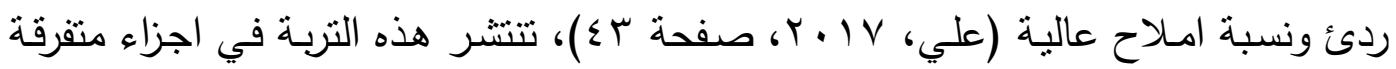

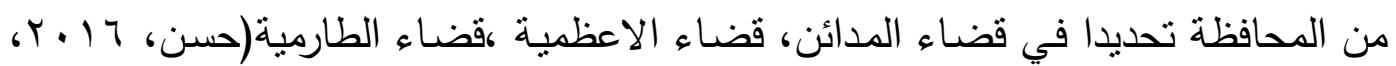

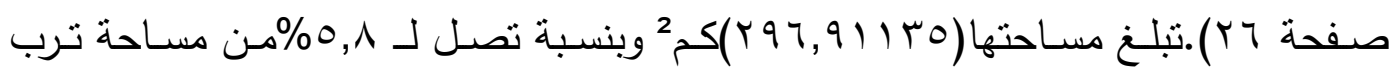

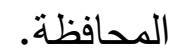

צ-ترية الكثبان المتنقلة: هي عبارة عن ترب معدنبة رملية تتكون من نسب جبس مرتفعة

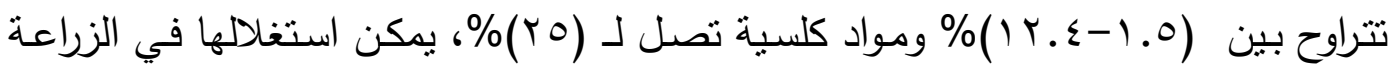

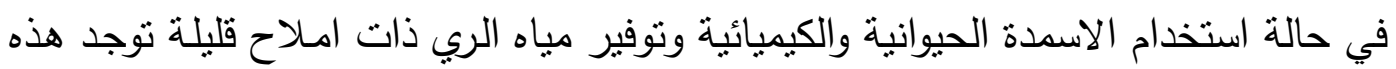
الترب في المحافظة بمحساذاة الجانب الايمسن مـن نهر ديالى تحديدا عند قضـاء المدائن

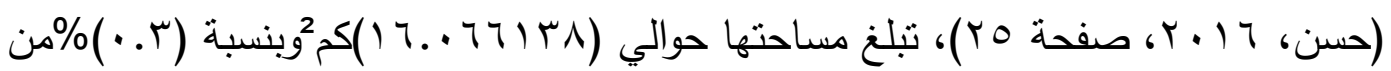

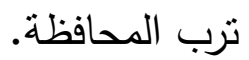

جدول (r)مساحات اصناف الترب في منطقة الاراسة ب(كم²) ونسبها المئوية

\begin{tabular}{|c|c|c|c|}
\hline النسبة \% & المساحة / كم² & 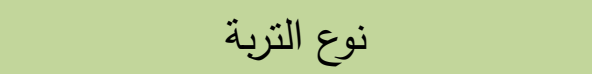 & التسلسل الت \\
\hline.$r$ & $17 . .771 \% 1$ & تربة الكثبان المتتقلة & 1 \\
\hline r.r & ITY.KYTA & تربة السهول النهرية القديمة المطمور & r \\
\hline r. & $1 r r . \Lambda \cdot 1 r$ & تربة حصوية جبسية & r \\
\hline 7 & rq7.9111\%० & تربة انخفاضات الاحواض & $\varepsilon$ \\
\hline iv & $\wedge \Sigma 0 .+r \wedge r$ & تربة كتوف الانهار & 0 \\
\hline VY. & rqq1.rT.V & تربة احواض الانهار المطمورة بالغرين & 7 \\
\hline $1 \ldots$ & $0.90 .0119 \mathrm{~V}$ & & المجموع \\
\hline
\end{tabular}

Source: Buringh.P. Soil المصدر: من عمل الباحثة باستخدام برنامجARC GIS9.3 عتالاعماد على and Soil Condition in Iraq, Ministry of Agriculture, Baghdad1960. 


\section{خريطة (؛) اصناف الترب في منطقة الاراسة}

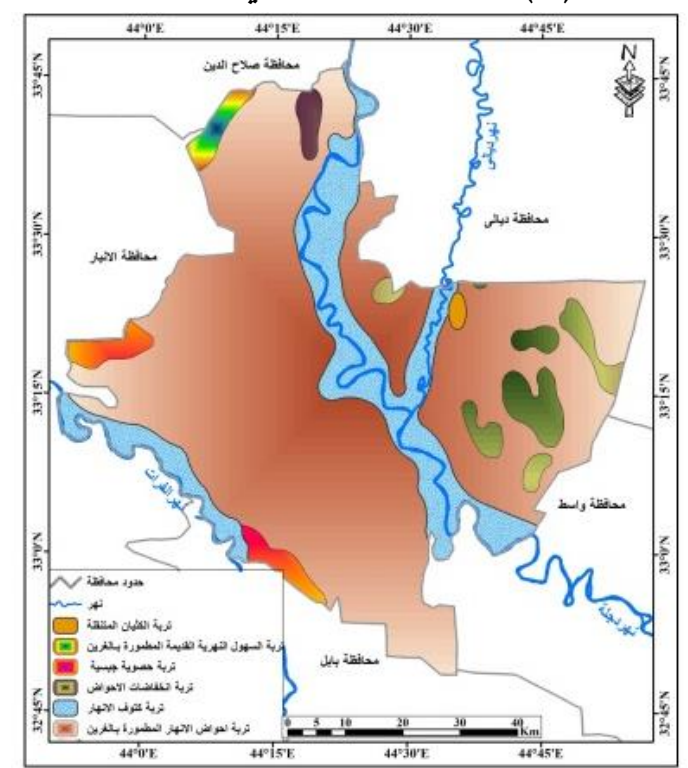

المصدر : من عمل الباحثة باستخدام برنامج ARC GIS9.3 وبالاعتماد على AR

Source: Buringh.P. Soil and Soil Condition in Iraq, Ministry of Agriculture,

Baghdad, 1960 -الموارد المائية: للموارد المائية دور مهم في تغير استعمالات الارض بزراعة النخيل في محافظة بغداد

تتمثل الموارد المائية بالمياه السطحية والجوفيـة والامطار التي سبق توضيحها في موضوع الخصائص المناخية فهي ذات كميات قليلة ومتذبذبة ولا تكفي منطلبات الزراعة. لذا ولاد

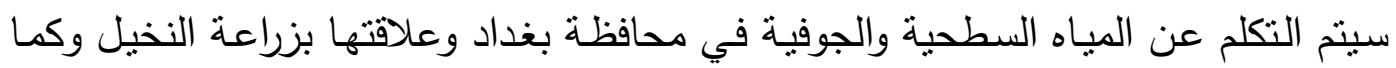
يأتي:

المياه السطحية: يعد نهر دجلة من اهم الموارد المائية في محافظة بغداد اذ له دور رئيس

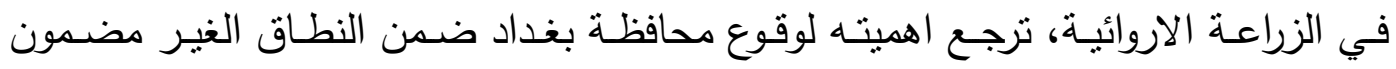

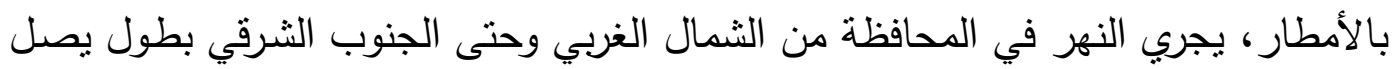

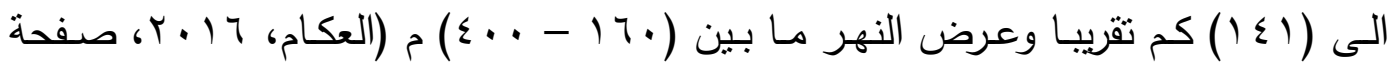

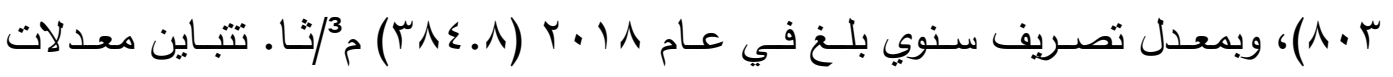
التصريف المائي لنهر دجلة بين سنة واخرى طبقا للسنه المائية اعلى المعدلات للتصاريف

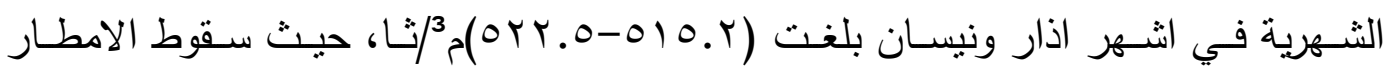

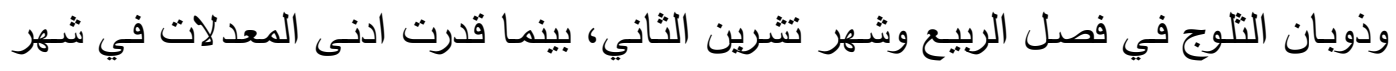

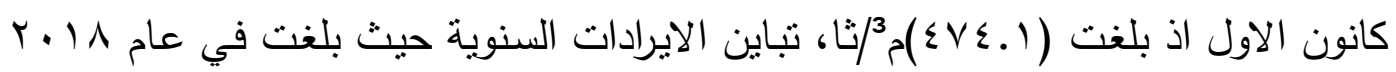

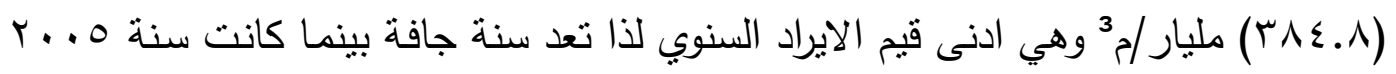

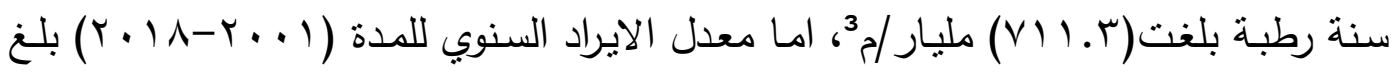

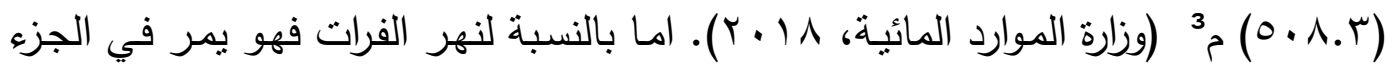


الجنوبي الغربي من منطقة الدراسة حيث يحادد كل من قضاء ابو غريب والمحمودية، ويبلغ

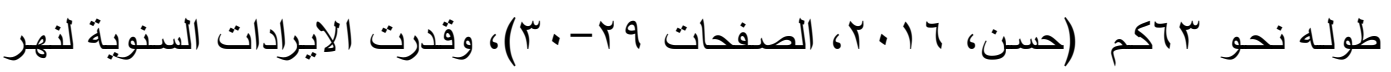

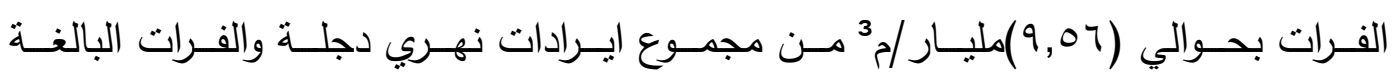

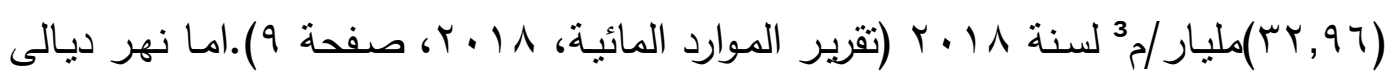
فيعد الرافد الخامس لنهر دجلة اذ يصب فيـه على بعد آسكم جنوب مدينة بغداد (مهنى،

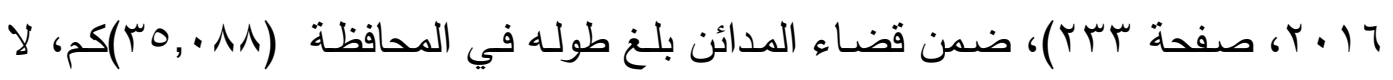

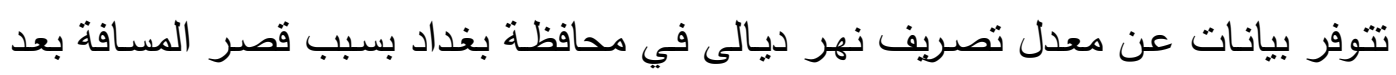
دخوله للمحافظة.

الميـاه الجوفيـة: تعد الميـاه الجوفيـة في المحافظـة المصدر الثاني للموارد المائيـة تتراوح

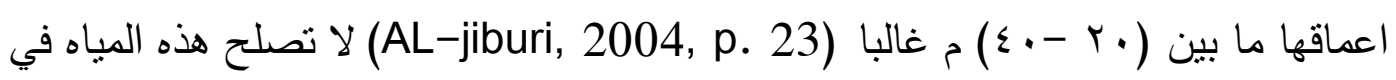

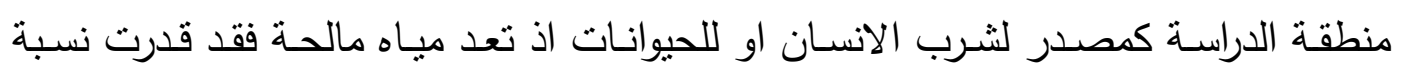

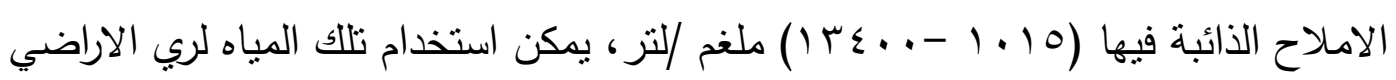

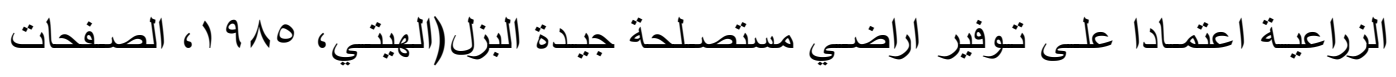

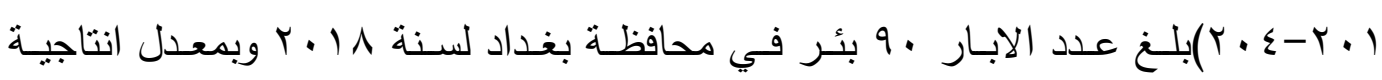

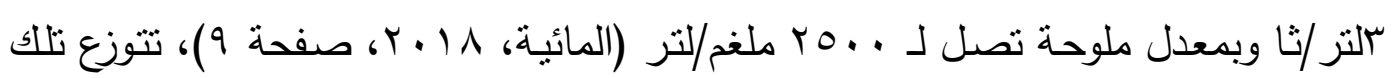
الابار في المناطق البعيدة عن مياه الانهار . العداه

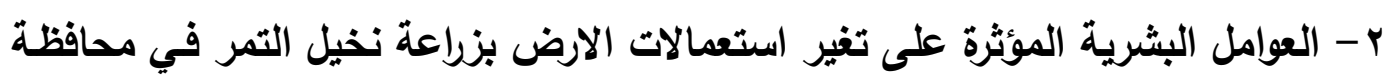
بغداد تعد العوامل البشرية ذات تأثير مباشـر في تغير استعمالات الارض بزراعـة النخيل

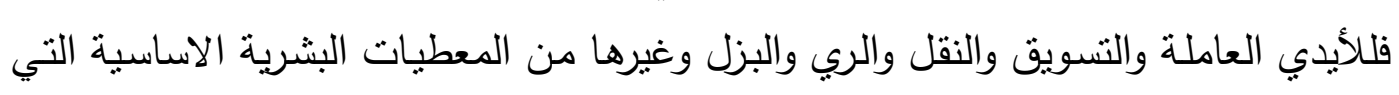
لها دور رئيس حتى وان توفرث العوامل الطبيعية.

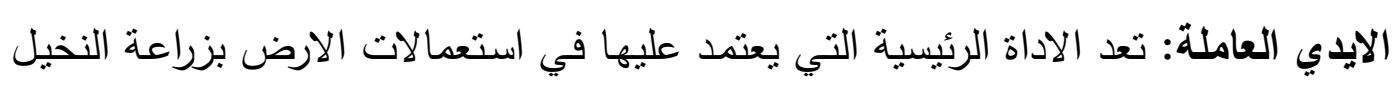

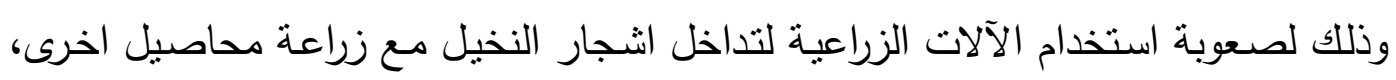

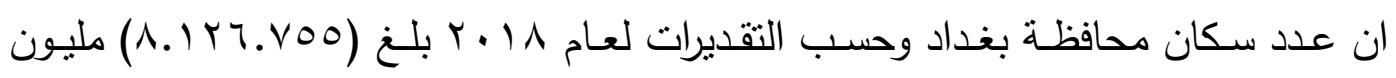

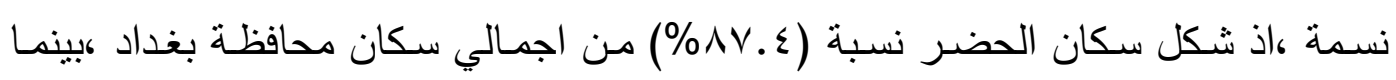

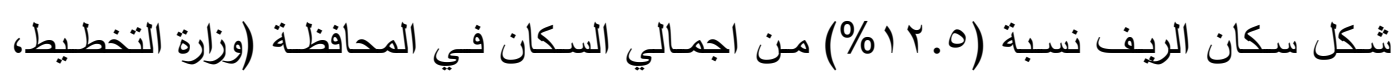

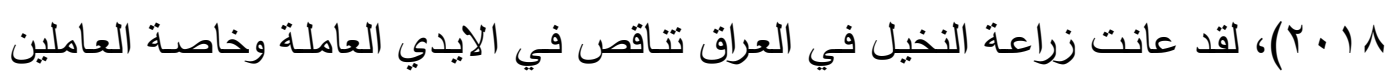

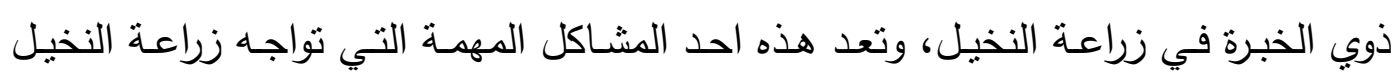

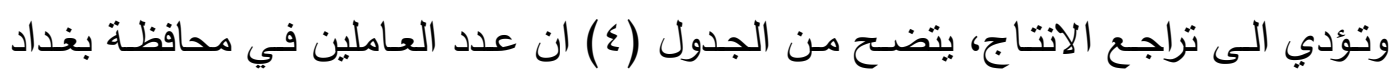

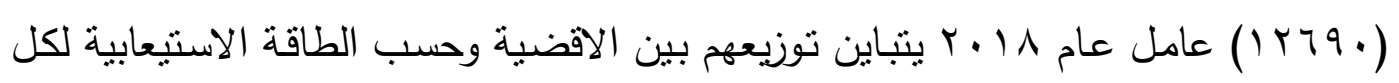


بستان، فنجد ان قضاء المحمودية يأتي بالمرتبة الاولى حيث بلغ عدد العاملين في بساتين

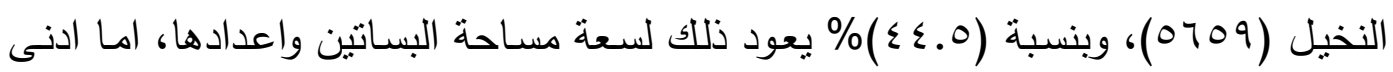

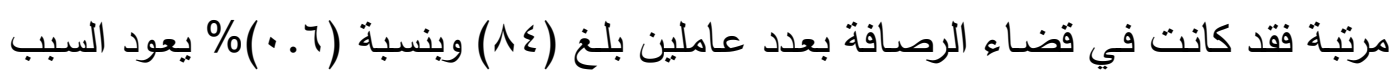

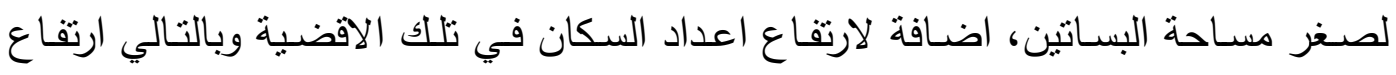

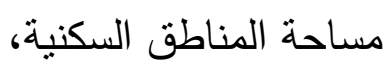

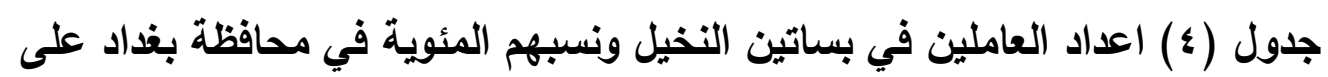

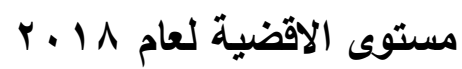

\begin{tabular}{|c|c|c|}
\hline$\%$ & عدد العاملين في بساتين النخيل & القضاء \\
\hline. .7 & $\Lambda \varepsilon$ & الرصافة \\
\hline 0.7 & $v \backslash V$ & الاعظمية \\
\hline 1.0 & $\leq 91$ & الكرخ الك \\
\hline 9 & $11 \leqslant 9$ & الكاظمية \\
\hline$\varepsilon \varepsilon .0$ & 0709 & المحمودية \\
\hline Ir. & WIT & ابي غريب \\
\hline 10.7 & 191. & الطارمية \\
\hline v & $\wedge 91$ & المدائن \\
\hline $1 \ldots$ & 1479. & المجموع \\
\hline
\end{tabular}

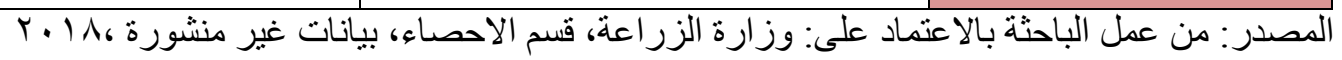

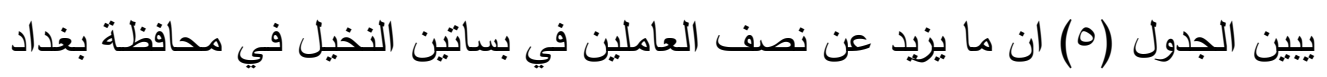

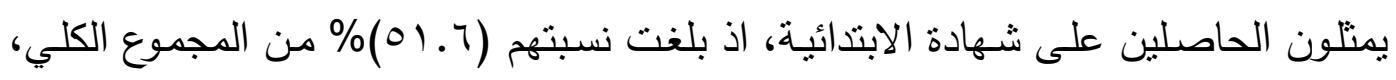
جاء بعدها حملة شهادة المتوسطة وبنسبة (7 (1)\% من اجمالي العدد الكلي للعاملين، يليهم

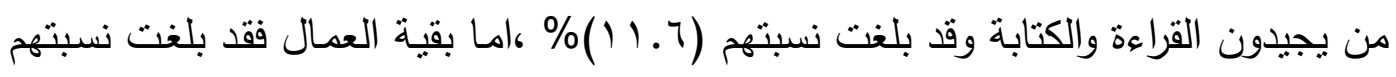

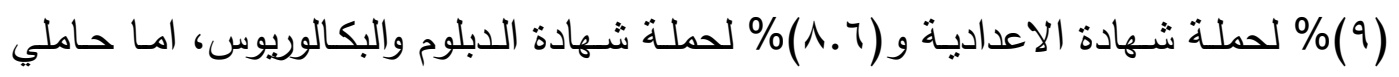

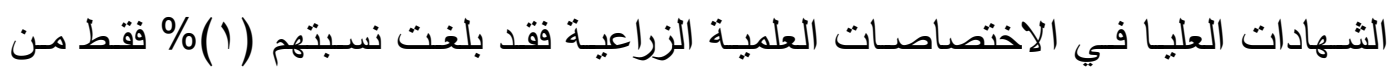

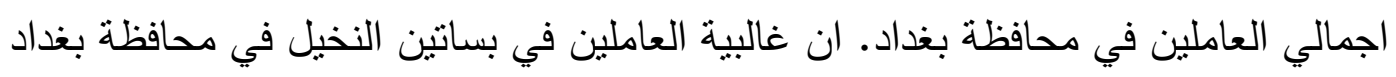

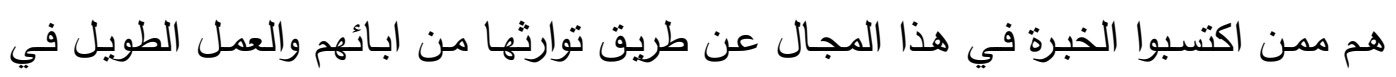

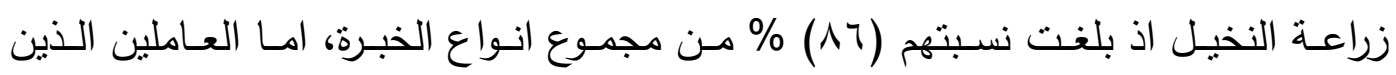

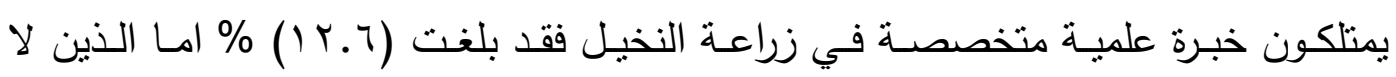

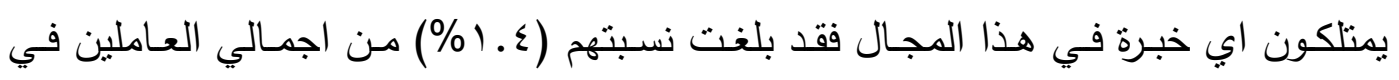

بساتين النخيل، يلاحظ الجدول (؟) والخريطة (؟). 

$ه|\varepsilon \varepsilon r / p r \cdot r|$
مجلة الآداب/ ملحق العدد بrا (آذار)

جدول (0) المستوى التعليمي للعاملين في بساتين النخيل في محافظة بغداد ^ ا ـ r

\begin{tabular}{|c|c|c|c|c|c|c|c|c|c|c|c|c|c|c|c|c|c|}
\hline \multicolumn{2}{|c|}{ المجموع } & \multicolumn{2}{|c|}{ شهادات } & \multicolumn{2}{|c|}{ ويكالوريوس } & \multicolumn{2}{|c|}{ اعدادية } & \multicolumn{2}{|c|}{ متوسطة } & \multicolumn{2}{|c|}{ ابتدائية } & \multicolumn{2}{|c|}{ يقرا ويكتب } & \multicolumn{2}{|c|}{ امي } & \multirow[t]{2}{*}{ الاقضية } & \multirow[t]{2}{*}{ ت } \\
\hline$\%$ & عدد & $\%$ & عدد & $\%$ & عدد & $\%$ & عدد & $\%$ & عدد & $\%$ & عدد & $\%$ & عدد & $\%$ & عدد & & \\
\hline .7 & $r$ & - & - & - & - & - & - & - & - & $1 \ldots$ & $r$ & - & - & - & - & الرصافة & 1 \\
\hline 0.7 & $r \wedge$ & - & - & $1 \cdot . v$ & $r$ & 11 & $r$ & $I V . \Lambda$ & - & or.o & 10 & 1 & $r$ & - & - & الاعظمية & $r$ \\
\hline r.A & 19 & - & - & - & - & - & - & 17 & $r$ & VT. T & $1 \varepsilon$ & $0 . r$ & 1 & $0 . r$ & 1 & الكرخ & $r$ \\
\hline 9 & $\leqslant 0$ & - & - & $\wedge . \wedge$ & $\varepsilon$ & $\varepsilon . \varepsilon$ & $r$ & Ir.r & 7 & IV & $r$. & 纟. & r & r.r & 1 & الكاظمية & $\varepsilon$ \\
\hline$\varepsilon \varepsilon . \wedge$ & YYE & $\cdot .1$ & r & $v .1$ & 17 & $\Lambda .9$ & $r$. & 11 & $\varepsilon$. & $01 . V$ & 117 & $1 . r r$ & $r r$ & r.l & v & المحمودية & - \\
\hline 14.7 & 71 & - & - & $11 . \mathrm{V}$ & $\wedge$ & $1 . r r$ & v & Ir & $\wedge$ & $r v$ & ro & ro & iv & $\varepsilon . r$ & $r$ & ابي غريب & 7 \\
\hline 10.0 & $\vee \wedge$ & - & - & $1 . r r$ & $\wedge$ & $1 . r r$ & $\wedge$ & 17.7 & ir & 00.1 & $\varepsilon r$ & $7 . \varepsilon$ & 0 & $1 . r$ & 1 & الطارمية & $v$ \\
\hline$v$ & ro & - & - & $11 . \varepsilon$ & $\varepsilon$ & $1 \leqslant . r$ & • & $1 \leq$ & - & $\varepsilon r$ & 10 & $1 \leqslant . Y$ & 0 & r.^ & 1 & المدائن & $\wedge$ \\
\hline $1 \ldots$ & $0 .$. & .. & $r$ & 1.7 & $\leqslant r$ & 9 & $\leqslant 0$ & 17 & $\Lambda$. & 01.7 & $Y \otimes \Lambda$ & 11.7 & $\Delta \wedge$ & Y.A & $1 \varepsilon$ & المجموع & \\
\hline
\end{tabular}

المصدر : من عمل الباحثة بالاعتماد على استمارة الاستبيان ،السؤ ال الثان هامن.

خريطة (0) التوزيع الجغرافي للمستوى التعليمي للعاملين

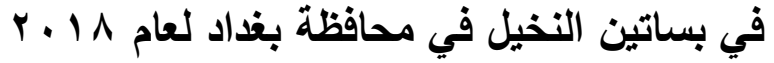

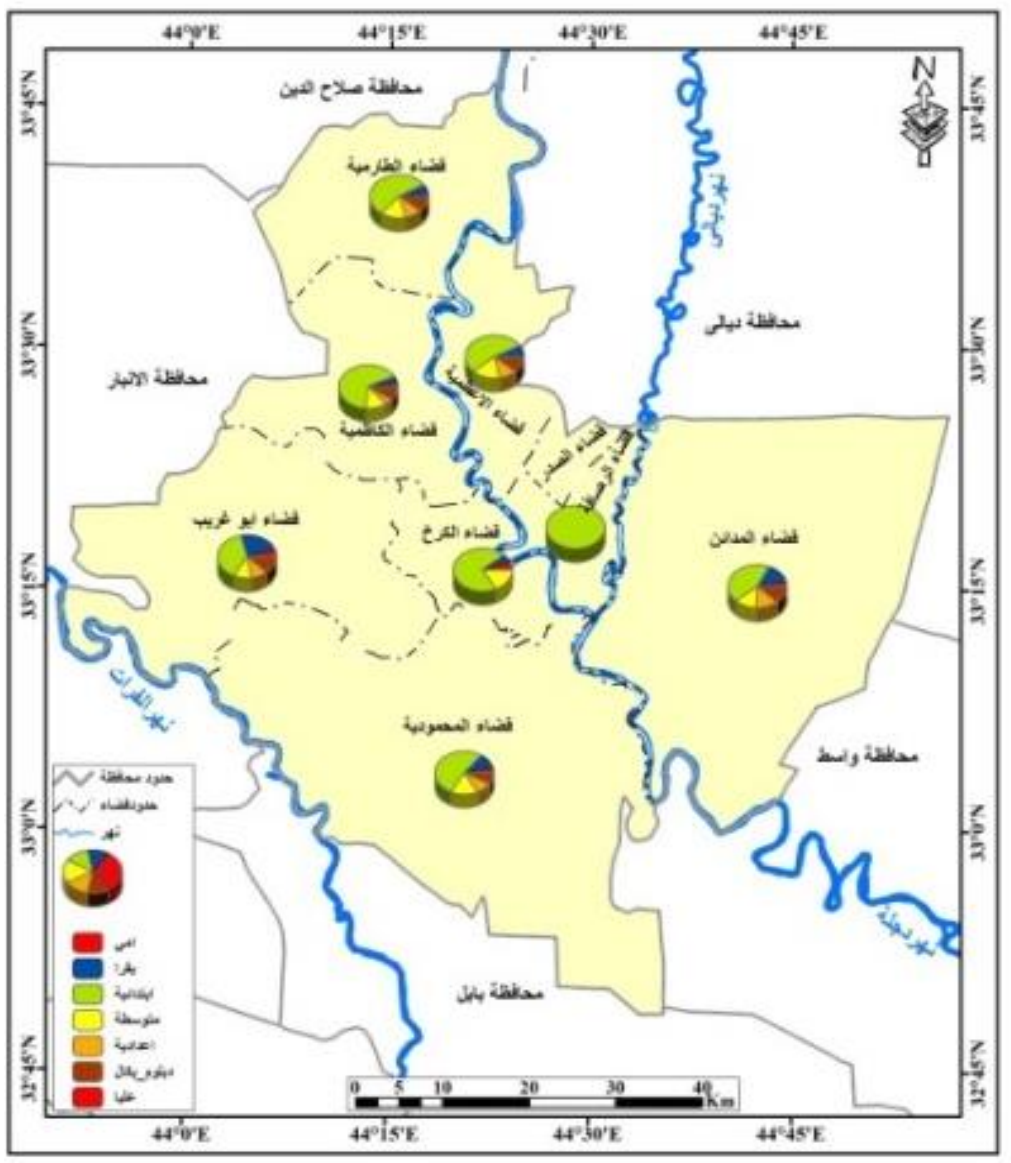

المصدر : من عمل الباحثة بالاعتماد على الجدول(0) وباستخدام برنامج ARC GIS9.3 


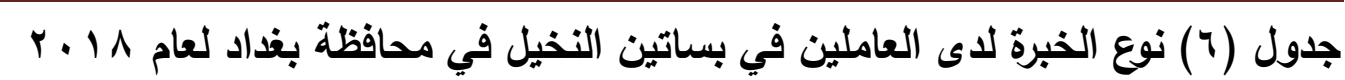

\begin{tabular}{|c|c|c|c|c|c|c|}
\hline$\%$ & لا توجد خبرة & $\%$ & خبرة علمية & $\%$ & خبرة مكتسبة & القضاء \\
\hline- & - & - & - &. .7 & $r$ & الرصافة \\
\hline$\because r$ & 1 & $\cdot . \wedge$ & $\varepsilon$ & $\varepsilon .7$ & rT & الاعظمبة \\
\hline- & - & - & - & $r . \wedge$ & 19 & الكرخ \\
\hline.$r$ & 1 & 1 & 0 & $\vee . \Lambda$ & rq & الكاظمية \\
\hline.$\wedge$ & $\varepsilon$ & $\varepsilon .7$ & rr & rq. & $19 V$ & المحمودية \\
\hline- & - & r & 1. & 11.7 & 01 & ابي غريب \\
\hline.$r$ & 1 & r.A & $1 \leqslant$ & Ir.T & Tr & الطارمبة \\
\hline- & - & $1 . \varepsilon$ & v & 0.7 & r^ & المدائن \\
\hline $1 . \varepsilon$ & v & $1 Y .7$ & $7 \varepsilon$ & $\wedge 7$ & $\varepsilon r q$ & المجموع \\
\hline
\end{tabular}

المصدر : من عمل الباحثة بالاعتماد على استمارة الاستبيان السؤال رقم 9. خريطة (7) التوزيع الجغرافي لنوع الخبرة لاى

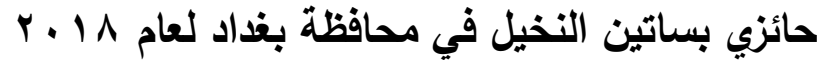

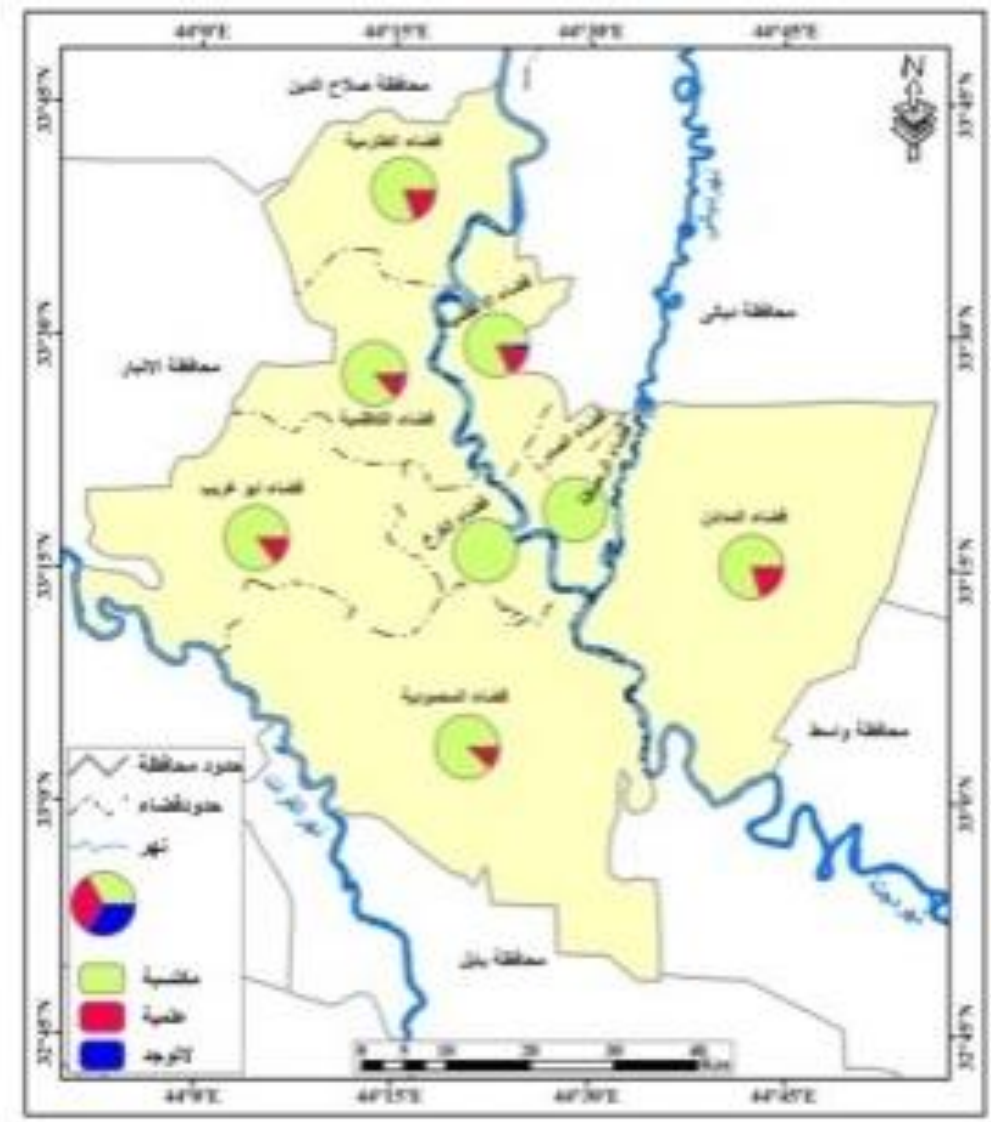

ARC GIS 9.3 المصدر : من عمل الباحثة بالاعتماد على الجدول (7 (1) وباستخدام برنامج 
طرق النقل والتسويق: ان طرق النقل لها دور كبير في تغير استعمالات الارض الزراعية اذ تعد المنفذ التجاري لتسويق المحاصيل وتعد طرق النقل الحلقة الرابطة بين مراكز الانتاج

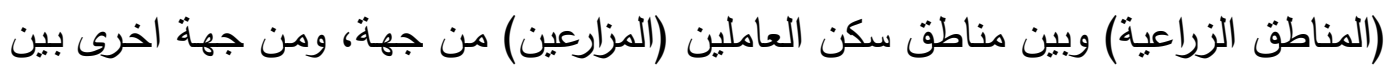

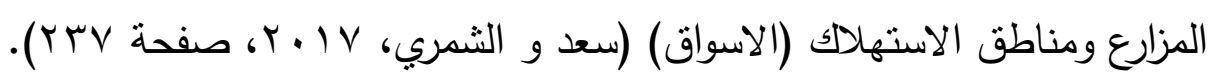

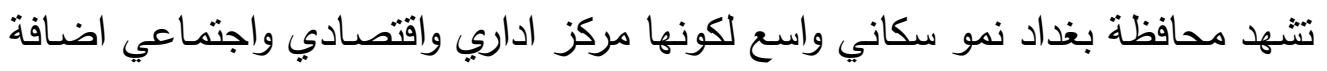

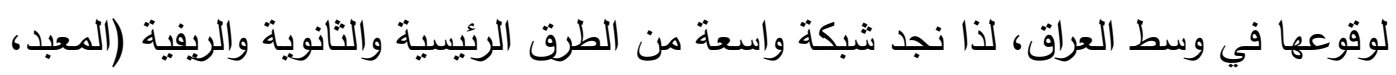

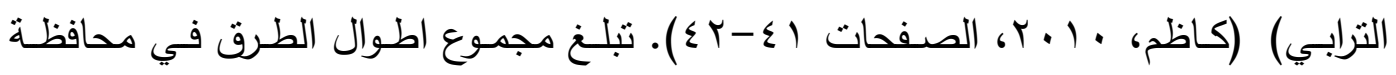

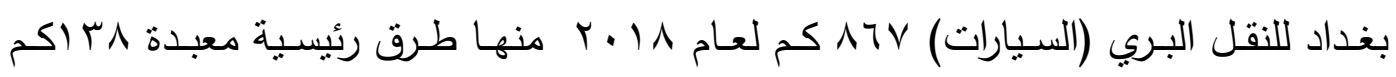

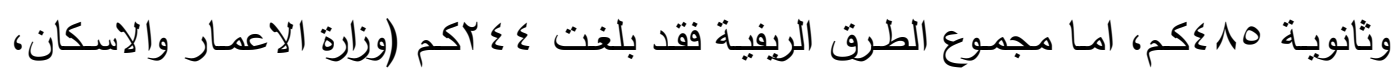

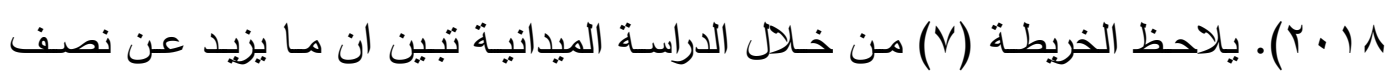

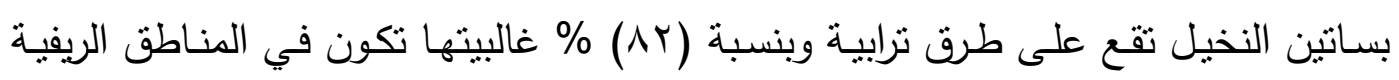

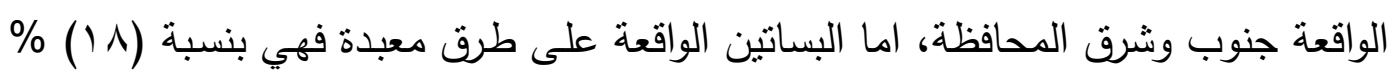

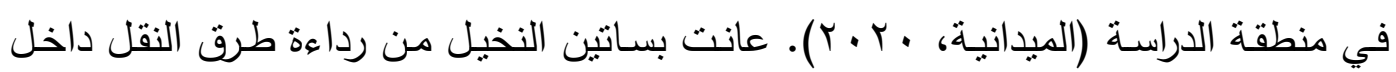
البستان مما اثر سلبا على جودة المحصول ونقله.

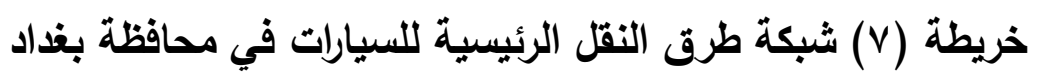

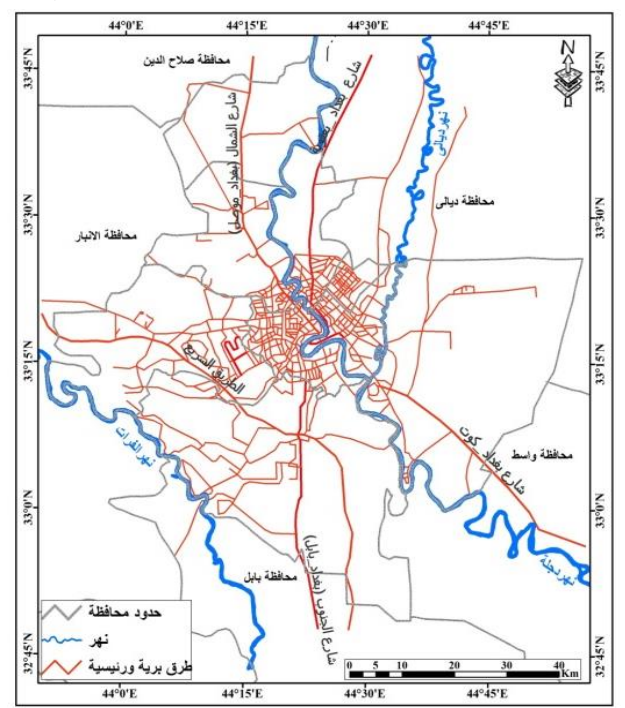

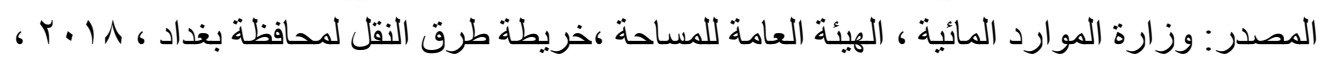

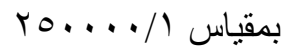

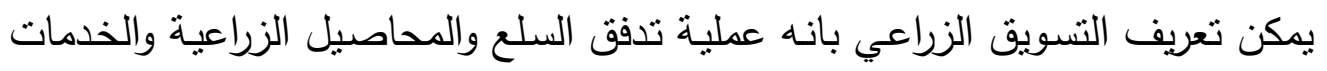

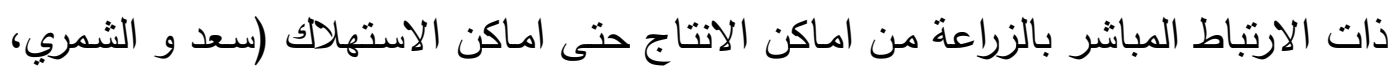

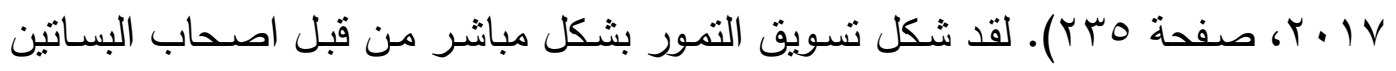

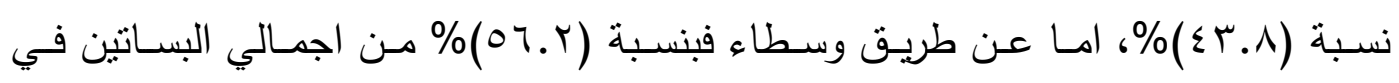

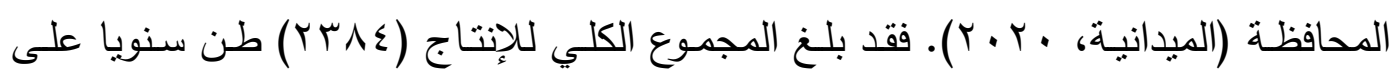


مستوى محافظة بغداد. بسبب عزوف الدولـة عن استلامه من المزارعين وتركت المزارع

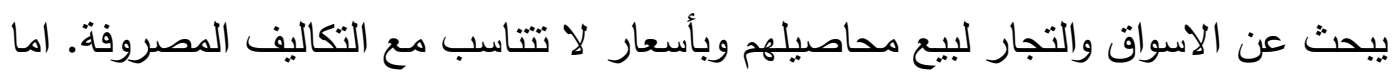
على مستوى الاقضية نجد هناك تباين في كميات الانتاج المسوقة من التمور ، فقد سجلت

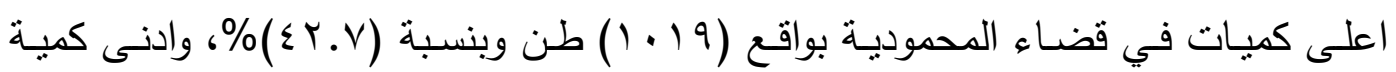

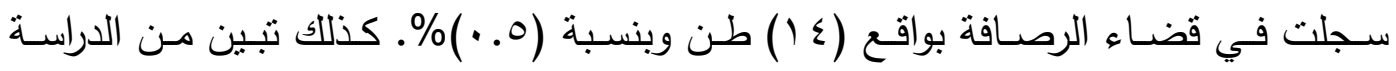

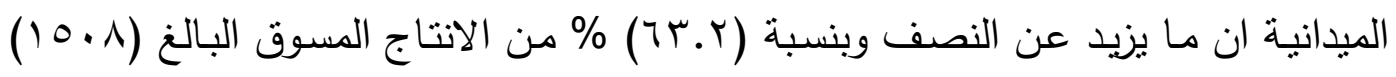

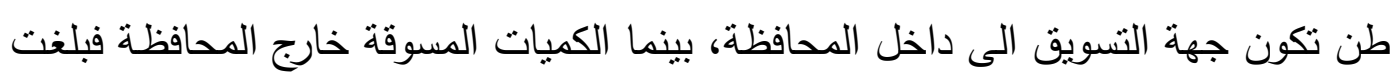

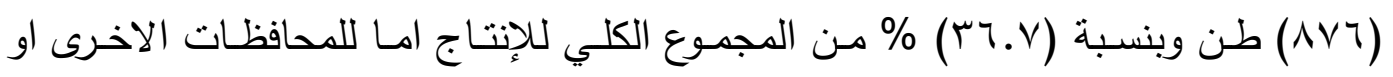

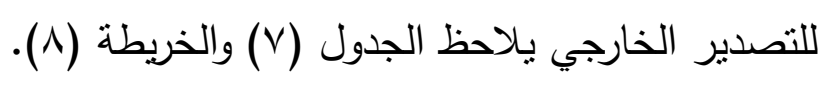

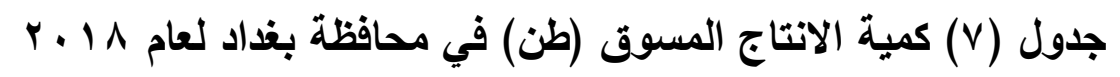

\begin{tabular}{|c|c|c|c|c|c|c|}
\hline \multicolumn{4}{|c|}{ جهة التسويق } & \multirow[t]{2}{*}{$\%$} & \multirow{2}{*}{ الاجمالتي كمية } & \multirow[t]{2}{*}{ القضاء } \\
\hline$\%$ & المحافظة & $\%$ & الدحافظة & & & \\
\hline - & - & $1 \cdots$ & $1 \varepsilon$ & $\because 0$ & $1 \varepsilon$ & الرصافة \\
\hline$r \Lambda$ & $0 \leqslant$ & 71.9 & 11 & 7 & $1 \leqslant Y$ & الاعظمية \\
\hline$r \Lambda_{.0}$ & rY & 7.4 & 01 & r.乏 & $A \Gamma$ & الكرخ \\
\hline$r \wedge$ & $9 \varepsilon$ & Tr & $10 \leqslant$ & $1 \cdot .4$ & $r \leqslant \wedge$ & الكاظمية \\
\hline r..v & $r v \leqslant$ & Tr.r & $7 \leqslant 0$ & $\varepsilon Y . V$ & 1.19 & المحمودية \\
\hline$r$. & IIr & $v \cdot$ & YIV & $1 \varepsilon$ & rYq & ابي غريب \\
\hline r9.4 & $1 \leqslant V$ & $\because \cdot . \wedge$ & YYA & $10 . \mathrm{V}$ & rvo & الطارمية \\
\hline r.. & $\pi$ & $\pi . V$ & 111 & V.r & $I V \leqslant$ & المدائن \\
\hline r..V & $\Lambda \vee \neg$ & 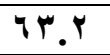 & $10 \cdot 1$ & $1 \ldots$ & $r T \Lambda \varepsilon$ & المجموع \\
\hline
\end{tabular}

خريطة (^) التوزيع الجغرافي للإنتاج المسوق

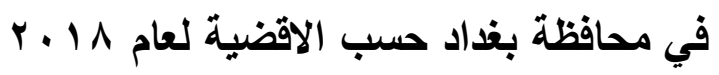

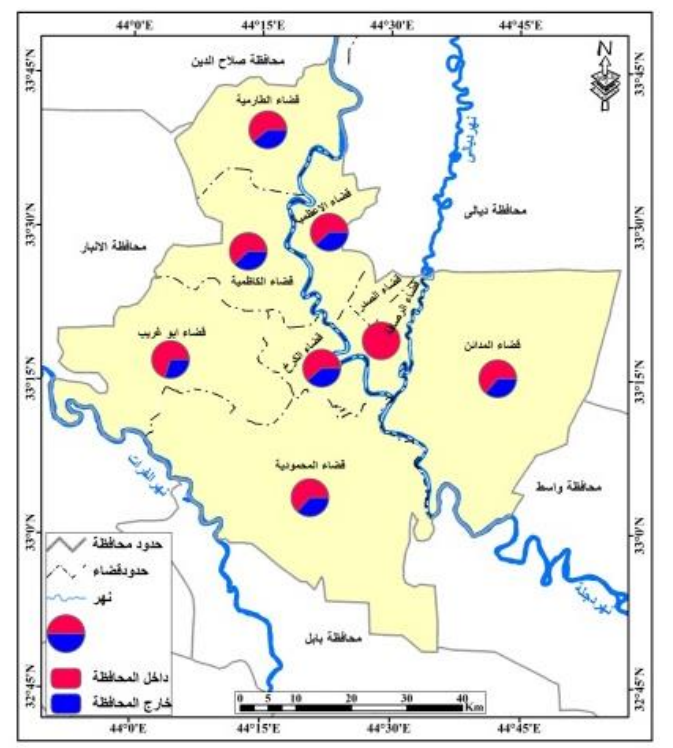

ARC GIS 9.3 المصدر : من عمل الباحثة بالاعتماد على الجدول (V) وباستخدام برنامج 
يعد الري احد الخدمات الزراعية الاساسية في بساتين النخيل خاصة في المناطق الجافة وشبه الجافة لقلة الموارد المائية (الامطار) فيها وتبلغ حاجة اشجار النخيل من مياه الري

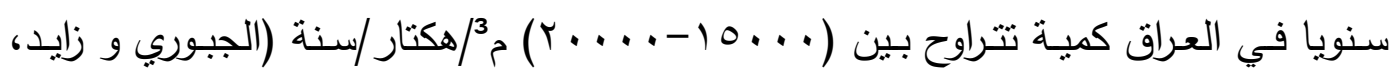

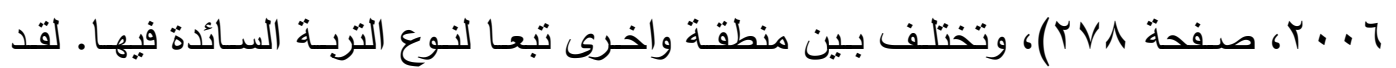
توصلت نتائج الدراسة الميدانية الخاصة بعينة البحث ان غالبية بساتين النخيل في محافظة بغداد تعتمد على الري بطرق تقليديـة والمتمنلة بـالري السيحي والري باستخدام المضـخات وكما يلي :

1- الري السيحي: تستخدم هذه الطريقة في المناطق التي تكون ضفاف الانهار قريبة من مستوى المياه، لذا نجد ان ما يزبد عن نصف تللك البساتين تعتمد على الري السيحي بنسبة (r (T) \% من اجمالي العاملين في بساتين النخيل وبمساحة بلغت ( • ع عـ) دونم (الميدانية، $\cdot(r \cdot r \cdot$ r- الري بالمضخات: تستخدم هذه الطريقة في مناطق كتوف الانهار حيث تكون مستوى

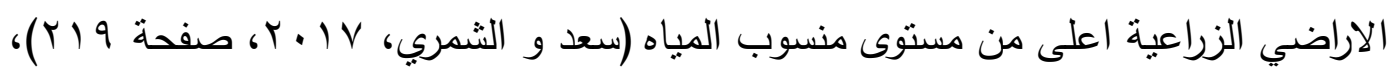
ان نسبة الفلاحين الذين يعتمدون على تلك الطريقة (هب)\% من مجموع مزارعي بساتين

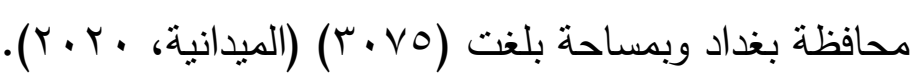
r-الاسـاليب الحديثة في الري (الرش، التنقيط): تستخدم هذه الطرق بنطاق ضيق ومحدود جدا في بساتين النخيل في محافظة بغداد لكونها تتطلب تكلفة عالية وجهد من قبل الفلاح، اذ تبـين ان نسـبة (r) \% مـن حسائزي بسـاتين النخيـل بسـتخدمون الاسـاليب الحديثـة لـري البساتين وغالبا ما تكون لري المساحات المزروعة بالخضروات في ارض البستان وبمساحة

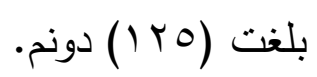
البزل: تعد عملية البزل من اساسيات الخدمات الزراعية الواجب توفيرها للأراضي الزراعية، هـي عبارة عن غسـل التربـة مـن الامـلاح وتخليصـها مسن الميـاه الزائدة خاصـة (السـدي،

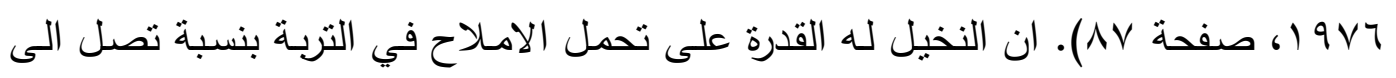

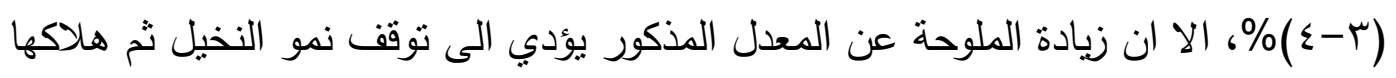
يوجد البزل في محافظة بغداد بطرق طبيعيـة وصناعية فالطبيعي منها تعود لطبيعة السطح وقرب الاراضي من ضفاف نهر دجلة مما يجعل عملية البزل بصورة طبيعية للنهر

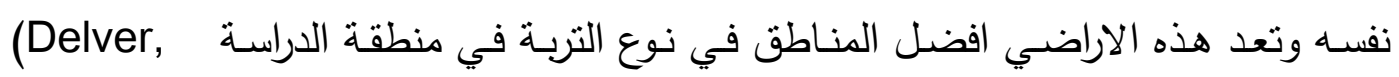
1962, p. 9)، اما البزل الصناعي فيوجد في المحافظة على شكل عدة شبكات وقنوات للري والبزل وفي معظم اجزاء المحافظة، ان مجموع اطوال المبازل في المحافظة وبجميع 


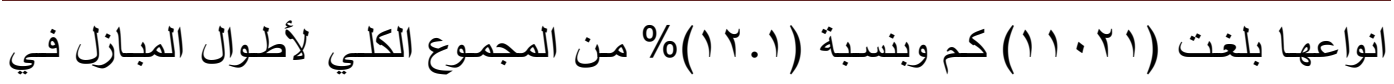

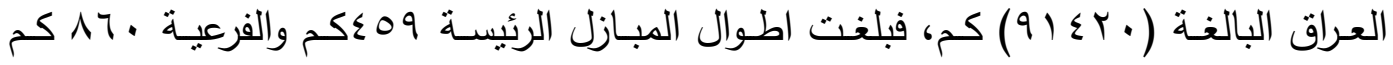

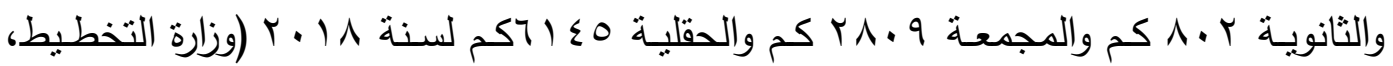

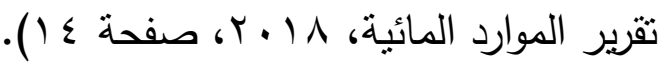
تطبيق الاستثـعار عن بعد لكثف التغير لاستعمالات الارض بزراعة بساتين النخيل في

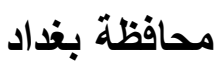

اتسع استخدام مرئيات الاستشعار عن بعد في البحث الجغرافي كونه مصدر للمعلومات

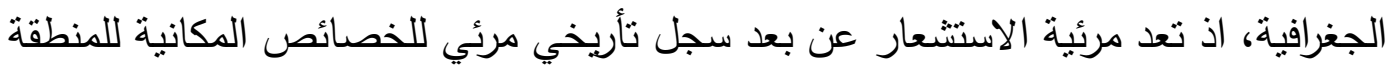

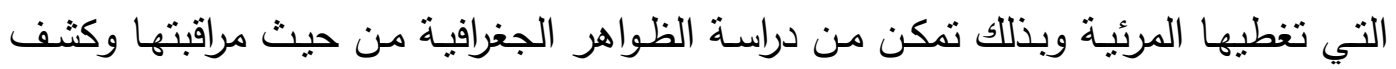
تغيرها واعداد خرائط لتوزيعها الجغرافي واخذ قياسات منها. تم استخدام المرئيات الفضائية

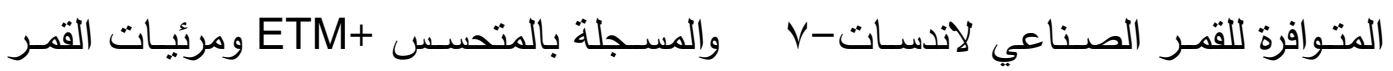

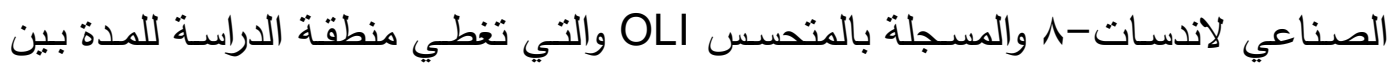

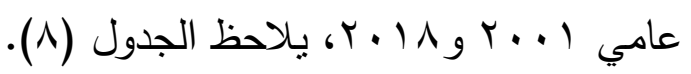

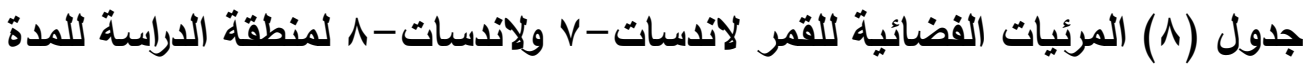
$r+1 \wedge, r+.1$

\begin{tabular}{|c|c|c|c|c|c|}
\hline القنوات الطيفية & Row الصف & path المسار & المتحسس & التاريخ & ت \\
\hline V & rV & 171 & ETM+ & $r \ldots l / 1 . / .0$ & 1 \\
\hline V & rV & 179 & ETM+ & $r \ldots 1 / \cdot q / 1$. & r \\
\hline 9 & TV & 171 & OLI & $r \cdot \mid 1 / \cdot 9 / r T$ & $r$ \\
\hline 9 & $r V$ & 179 & OLI & $r \cdot 1 / / \cdot 9 / \cdot 1$ & $\varepsilon$ \\
\hline
\end{tabular}

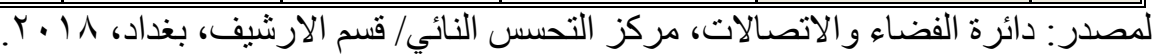

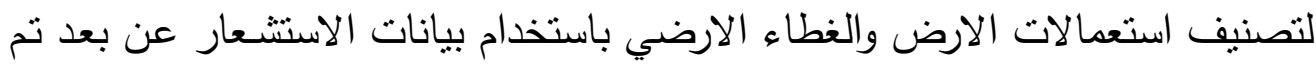
اعتماد نظام اندرسون واخرون المعتمد من قبل هيئة المسح الجيولوجي الامريكي (ASGS) .(Anderaon \& Others, 1976, pp. 5-8)

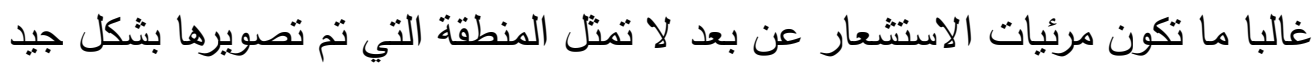

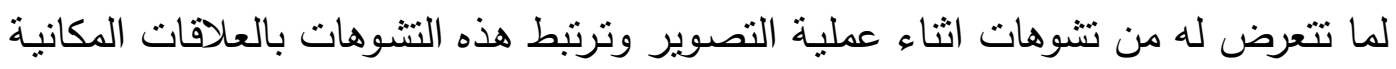

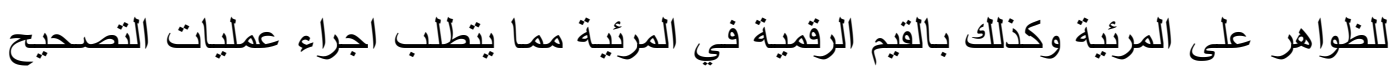

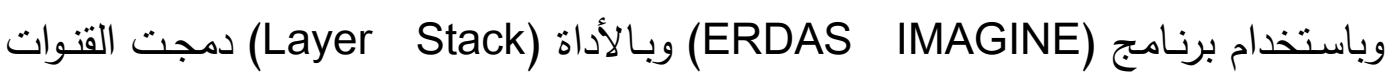
الطيفية المستخدمة في البحث، وبعد تصحيح الخرائط الموضوعية والطوبوغرافية ومطابقتها

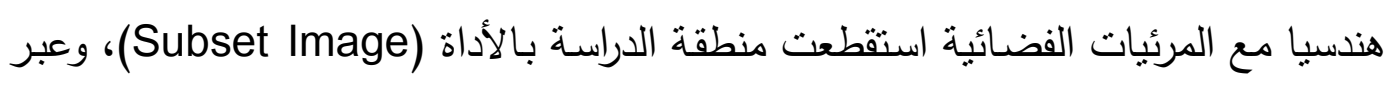

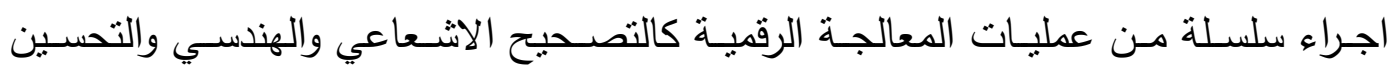


الاشعاعي والطيفي والمكاني والتصنيف غير الموجه والتصنيف الموجه لأصناف استعمالات الارض والغطاء الارضي بصورة عامة واستعمالات الارض بزراعة بساتين النخيل بصورة

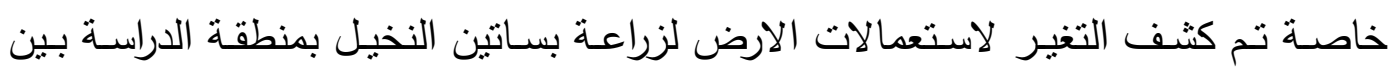
عامي 2001 و 2018 وفق الخطوات التالية: - تصحيح المرئية

تصـيح المرئيـة يؤوبي الـى الحصـول على بيانـات افضـل لتمنيـل المرئيـة الاصـلية

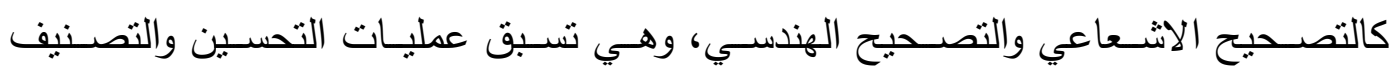
لاستعمالات الارض الزراعية والغطاء الارضي في منطقة الدراسة.

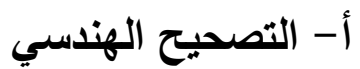

يهدف التصحيح الهندسي للمرئية الفضائية الى تصحيح المرئية وجعلها موحدة هندسيا

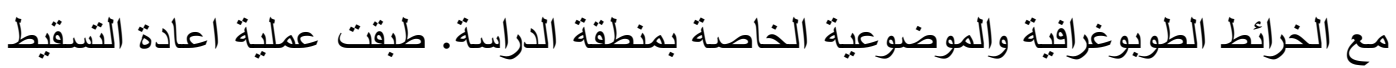
وفاستخدام طريقة المجاور (WGS 84 UTM Zone 38N) وفق مسفة (Reproject) الاقرب (Nearest Neighbor) للبيانـات المكانيـة التي تغطي منطقة الدراسـة للأعوام

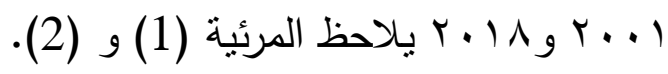
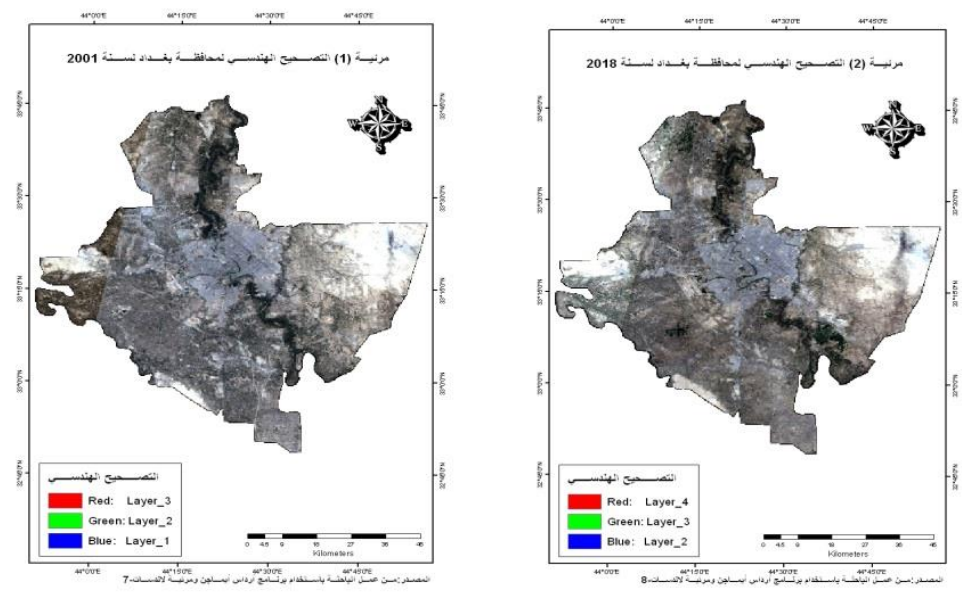

$$
\text { التصحيح الاشعاعي }
$$

يهدف التصحيح الاثتعاعي الى تصحيح التشويه الذي يرتبط بالقيم الرقميـة للأشعة

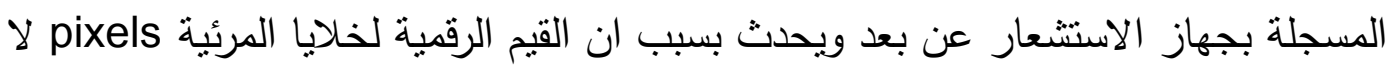

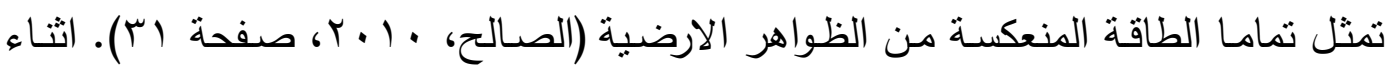

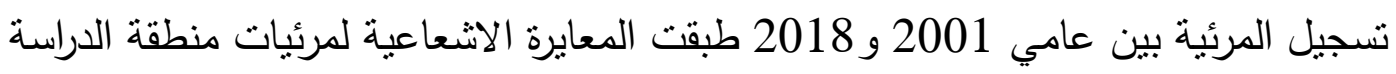

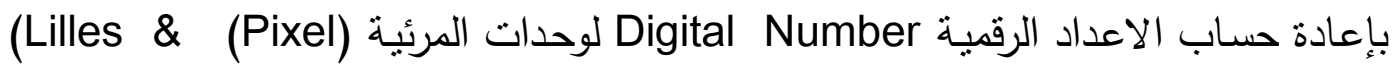
(Meta Data) وبالاعتماد على البيانات الوصفية الاضافية other, 2000, p. 400)

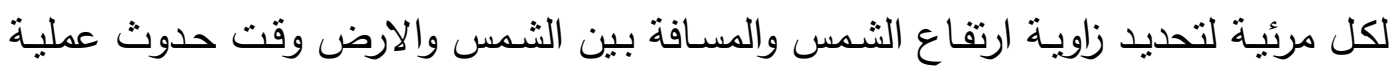


الاستشعار وتحديد المسار Path، والصف Row، وتأريخ التصوير لكل مرئية وتم اجراء التصحيح الاشعاعي والحصول على مرئية مصححة انشعاعيا يلاحظ المرئية (3) و (4).
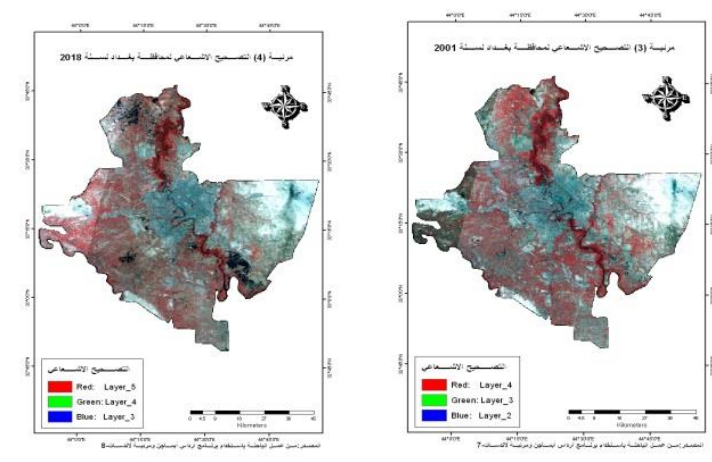

- تحسين المرئيات الفضائية

الهذف الرئيس من التحسين هو معالجة المرئية الرقمية لتكون أكثر ملائمة من المرئية

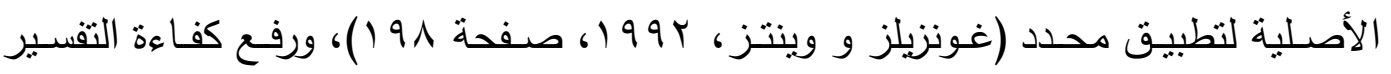
البصري والقدرة على تمييز الاختلافات الاشتعاعية التي تعكسها القيم الرقمية لخلايا المرئية وتشمل ما يأني:

أ- التحسين المكاني( دمج المرئيات)

للحصول على ميز مكاني عال للمرئية الرقمية ودقة عزل أكبر وتمييز للأغطية

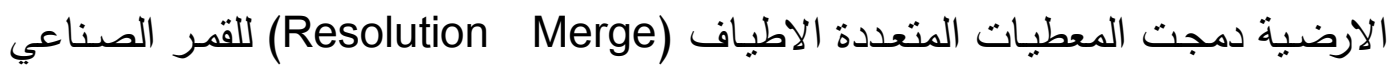

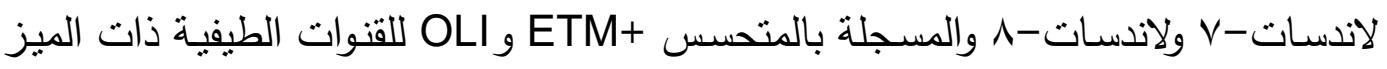
المكاني المنخفض 30 متر مـع القناة الطيفية البانكروماتية ذات الميز المكاني المرتفع 15 متر ، باستخدام الحقيبة البرامجية (ERDAS IMAGINE)، بملاحظة المرئية (5) و (6).
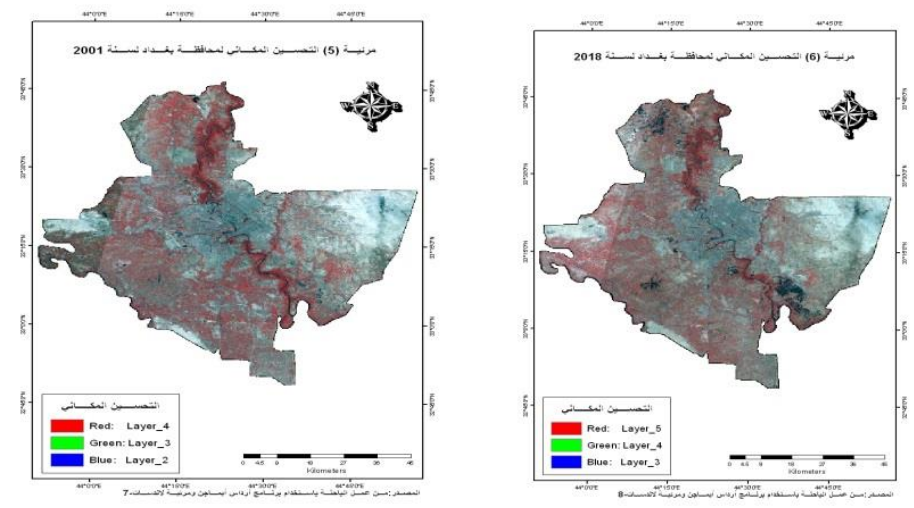

ب- التحسين الاشعاعي

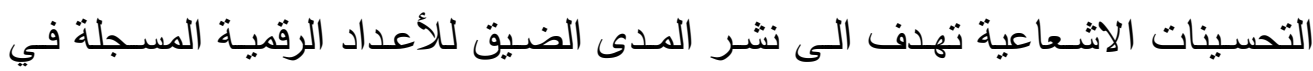

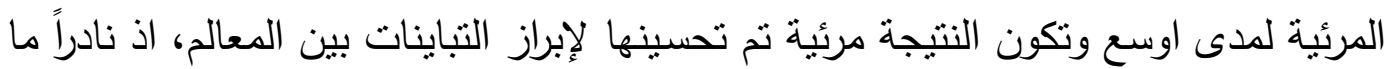

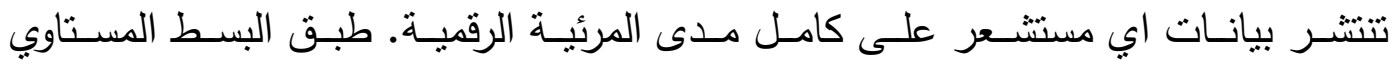


الهيتوغرام (Histogram Equalized) على المرئية الفضائية التي تغطي منطقة الدراسة،

يلاحظ المرئية (7) و (8).
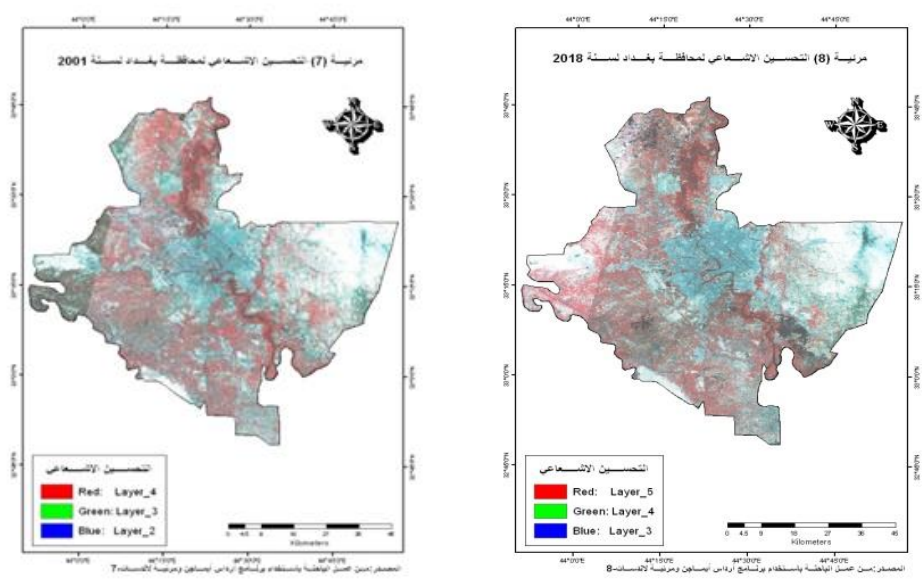

ج- التحسين الطيفي

التحسينات الطيفية تضمنت نوعين من التحسينات وهي تحليل المكونات الرئيسية

Principal Component Analysis

$$
\text { 1 - تحليل المكونات الرئيسية }
$$

يستخدم تحليل المكونات الرئيسية (Principal Component Analysis) لمعالجة التداخل بين القنوات الطيفية فضلا عن ضغط البيانات، اذ تظهر البيانات الرقمية تشابها في قنوات البئل

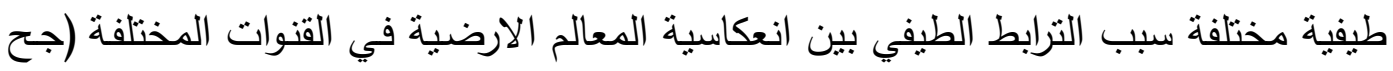

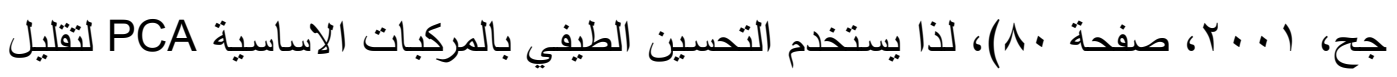

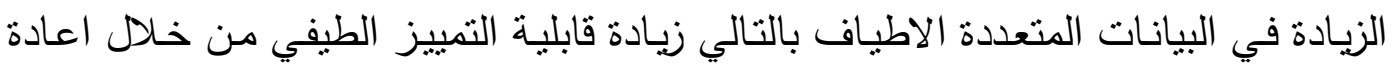

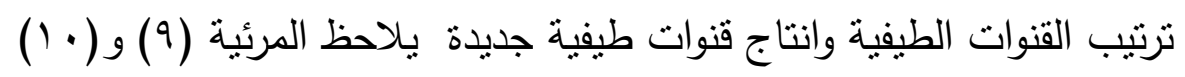
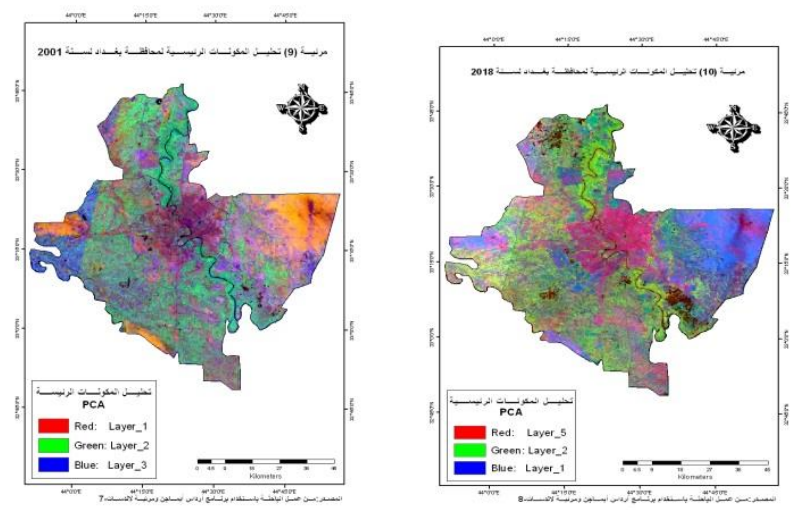

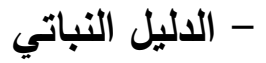

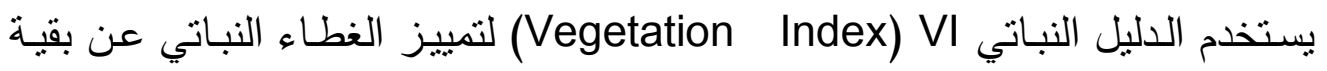

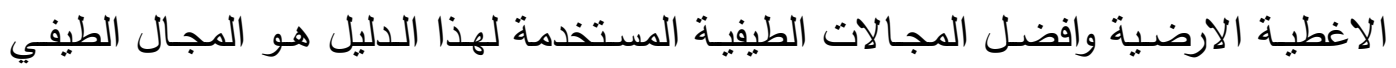


للمنطقة الحمراء (R) والدجال الطيفي للمنطقة تحت الحمراء القريبة (NIR) وحسب الدليل

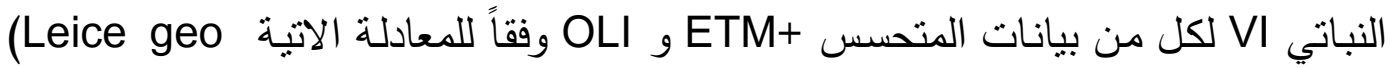
:system Erdas field Guide TM, 2002, pp. 180-182)

$$
\mathrm{VI}=(\mathrm{NIR})-(\mathrm{R}) \ldots
$$

حيث ان R تمثل القــاة الطيفيـة الحمـراء وNIR تمثنل القناة الطيفيـة تحت الحمـراء بملاحظة المرئية (11) و (12) يظهر ان مناطق الانعكاسية العالية لها غطاء نباتي كثيف امـا المناطق ذات الانعكاسية الواطئة فغطاءها النباتي ضعيف او معدوم، والتغير الزماني لقيم الدليل النباتي للمدة بين عامي 2001 و 2018 تبين ان القيم الموجبـة بلغت 121 و 28584 والقيم السالبة بلغت - 93 و - 15828 لكل منها على النوالي
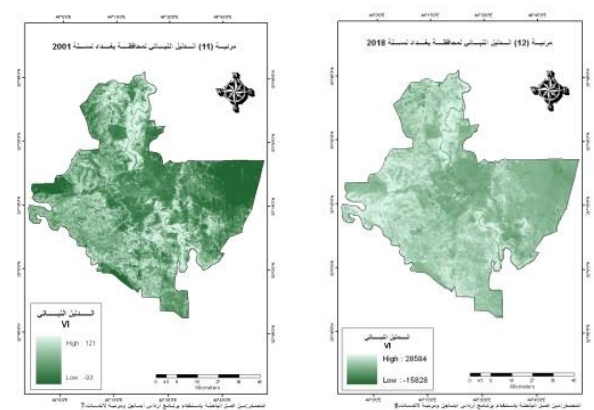

- - دليل الاختلاف النباتي القياسي

Nليل الاختلاف النباتي القياسي Normalized Different Vegetation JNVI Index يمثل احد التحسينات الطيفية المستخدمة بشكل واسع في التقدير الكمي والنوعي للغطاء النباتي وحساب المادة الحية للنبات ومراقبة الجفاف والرطوبة وحالة النباتات والتنتؤ

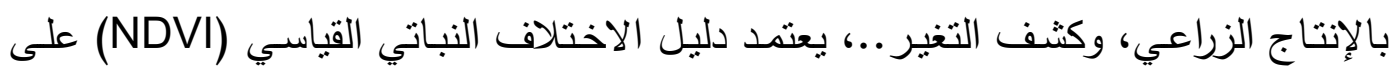
الانعكاسية العالية للنبات في النطاق تحت الاحمر القريب (NIR) والانعكاسية المنخفضة في النطاق الاحمر المرئي (Raul m, 2001, p. 8) (R) ، وحسب دليل الاختلاف النباتي

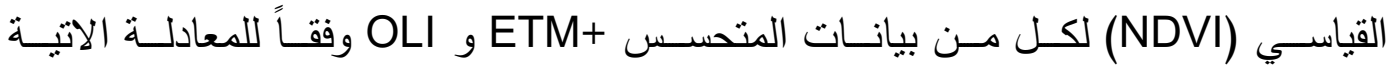
:(Jensen, 2000, p. 363)

$$
N D V I=(N I R-R) /(N I R+R) \ldots 2
$$

بملاحظة المرئية (r () و (ع () يظهر ان مناطق الانعكاسية العالية لها غطاء نباتي

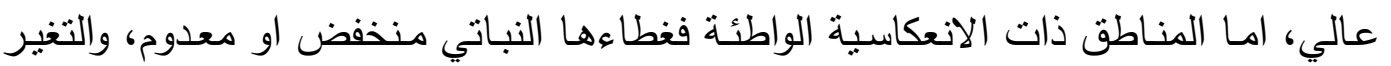

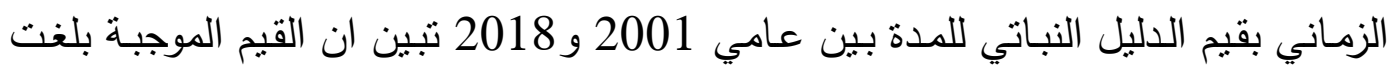
0.64 و 0.59 والقيم السالبة بلغت - 0.49 و - 1 لكل منها على التوالي لئي 

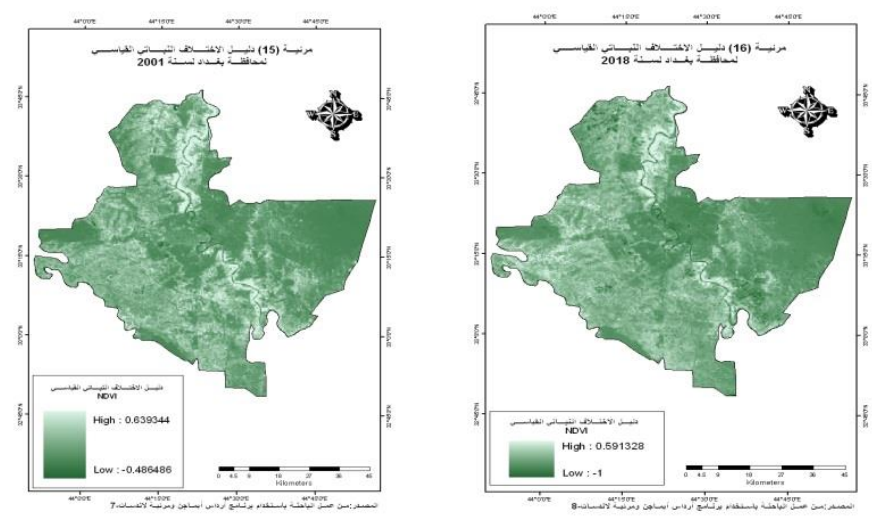

\section{- تصنيف المرئية}

التصنيف الرقمي للمرئية الفضائية يهدف الى انتاج خرائط موضوعية توضح اصناف

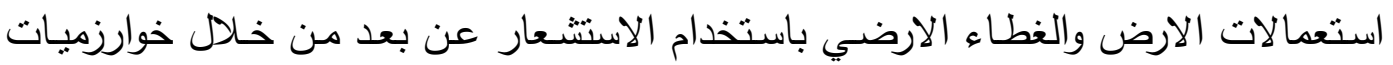

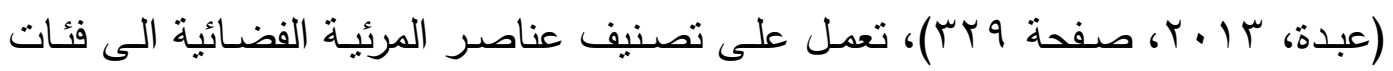

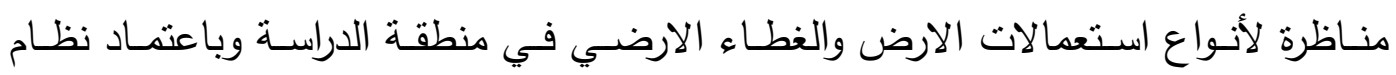

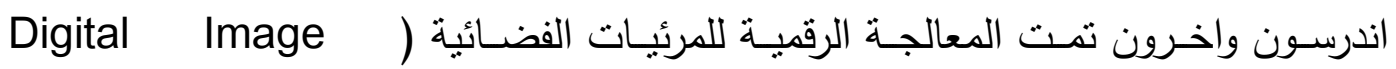
(Processing باستخدام برنامج ERDAS IMAGINE وبطريقة التصنيف الغير موجهـ Supervised و والتصـنيف الموجسه (Unsupervised Classification) (Classification بساتين النخيل بصورة خاصة بمنطقة الدراسة بين سنتي 2001 و و 2018. أ- التصنيف غير الموجه

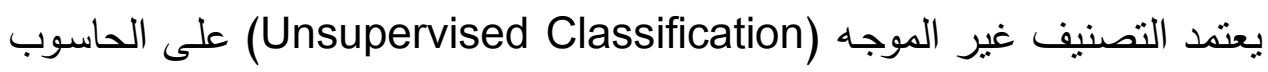
في تحديد الفئات او الاصناف الرقمية كون المفسر لا يمنلك تقييم مبئي للبيانات او معرفة علية

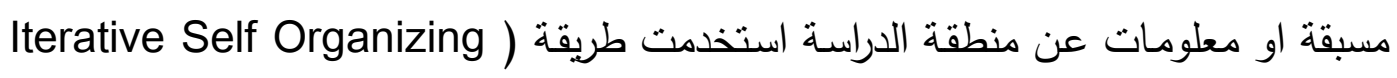
(Data Analysis Technique

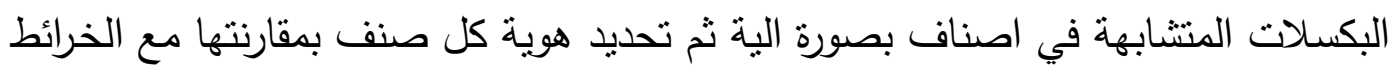

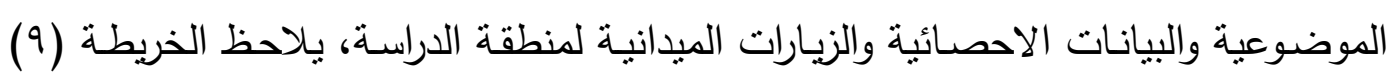

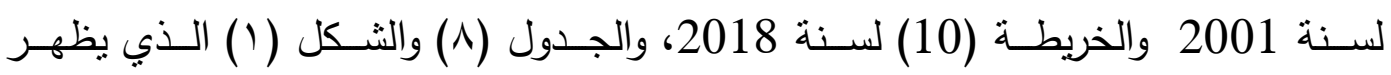
المساحات التي تغطيها اصناف استعمالات الارض بمنطقة الدراسة لسنة 2001، اذذا تنـغل

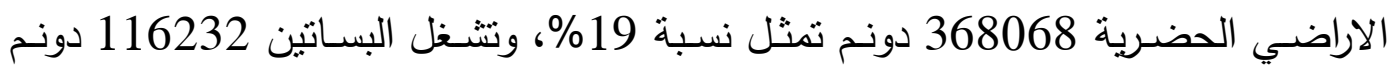
تمثل نسبة 6\%، وتتـغل المحاصيل الحقليـة

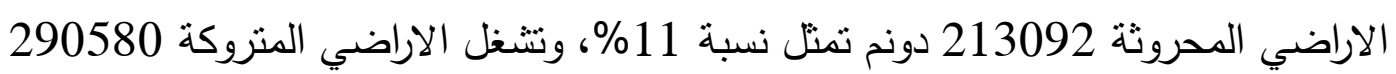


تمثل نسبة 15\%، وتتـغل المياه 38744 دونم تمثل نسبة 2\% والاراضي الجرداء تشغل 561788 دونم تمثل نسبة 29\% من المساحة الكلية لمنطقة الدراسة.

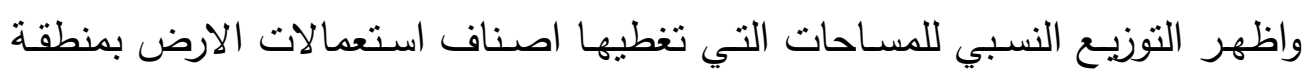

الدراسة لسنة 2018، تشغل الاراضي الحضرية مساحة 445556 دونم تمثل نسبة 23\%، وتثغل البساتين 96860 دونم تمنل نسبة 5\%، وتشغل المحاصيل الحقلية

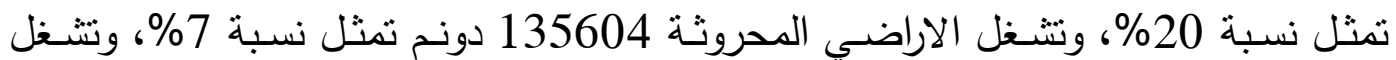
الاراضي المتروكة 232464 تمثل نسبة 12\%، وتتشغل المياه 58116 دونم تمثل نسبة

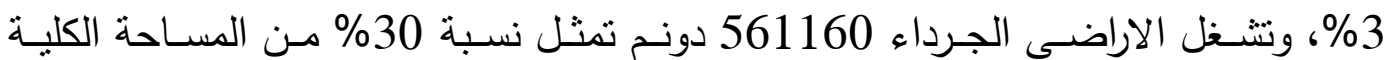

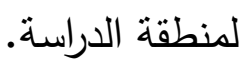
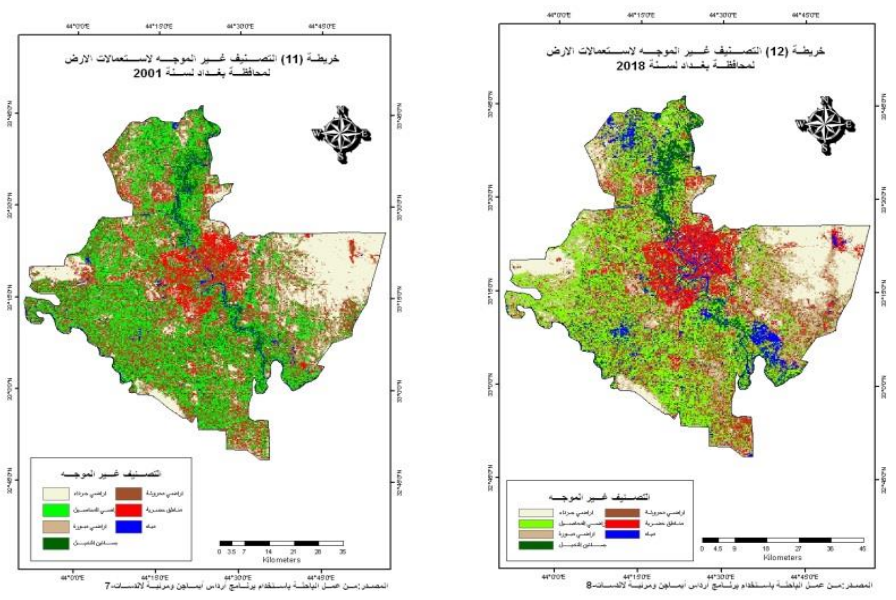

جدول (9) التصنيف غير الموجه لاستعمالات الارض في منطقة الدراسة للمدة بين عامي 2001 و 2018.

\begin{tabular}{|c|c|c|c|c|c|c|}
\hline \multicolumn{3}{|c|}{ سنة 2018} & \multicolumn{3}{|c|}{ سنة 2001} & \multirow{2}{*}{ اصناف استعمالات الارض } \\
\hline$\%$ & دونم & كمَ & $\%$ & دونم & كمَ & \\
\hline 23 & 445556 & 1114 & 19 & 368068 & 920 & المناطق الحضرية \\
\hline 5 & 96860 & 242 & 6 & 116232 & 291 & البساتين \\
\hline 20 & 387440 & 969 & 18 & 348696 & 872 & المحاصيل الحقلية \\
\hline 7 & 135604 & 339 & 11 & 213092 & 533 & الاراضي المحروثة \\
\hline 12 & 232464 & 581 & 15 & 290580 & 726 & الاراضي المتروكة \\
\hline 3 & 58116 & 145 & 2 & 38744 & 97 & المياه \\
\hline 30 & 581160 & 1453 & 29 & 561788 & 1404 & الاراضي الجرداء \\
\hline 100 & 1937200 & 4843 & 100 & 1937200 & 4843 & المساحة الكلية \\
\hline
\end{tabular}

المصدر: من عمل الباحث بالاعتماد على الخريطة (9) والخريطة (10) للانصنيف غير الموجه. 


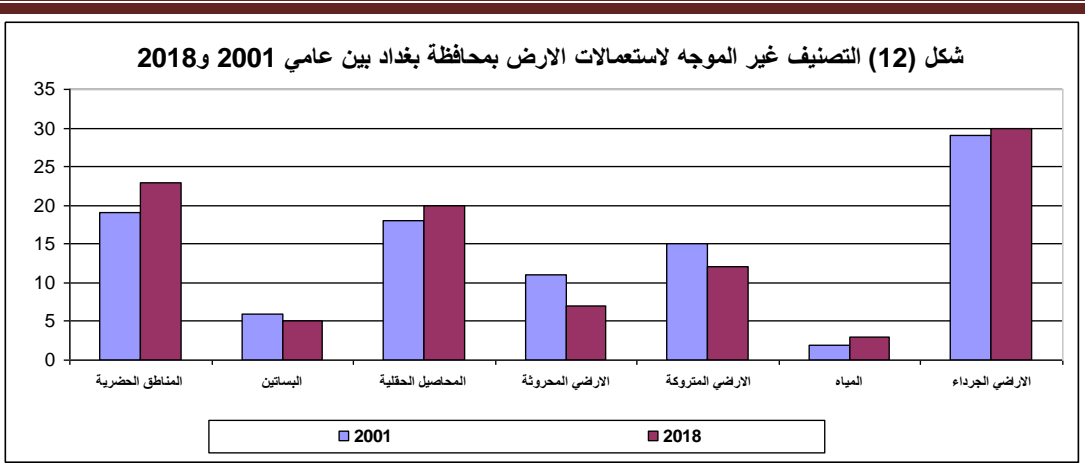

المصدر: من عمل الباحث بالاعتماد على جدول (9) (9)

التصنيف الموجه (Supervised Classification) مسيطر عليه من قبل المفسر اكثر من التصنيف غير الموجه اذ يقوم المحلل بتوجيه الحاسوب لتمييز الاغطية الارضية عن

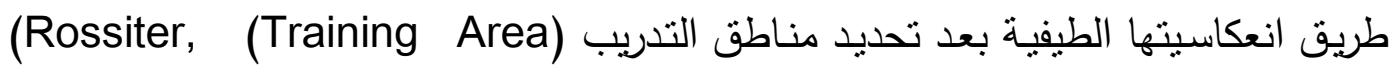
1995, p. 190) لكل نوع ينوقع وجوده في منطقة الدراسة وينبغي ان تمتاز مناطق

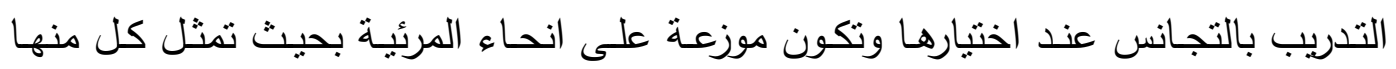

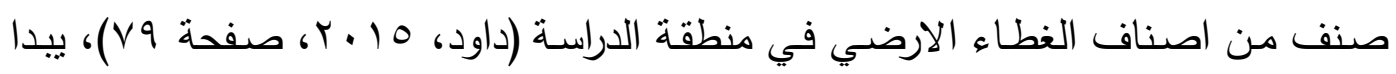
بنـاء ملف مناطق التدريب (Signature Editor File) وبطريقة الاحتمالية العظمى فئس Maximum Likelihood بالصنف الاكثر احتمالاً للحصول تصنيف لاستعمالات الارض والغطاء الارضي في فئل في منطقة الدراسة. تبـين الخريطـة (11) لســنة 2001 والخريطـة (12) لسـنـة 2018، والجـدول (· ( ) والثكل (Y) ان التوزيع النسبي للمساحات التي تغطيها اصناف استعمالات الارض بمنطقة

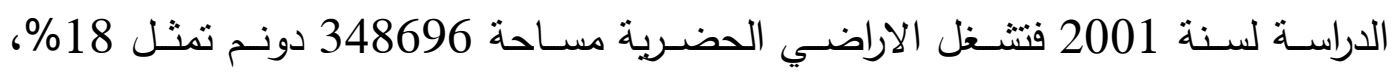

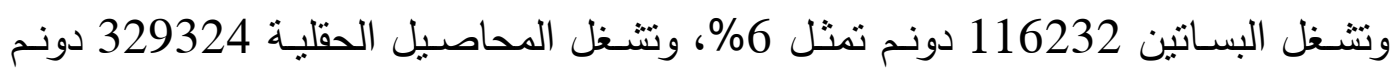

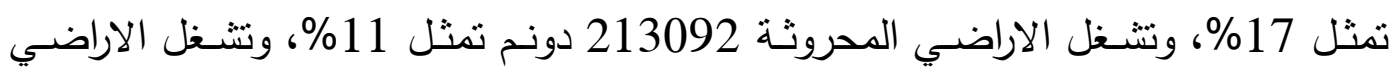

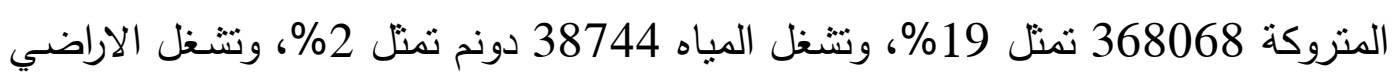
الجرداء 503672 دونم تمنل 26\% من المساحة الكلية لمنطقة الدراسة.

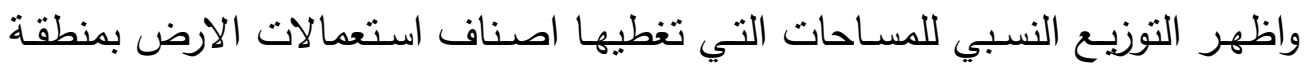

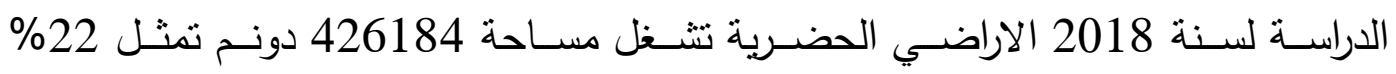
والبساتين تشغل 96860 دونم تمثل 5\% والمحاصيل الحقلية تشغل

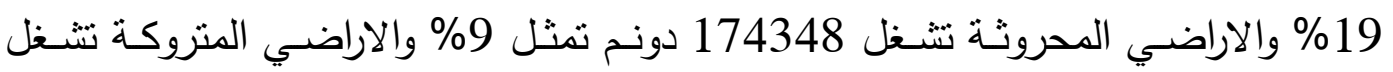

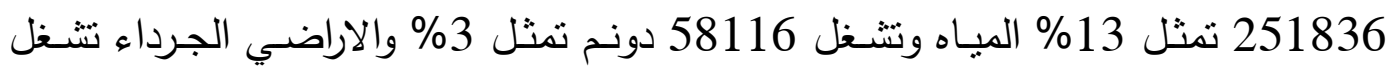
542416 دونم تمثل 28\% من المساحة الكلية لمنطقة الدراسة. 

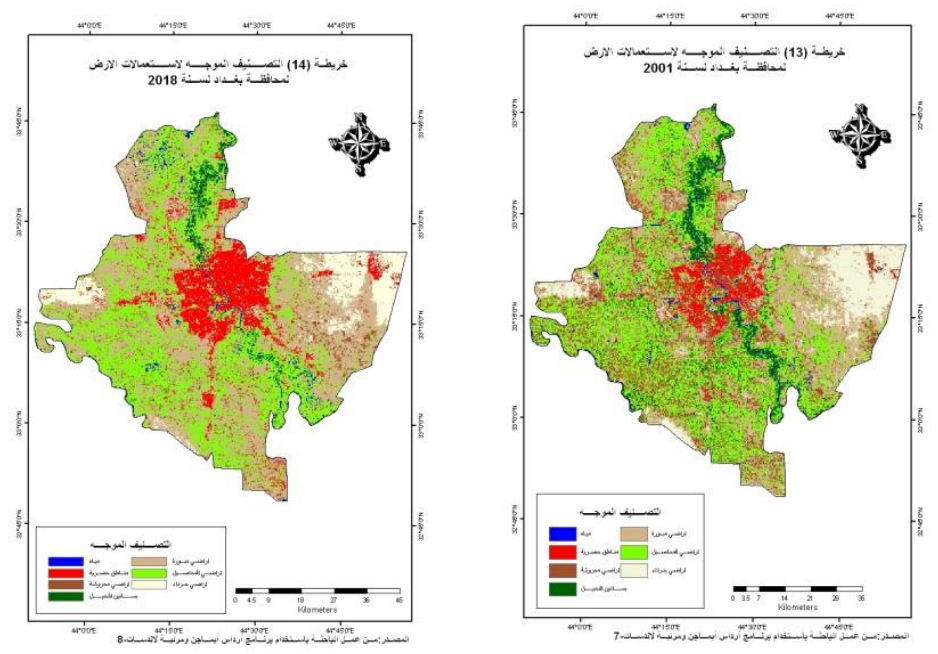

جدول (· ( ) التصنيف الموجه لاستعمالات الارض في منطقة الدراسة للمدة بين عامي .2018-2001

\begin{tabular}{|c|c|c|c|c|c|c|}
\hline \multicolumn{3}{|c|}{ سنة 2018} & \multicolumn{3}{|c|}{ سنة 2001} & \multirow{2}{*}{ صناف استعمالات الارض } \\
\hline$\%$ & دونم & كمَ & $\%$ & دونم & كمَ & \\
\hline 22 & 426184 & 1065 & 18 & 348696 & 872 & الدناطق الحضرية \\
\hline 5 & 96860 & 242 & 6 & 116232 & 291 & البسانين \\
\hline 19 & 368068 & 920 & 17 & 329324 & 823 & المحاصيل الحقلية \\
\hline 9 & 174348 & 436 & 11 & 213092 & 533 & الاراضي المحروثة \\
\hline 13 & 251836 & 630 & 19 & 368068 & 920 & الاراضي المتروكة \\
\hline 3 & 58116 & 145 & 2 & 38744 & 97 & المياه \\
\hline 28 & 542416 & 1356 & 26 & 503672 & 1259 & الاراضي الجرداء \\
\hline 100 & 1937200 & 4843 & 100 & 1937200 & 4843 & المساحة الكلية \\
\hline
\end{tabular}

المصدر: من عمل الباحث بالاعتماد على الخريطة (11) و الخريطة (12) للتصنيف الموجه.

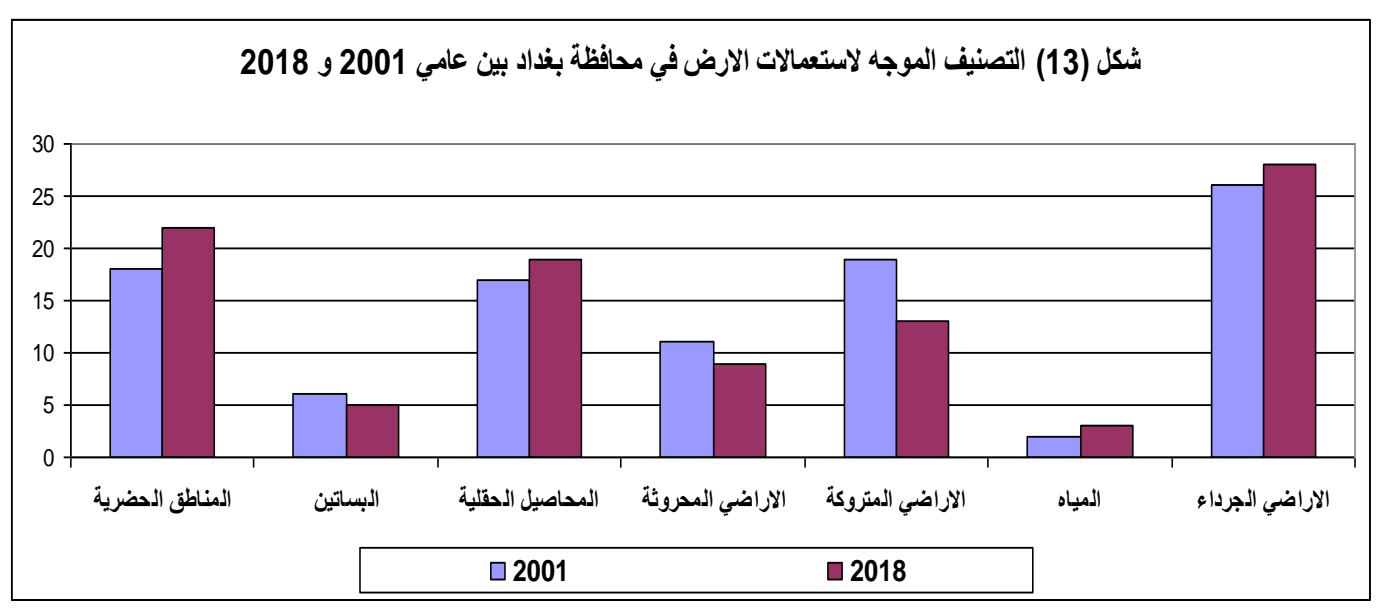

المصدر: من عمل الباحث بالاعتماد على جدول (·) 
رابعـا- التغير باستعمالات الارض لبسـاتين النخيل في محافظة بغداد للمدة ( 1 ـ. ؟ -

كثف التغير يستخدم لمسح ومراقبة استعمالات الارض والغطاء الارضي وبيان دور العوامل الطبيعية والبشرية المؤثرة والنتائج المتحققة عبر سلسلة زمنية محددة، وتعد بيانات الاستشعار عن بعد من الوسائل والتقنيات المهمة والرئيسية لتحقيق الاهداف المرجوة بهذا الخصوص. يلاحظ الجدول (11) والثنكل (r) لكثف التغير باستعمالات الارض لزراعـة بساتين النخيل بمحافظة بغداد بين عامي 2001 و 2018 حسب الاقضية . ان اتجاه تغير مساحات استعمالات الارض الزراعية لبساتين النخيل في محافظة بغداد كان تغير سالب نحو النقصان في جميع اقضية المحافظة عدا قضاء الطارمية حيث كان

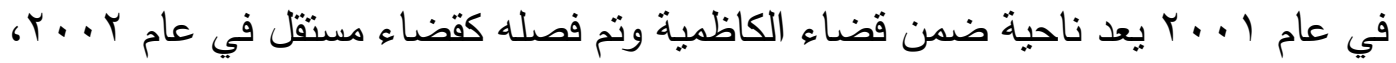
ان اعلى نسبة تغير بين عامي 2001 و 2018 كانت في قضائي الصدر الاولى والثانية احتلت المرتبة الاولى بلغت - 100\% فبعدما كانت تمنلك 1005 دونم من استعمالات الارض بزراعـة النخيل في سنة 2001 اختقت جميعها في قضائي الصدر سنة 2018 وذلك بسبب النتسع العمراني نتيجة زيادة عدد السكان وعدم تخصيص اراضي سكنية ادى الى التوجه نحو قطع الاراضي الزراعية وتحويل جنسها الى سكني. جدول (11) تغير مساحات بساتين النخيل بمحافظة بغداد بين عامي 2001 و 2018

\begin{tabular}{|c|c|c|c|c|c|c|c|c|c|c|}
\hline \multicolumn{3}{|c|}{ تغير مساحات بساتين النخيل } & \multicolumn{3}{|c|}{2018} & \multicolumn{3}{|c|}{2001} & \multirow[b]{2}{*}{ القضاء/السنة } & \\
\hline ن التفبة" & كم & دونم & $\%$ & كم & دونم & $\%$ & كم & دونم & & \\
\hline $37-$ & -5 & $55-$ & 3 & 8 & 3353 & & 13 & 5308 & الرصافة & 1 \\
\hline $37-$ & -23 & 9002- & 16 & 39 & 1556 & 21 & & 2456 & الاعظمية & 2 \\
\hline $3-$ & $1-$ & $279-$ & 8 & 19 & 77 & & 20 & 799 & المدائن & 3 \\
\hline $27-$ & $0_{-}$ & 84 - & 5 & 13 & 52 & 6 & 18 & 710 & الكرخ & 4 \\
\hline $77-$ & $25-$ & 097. & 9 & 2 & & 34 & 97 & & الكاظمية & 5 \\
\hline $15-$ & $\Lambda_{-}$ & $3255-$ & 20 & 47 & 1898 & 19 & 56 & 22241 & المحمودية & 6 \\
\hline $6-$ & $1-$ & $568-$ & 9 & 22 & 8629 & 8 & 23 & 9197 & ابي غريب & 7 \\
\hline $1 \ldots$ & 71 & 28454 & 29 & 71 & 28454 & & - & - & الطارمية & 8 \\
\hline $100-$ & $r_{-}$ & $1005-$ & 0 & 0 & 0 & 1 & 3 & 1005 & الصدر & 9 \\
\hline-17.1 & $50-$ & -19591 & 100 & 241 & 96809 & 100 & 291 & 116400 & المجموع & \\
\hline
\end{tabular}

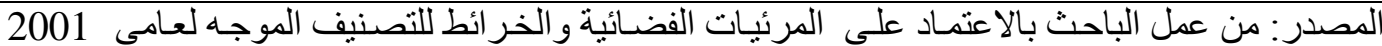
.2018 * ت تمساب التغير المطلق بالاعتماد على المعادلة : التغير المطلق = سنة المقارنة سسنة الاساس الاس

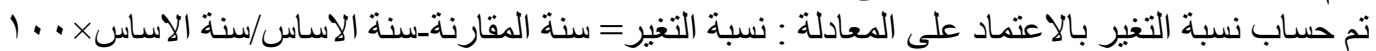

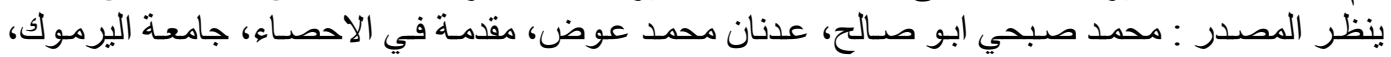


شكل (r) تغير مساحات بساتين النخيل (دونم) بمحافظة بغداد بين عامي 2001 و 2018

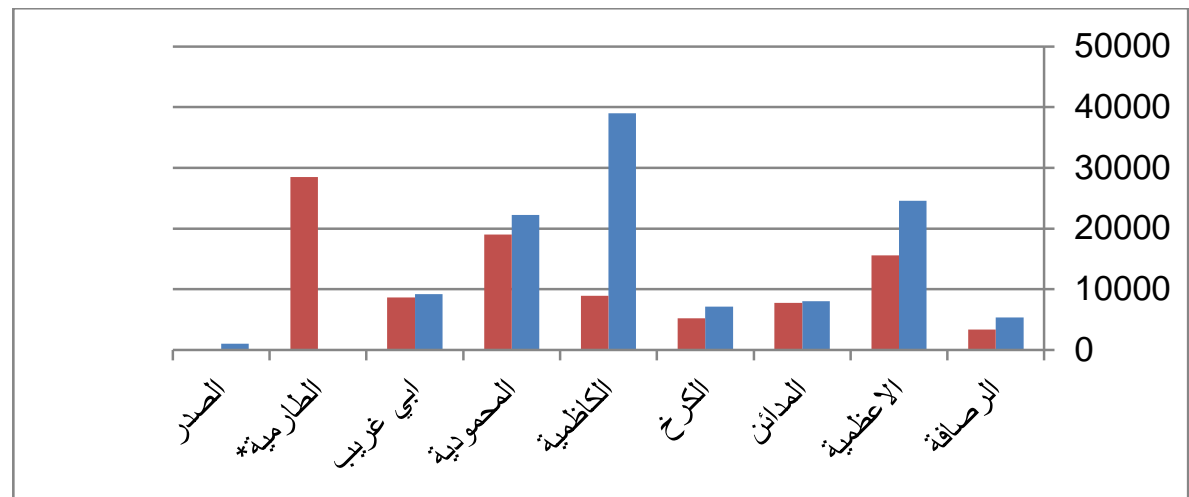

المصدر: من عمل الباحث بالاعنماد على جدول (11)

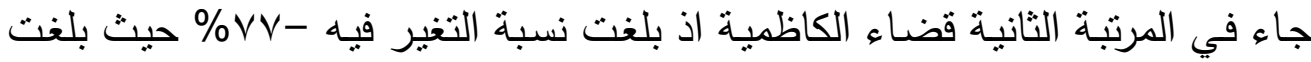

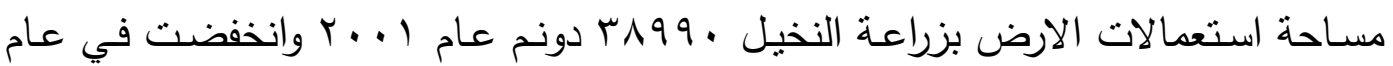

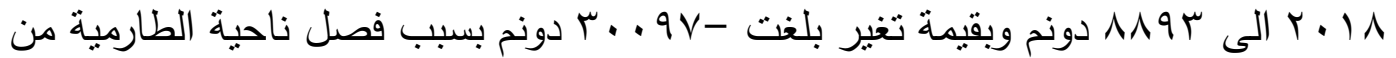

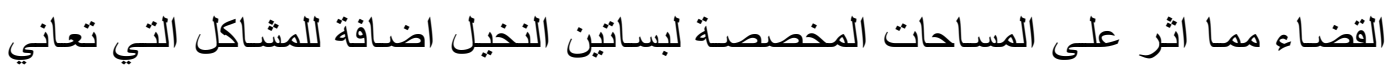
منها استعمالات الارض بزراعة النخيل كالزحف العمراني على حساب الاراضي الزراعية

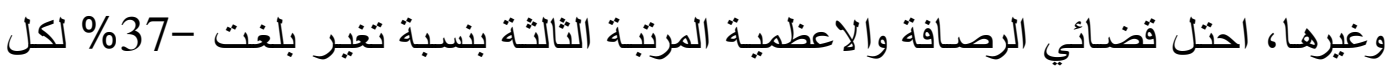
منهما اذ بلغت مساحة بسـاتين النخيل 5308 و 24563 دونم على التوالي لسنة 2001 انخفضت الى 3353 و 15561 دونم على التوالي سنة 2018 بقيمة تغير بلغت - 1955 دونم بسبب التوسع العمراني على البساتين الزراعية في تلك الاقضية لازدياد اعداد السكان

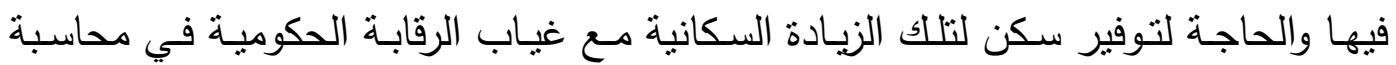
المتجاوزين، وجاء بالمرتبة الرابعة قضاء الكرخ بنسبة تغير بلغت - Y Y اذ بلغت مساحة

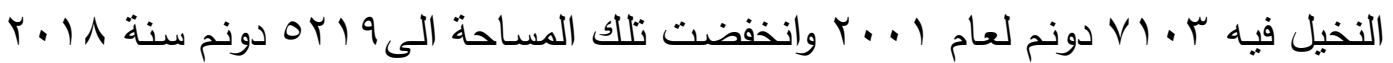
وبقيمة تغير بلغت - ع 1 ا بسبب التوسع العمراني على حساب بساتين النخيل ايضا، اما قضاء المحمودية فقد جاء بالمرتبة الخامسة حيث بلغت نسبة التغير في استعمالات الارض الترابل

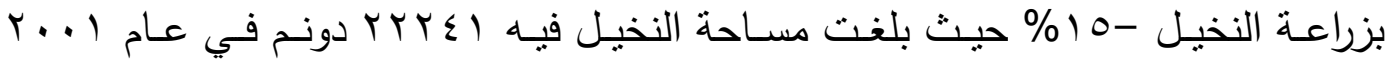

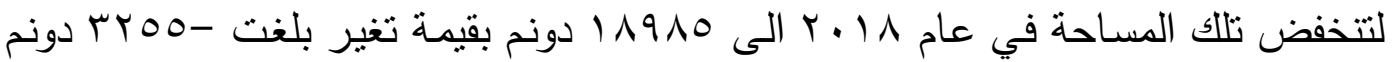

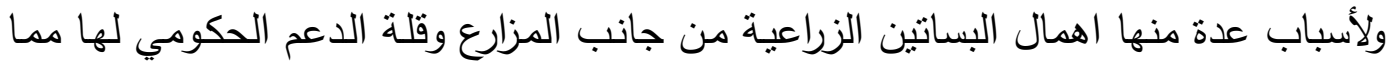
دفع المزارع لتغير جنس الارض الزراعية الى استعمالات اخرى.

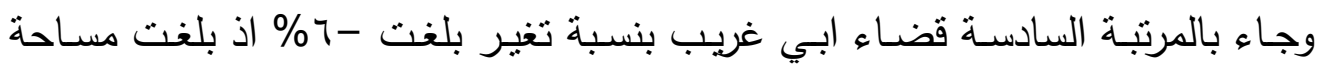

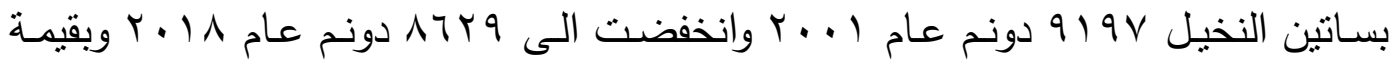

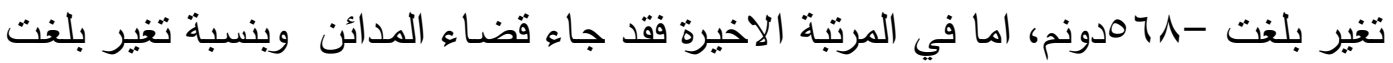

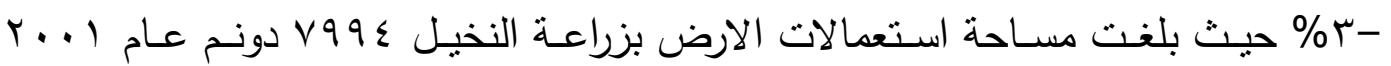




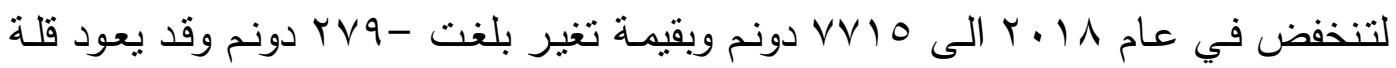
نسبة التغير فيه لسعة مسـاحة القضـاء مقارنـة مـع عدد السكان. ان التغير في استعمالات الارض بزراعـة النخيـل يعـود لأسـباب عديـدة منهـا التوسـع العمراني والاهمـال وقلــة الـــمم الحكومي وعدم توفر الرقابة من جانب الجهات المختصـة لمنع تحوبل جنس الارض اضافة

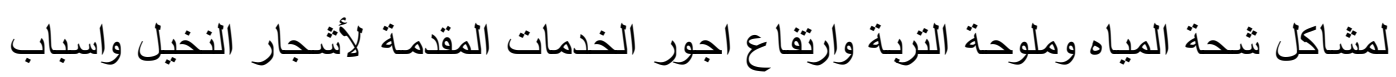
اخرى.

الاستنتاجات

1- ان مساحة محافظة بغداد الواسعة والبالغة ( . . . 9 I I ) دونم جعلها تمتلك معطيات

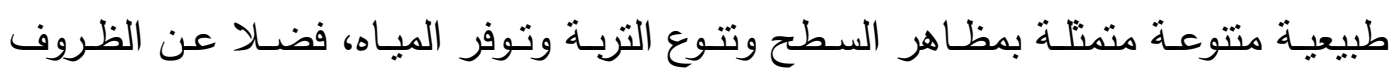
المناخية المالئمة لزراعة اشجار النخيل وانتاج التمور ـ اذ يعد السهل الرسوبي القسم الاكبر من مظاهر سطح المحافظة، وهو اكثر الاقسام ملائمسة لزراعة النخيل اذ يتراوح ارتفاعه ما

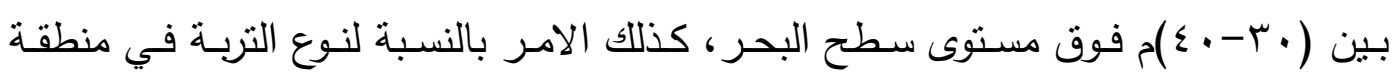
الدراسة والتي تتميز بملائمتها لزراعة النخيل خاصة الترب القريبة من احواض الانهار مثل تربة كتوف الانهار التي تبلغ نسبتها VI\%، ويعد نهر دجلة شريان الحياة في محافظة بغداد حيث تنتشر على ضفافه معظم بساتين نخيل المنطقة، اما عناصر المناخ مجتمعة لها الاثز الاكبر في نجاح زراعة اشجار النخيل وانتاج التمور في محافظة بغداد اذ ما تم استخلالها

بصورة صحيحة.

r- ان للعوامل البشرية الاثر الاكبر على بساتين النخيل في منطقة الدراسـة اذ كانت السبب الاكبر في تراجع مساحات بساتين النخيل واعداد اشجار النخيل، من خلال تدني العمليات الزراعيـة بسبب ارتفاع كلفة الانتاج واستخدام الاسـاليب التقليديـة في الزراعـة، اضف لذلك لك عدم الاهتمام بالتسميد ومكافحة افات وامراض النخيل واستخدام الاسـاليب التقليديـة في ري البساتين مما اثر على التربـة سلبا من خلال تملحها وتغدقها حيث بلغت مساحة البساتين

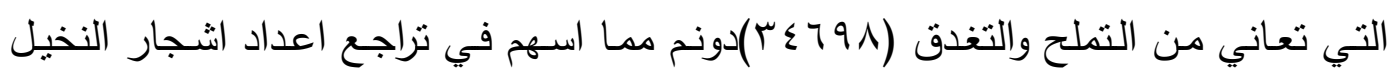
وانتاج التمور . r- اظهر استخدام التقنيات الحديثة والمتمثلة بالاستشعار عن بعد بالقمر الصناعي لانسات

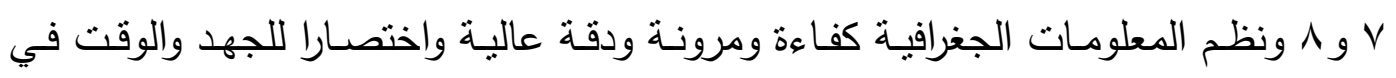
تصـنيف اسـتعمالات الارض الزراعيـة والغطـاء الارضـي باعتمـاد نظــام اندرسـون واخـرون وباستخدام برنامج ERDAS IMGEN\&GIS لأغراض اجراء عمليات التصحيح والتحسين

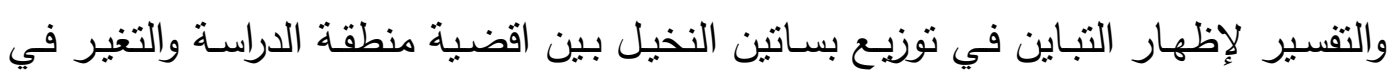
استعمالات الارض بزراعة اشجار النخيل. 
ع - تبين ان التغير في مسـاحات استعمالات الارض بزراعـة النخيل اتجهـ نحو التغير

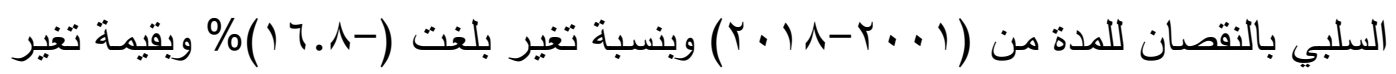

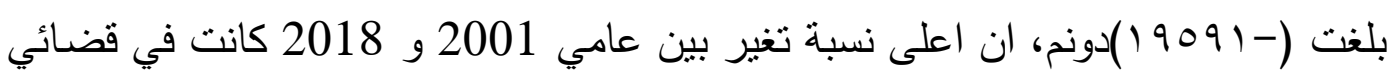

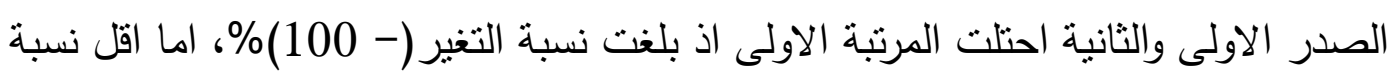

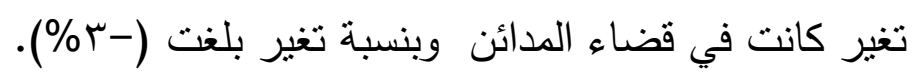
التوصسيات : التير

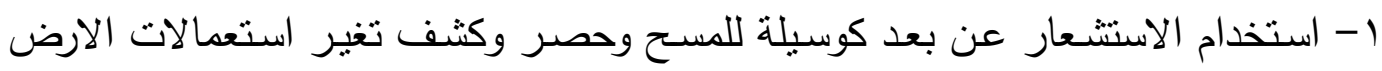

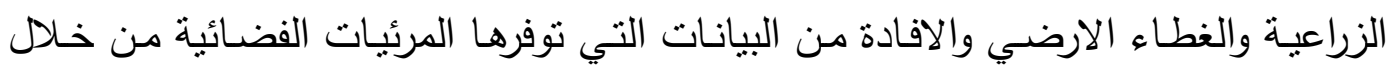
تفسيرها وتحليلها وسد النفص بوقت وجهد اقل ودقة عالية بما يسهم في معالجة المشـاكل التي تواجه استعمالات الارض بزراعة النخيل.

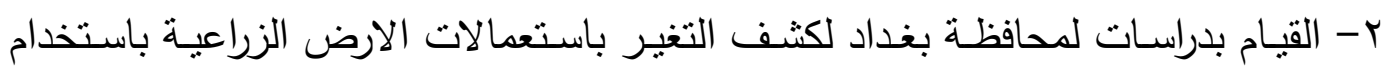

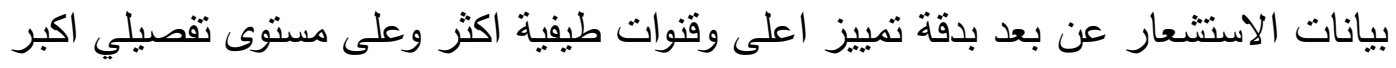
للوقوف على التغيرات واسبابها ومعالجة مشاكلها بما يخدم الخطط التنموية الزراعية. المـصادر العربية

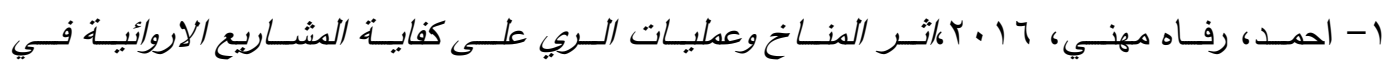

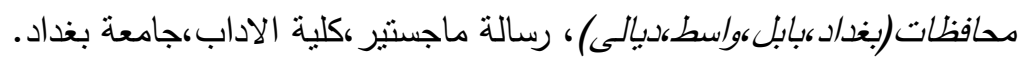

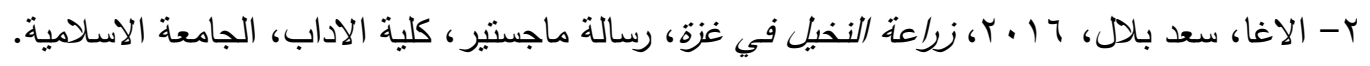

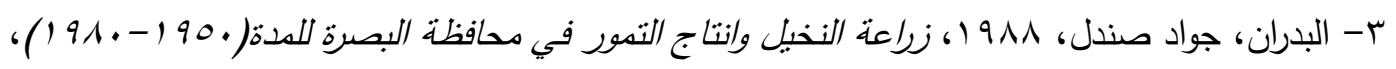
رسالة ماجستير ، كلية التربية الاساسية،جامعة البصرة.

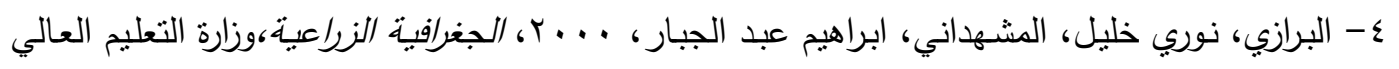

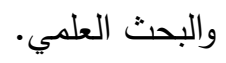

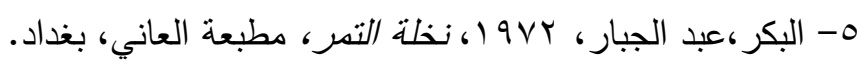

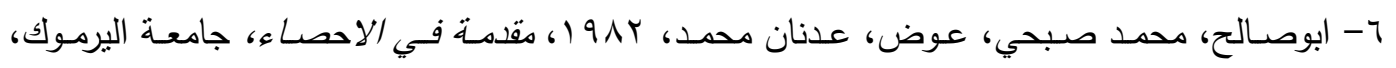

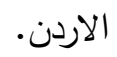

V- التخطيط، وزارة، 11 ـ ب، الايرادات السنوية لنهري دجلة والفرات وروافدهما، تقرير الموارد المائية.

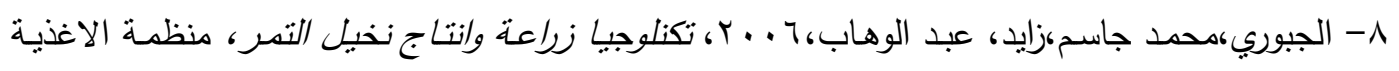
والزراعة التابعة للامم المتحدة(فاو)، القاهرة.

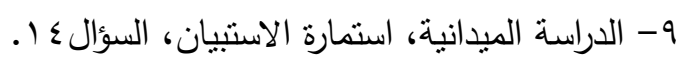

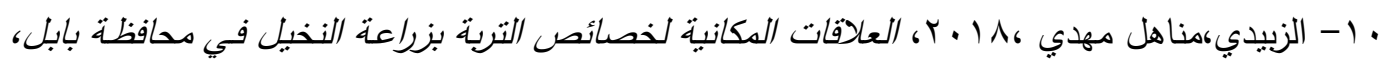

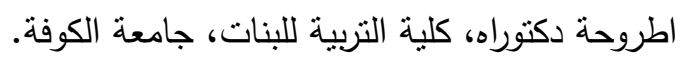

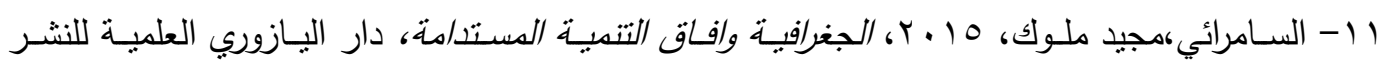
والتوزيع. 
r ا - السعدي، عباس فاضل، 9 ( I ، محافظة بغداد (دراسة في الجغرافية الزراعية)، جامعة بغداد، دار

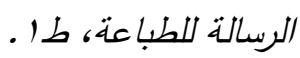

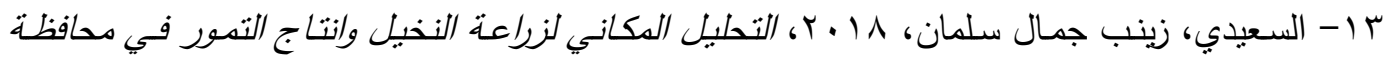
واسط، رسالة ماجستير ، كلية التربية، جامعة واسط.

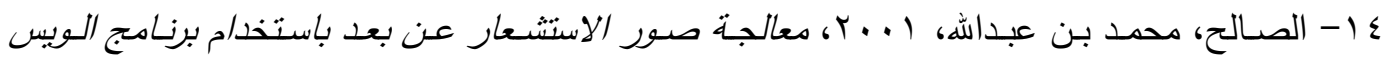
Ilwis

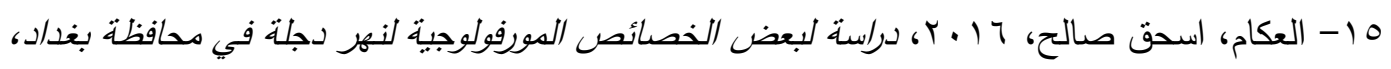

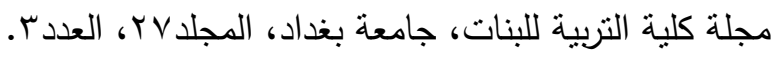

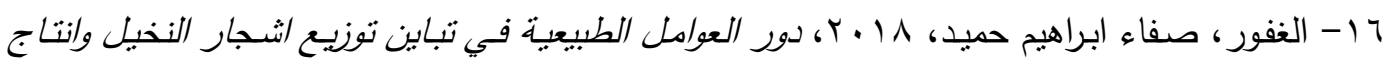

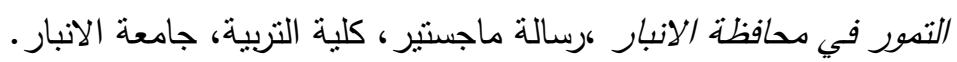

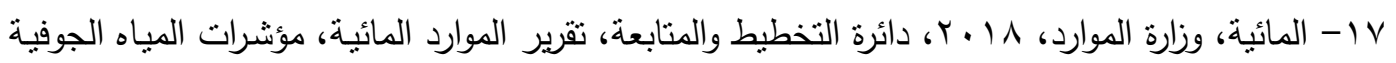
في العراق. 1 1 - الهيتي، بيان محي حسين، 910 (، دراستة نوعية المباه الجوفية في منطقة بغداد، رسالة ماجستير، كلية العلوم، جامعة بغداد.

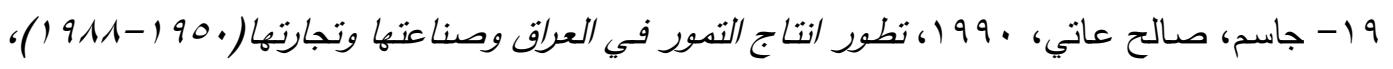

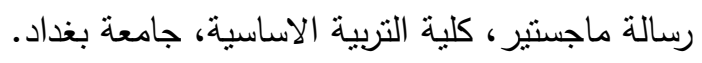

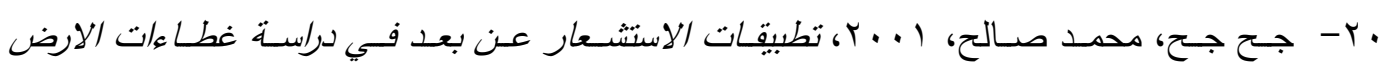
واستخد/ماتها في منطقة المقد/دية، رسالة ماجستير، كلية العلوم، جامعة بغداد.

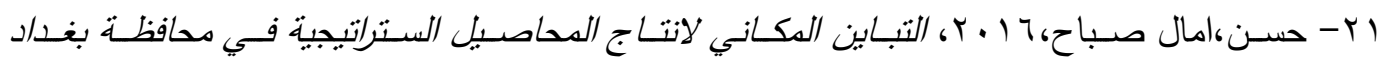

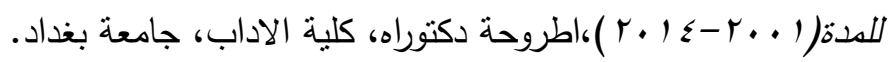

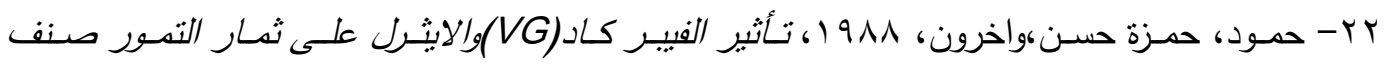

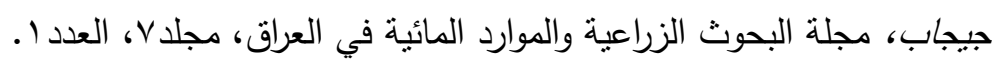

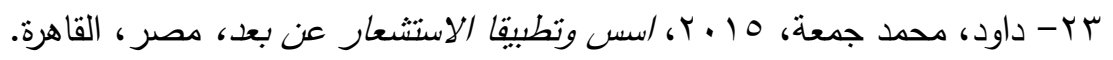

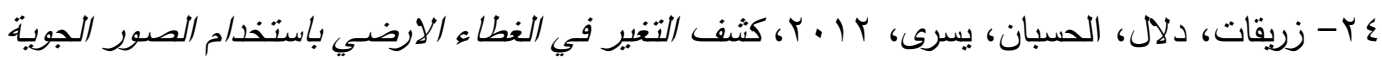

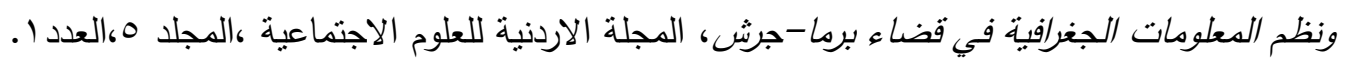

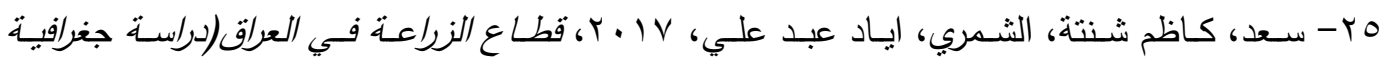
للمعوقات والمشاكل والحلول)، مركز العراق للدراسات، مطبعة الساقي للطباعة والنشر، ،طبعة ا. .

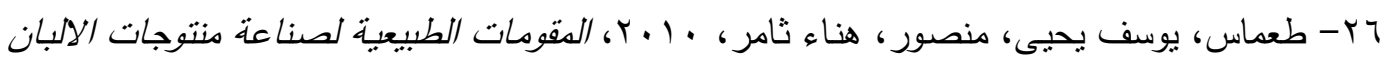

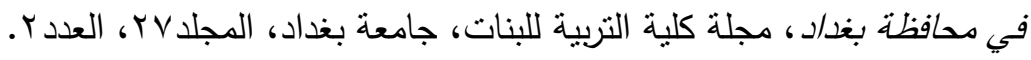

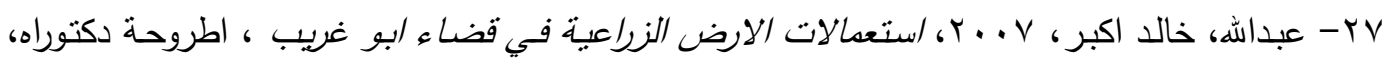
كلية التربية للبنات ،جامعة بغداد.

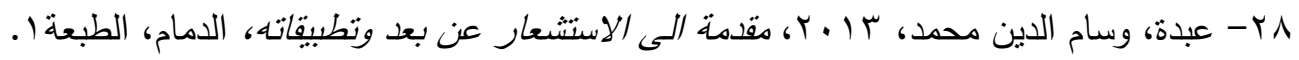

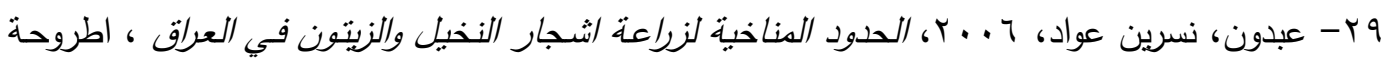
دكتوراه ،كلية الاداب ،جامعة بغداد. 


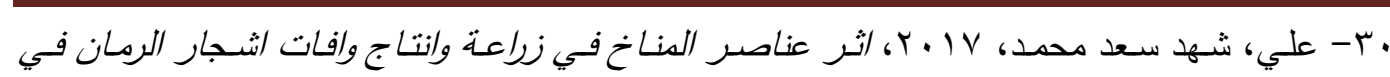
محافضتي(بغداد وصلاح الدين)، رسالة ماجستير ،كلية التربية للبنات،جامعة بغداد.

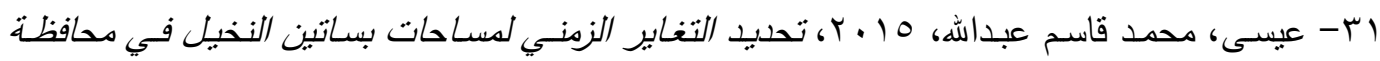

المثنى باستخد/م وسائل الاستشعار عن بعد، رسالة ماجستير، كلية الزراعة ،جامعة المثنى .

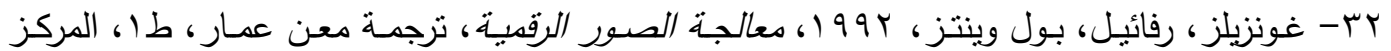
العربي للتعريب والترجمة والتأليف والنشر ، دمشق.

سب- كاظم، عبد الستار عبود، 1 ـ r، كفاءة الطرق الريفية في قضاء المحعودية ، رسالة ماجستير ، كلية التربية ابن رشد،جامعة بغداد.

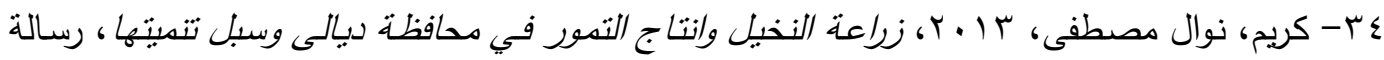
ماجستير ، كلية التربية ،جامعة ديالى.

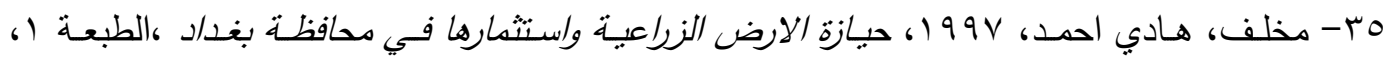
مطبعة الارشاد كبغداد.

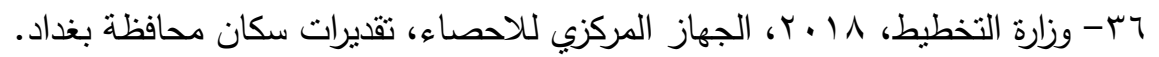

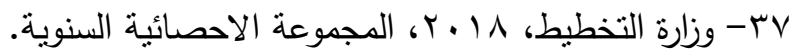

\section{References:}

1. AL-jiburi, H. K. (2004). hydrogel and hydro chemical study of baghdad quadrangle. Baghdad.

2. Anderaon, J. R., \& Others. (1976). Landuse and landcover Classification system use with Remote sensor Data. U.S.Geological Survery proessional.

3. Buringh, .. (1960). Soil and Condition in Iraq. Baghdad: Ministry of Agriculture.

4. Delver, I. P. (1962). Saline soils in the lower Mesopotamiaplain, Republic of Iraq. Directorate General of Agricultural Research and prolects.

5. Jensen, J. R. (2000). Remote Sensing of the Environment an Earth Resource Perspective. New lersey: USA.

6. Leice geo system Erdas field Guide TM. (2002). gis\& Mapping. USA: Georgia.

7. Lilles, T. M., \& other. (2000). Remte sensing and image interpreta on . USA: john wiley and sons.

8. paul m, B. t. (2001). Classification methods for remotely sensed date. London: tylor\& francis.

9. Rossiter, D. G. (1995). Data sources for land evaluate. Cornell Univ: USA.

10. Ahmad, Rafah Mhanna, 2016, The Impact of Climate and Irrigation Operations on the Adequacy of Irrigation Projects in the Governorates (Baghdad, Babil, Wasit, Diyala), Master Thesis, College of Arts, University of Baghdad.

11. Al-Agha, Saad Bilal, 2016, Palm Planting in Gaza, Master Thesis, Faculty of Arts, Islamic University. 
12. Al-Badran, Jawad Sandal, 1988, date palm cultivation and date production in Basra Governorate for the period (1950-1980), Master Thesis, College of Basic Education, University of Basra

13. Al-Barazi, Nuri Khalil, Al-Mashhadani, Ibrahim Abdel-Jabbar, 2000, Agricultural Geography,

14. Ministry of Higher Education and Scientific Research.

15. Al-Bakr, Abdul-Jabbar, 1972, Date Palm, Al-Ani Press, Baghdad.

16. Abu Saleh, Muhammad Subhi, Awad, Adnan Muhammad, 1982, Introduction to Statistics, Yarmouk University, Jordan.

17. Planning, Ministry, 2018, Annual revenues of the Tigris and Euphrates and their tributaries, Water Resources Report.

18. Al-Jubouri, Muhammad Jassim, Zayed, Abdel-Wahab, 2006, Technology of cultivation and production of date palms, Food and Agriculture Organization of the United Nations (FAO), Cairo.

19. Field study, questionnaire form, question 14.

20. Al-Zubaidi, Manahel Mahdi, 2018, Spatial Relationships of Soil Properties in Date Palm Cultivation in Babil Governorate, $\mathrm{PhD}$ thesis, College of Education for Girls, University of Kufa.

21. Al-Samarrai, Majid Melouk, 2015, Geographical and Sustainable Development Prospects, Al-Yazouri Scientific Publishing and Distribution House

22. Al-Saadi, Abbas Fadel, 1976, Baghdad Governorate (Study in Agricultural Geography), University of Baghdad, Dar Al-Resalah for Printing, 1st Edition.

23. Al-Saeedi, Zainab Jamal Salman, 2018, Spatial Analysis of Date Palm Planting and Date Production in Wasit Governorate, Master Thesis, College of Education, Wasit University.

24. Al-Saleh, Muhammad bin Abdullah, 2001, Processing of remote sensing images using ILWIS software, Riyadh.

25. Al-Akam, Ishaq Salih, 2016, A study of some morphological characteristics of the Tigris River in Baghdad Governorate, Journal of the College of Education for Girls, University of Baghdad, Volume 27, Issue 3.

26. Al-Ghafoor, Safaa Ibrahim Hamid, 2018, The role of natural factors in the variation in the distribution of palm trees and the production of dates in Anbar Governorate, Master Thesis, College of Education, Anbar University.

27. Water, Ministry of Resources, 2018, Planning and Follow-up Department, Water Resources Report, Groundwater Indicators in Iraq.

28. Al-Hiti, Bayan Mohi Hussein, 1985, Study of Groundwater Quality in the Baghdad Region, Master Thesis, College of Science, University of Baghdad.

29. Jassim, Saleh Aati, 1990, The Evolution of Dates Production, Industry and Trade in Iraq (1950-1988), Master Thesis, College of Basic Education, University of Baghdad. 
30. Jah Jah, Muhammad Salih, 2001, Remote Sensing Applications in the Study of Land Coverings and Their Uses in Al-Muqdadiya Region, Master Thesis, College of Science, University of Baghdad.

31. Hassan, Amal Sabah, 2016, Spatial variation in the production of strategic crops in Baghdad governorate for the period (2001-2014), PhD thesis, College of Arts, University of Baghdad.

32. Hammoud, Hamza Hassan, and others, 1988, The Effect of Fiber CAD (VG) and Etherl on the Fruits of Gigab Dates, Journal of Agricultural Research and Water Resources in Iraq, Volume 7, Issue 1.

33. Daoud, Mohamed Gomaa, 2015, The foundations and application of remote sensing, Egypt, Cairo.

34.Zureikat, Dalal, Al-Husban, Yosra, 2012, Detecting the change in land cover by using aerial photos and geographic information systems in the Berma-Jerash district, The Jordanian Journal of Social Sciences, Volume 5, Issue 1.

35. Saad, Kazem Shanta, Al-Shammari, Iyad Abd Ali, 2017, The Agriculture Sector in Iraq (A Geographical Study of Obstacles, Problems and Solutions), Iraq Center for Studies, Al-Saqi Printing Press for Printing and Publishing, Edition 1.

36. Tomas, Youssef Yahya, Mansour, Hanaa Thamer, 2010, The Natural Constituents of Dairy Products Industry in Baghdad Governorate, Journal of the College of Education for Girls, University of Baghdad, Volume 27, Issue 2.

37. Abdullah, Khaled Akbar, 2007, The uses of agricultural land in Abu Ghraib district, $\mathrm{PhD}$ thesis, College of Education for Girls, University of Baghdad.

38. Abdah, Wissam al-Din Muhammad, 2013, Introduction to remote sensing and its applications, Dammam, 1st edition.

39. Abdoun, Nasreen Awad, 2006, Climate Limits for Cultivation of Palm Trees and Olives in Iraq, $\mathrm{PhD}$ thesis, College of Arts, University of Baghdad. Ali,shed Saad Muhammed, 2017, the effect of climate elements on planting and producing pomegranate trees in governorates (Baghdad And Salah Al-Din), Master Thesis, College of Education for Women, University of Baghdad.

40. Issa, Muhammad Qasim Abdullah, 2015, Determining the temporal variance of palm groves in Al-Muthanna Governorate using remote sensing methods, Master Thesis, College of Agriculture, Al-Muthanna University.

41. Gonzels, Raphael, Paul Wentz, 1992, Digital Image Processing, translated by Maan Ammar, 1st Edition, Arab Center for Arabization, Translation, Authoring and Publishing, Damascus.

42. Kazim, Abdul Sattar Abboud, 2010, Efficiency of Rural Roads in Mahmoudiya District, Master Thesis, Ibn Rushd College of Education, University of Baghdad. 


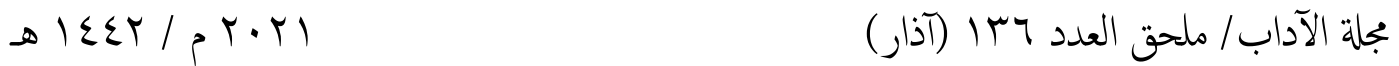

43. Karim, Nawal Mustafa, 2013, Date palm cultivation and date production in Diyala Governorate and ways to develop them, Master Thesis, College of Education, Diyala University.

44. Mikhlif, Hadi Ahmad, 1997, Possession of agricultural land and its investment in the governorate of Baghdad, 1st edition, Al-Irshad Press, Baghdad.

45. Ministry of Planning, 2018, Central Bureau of Statistics, Baghdad Governorate population estimates.

46. Ministry of Planning, 2018, Annual Statistical Abstract. 